\title{
EMERGENCY DEPARTMENT RE-PRESENTATIONS FOLLOWING INTENTIONAL SELF-HARM
}

by

Silke Kuehl

A thesis submitted to the Victoria University of Wellington

in partial fulfilment of the

requirements for the degree of

Master of Nursing (Clinical)

Victoria University of Wellington

2008 


\section{Abstract}

Repeat intentional self-harm (ISH) episodes are strongly correlated to suicide. Intentional self-harm for this thesis includes suicide attempts, deliberate self-harm and suicidal ideation. The aim was to describe what factors contribute to people re-presenting to the emergency department (ED) within one week of a previous visit for intentional self-harm. Objectives identified were to describe the people using demographic and clinical features; describe and evaluate ED management; and identify possible personal or system reasons as to why people re-present to ED within one week. A retrospective observational design was selected for a period of one year. The data was collected from electronic clinical case notes. The sample consisted of 48 people with 73 presentations and re-presentations. Descriptive and inferential analyses were undertaken using the Statistical Programme for Social Science (SPSS). Missing data limited the number of inferential analyses. Outcome measures were divided into information regarding the person and the presentation. This study made several discoveries: many representations (55\%) occurred within one day; the exact number of people who represented many times to ED is unknown, but is far higher than reported in other studies; fewer support people were present for the second presentation; the documentation of triage and assessments by ED staff was often minimal, though frequently portrayed immense distress of this population; cultural input for Māori was missing; physical health complaints and psychosis were found with some intentional self-harm presentations; challenging behaviours occurred in at least a quarter of presentations; and the medical and mental health inpatient admission rates were approximately $50 \%$ higher for second presentations. Recommendations in regard to the use of a triage assessment tool, the practice of reviewing peoples' past presentations and the need for a mental health consultation liaison nurse in ED are made. Staff education, collaboration between services with consumer involvement and further research of this group are required. This study supports the need for holistic and expert care for people who present ED with intentional self-harm. Such care needs to be provided in a safe way with the intent on reducing the distress experienced by people who intentionally self-harm.

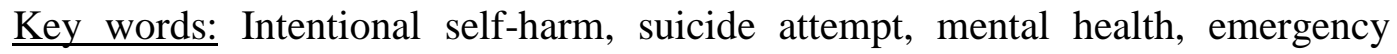
department, repeat presentation, frequent user. 


\section{Acknowledgements}

My partner Stephen initially welcomed the anticipated 'peace' with me doing this research. His support, computer knowledge and the critical questions were deeply appreciated.

The Graduate School of Nursing, Midwifery, and Health, Victoria University of Wellington, has been an inspiring place of learning. The enthusiasm of the staff, and the faith they had in me and my research was hugely inspiring. Many thanks to my amazing supervisor Kathy Nelson, who never seemed to judge me for 'being behind', but encouraged me all the way.

Charlotte Thompson and Suzanne Rolls my 'study pals' invested precious weekends to feed me, 'unstuck' me and believed that I could do it. Dr. Nikki Coupe and Debs Jordan gave me unlimited support.

I very much appreciated the financial support of the DHB where this study was done, New Zealand Guidelines Group and the New Zealand Nurses Organisation.

Thank you to my family and friends, who did not bother me too much with coffee invites but continued to listen to my enthusiastic reports of latest findings.

And I appreciated that black cat that always seemed to stroll in when I was in need of animal therapy. 


\section{Table of Contents}

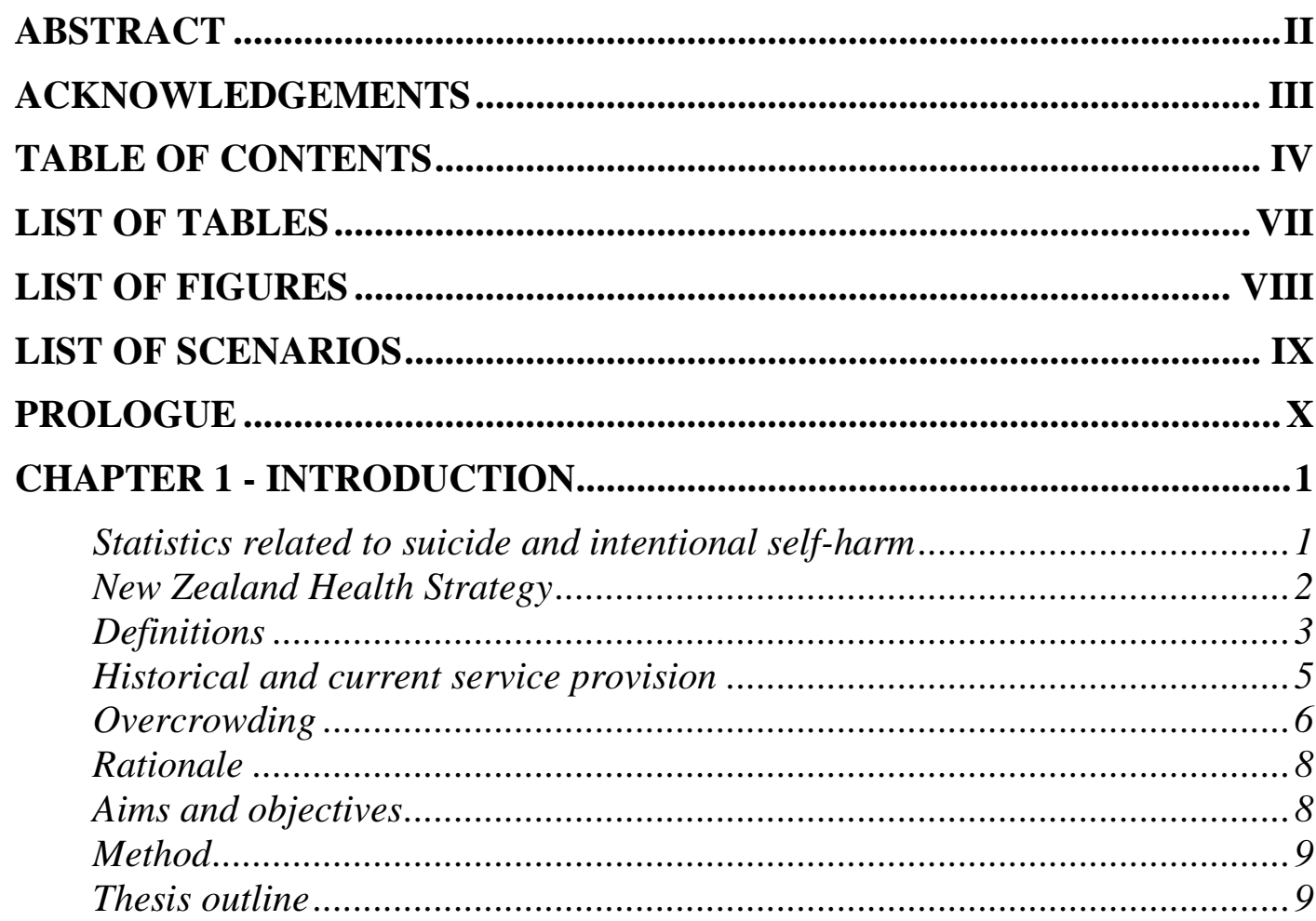

CHAPTER 2 - LITERATURE REVIEW .....................................................11

RE-PRESENTATIONS TO THE EMERGENCY DEPARTMENT ..................................... 12

Repeat intentional self-harm presentations to ED..................................... 12

Link between physical and mental health presentations............................. 15

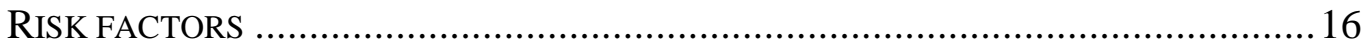

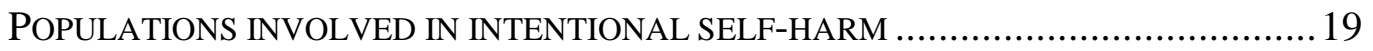

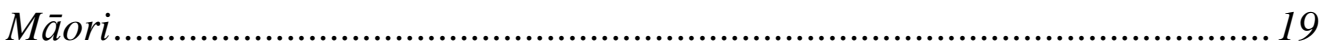

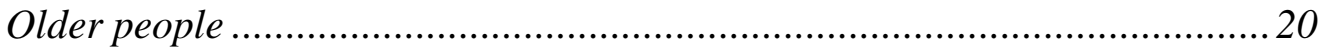

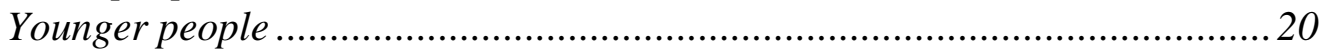

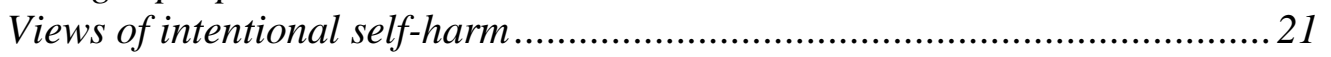

Emergency Department staff .............................................................. 21

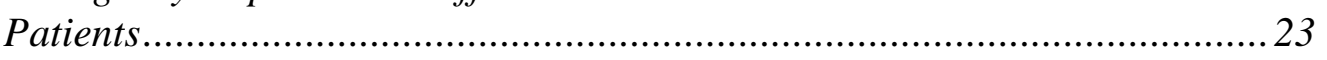

CHAPTER 3 - CLINICAL VIEW ................................................................227

ARRIVAL AT THE EMERGENCY DEPARTMENT ..................................................2 27

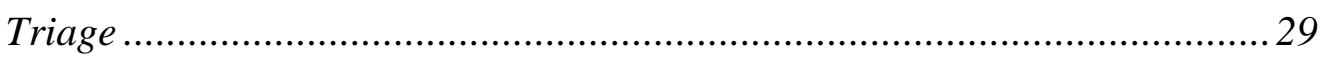

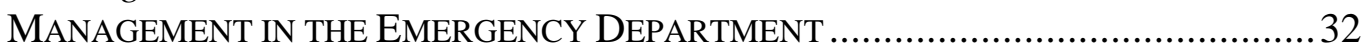

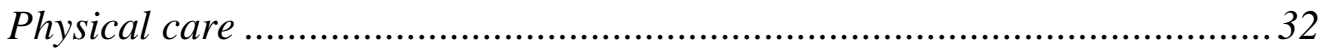

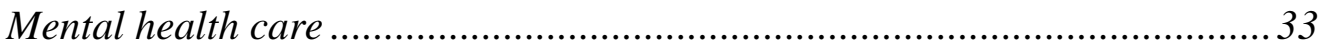

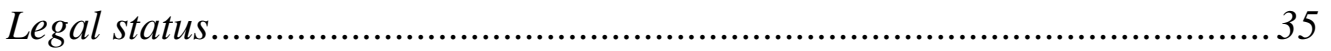

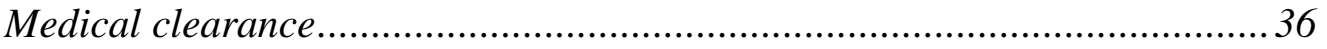

DEPARTURE FROM THE EMERGENCY DEPARTMENT ...............................................38 


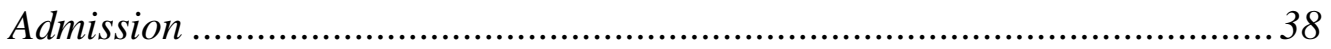

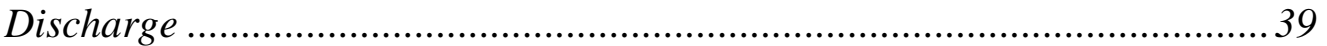

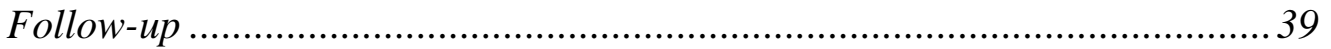

Community management ............................................................................ 41

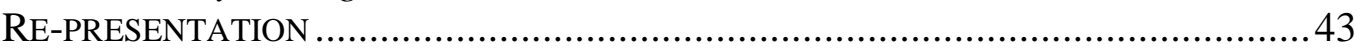

Emergency department management ..................................................... 43

CHAPTER 4 - METHODOLOGY ..........................................................45

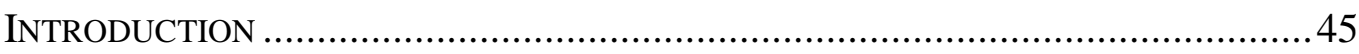

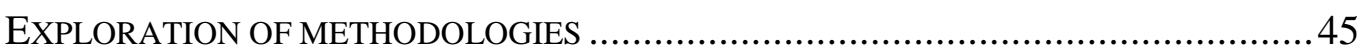

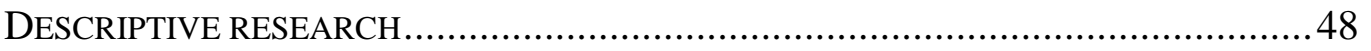

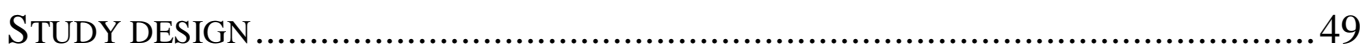

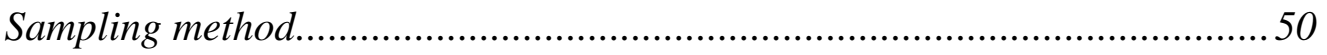

Development of the data extraction tool .....................................................52

Variables related to the person......................................................................5. 53

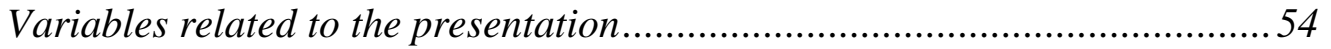

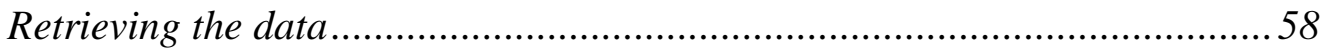

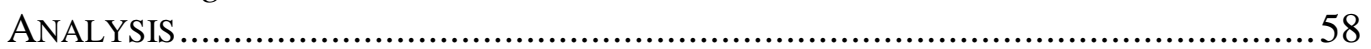

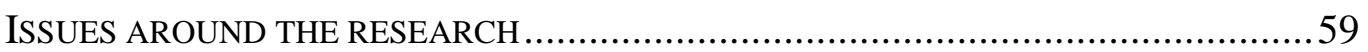

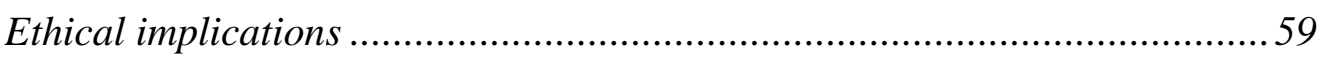

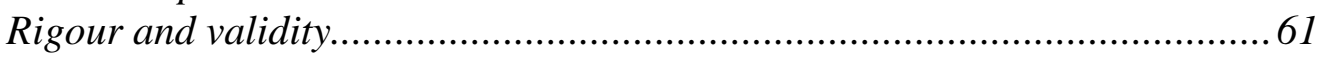

CHAPTER 5 - FINDINGS .........................................................................62

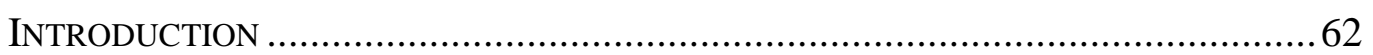

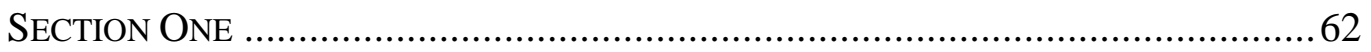

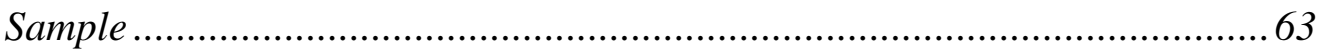

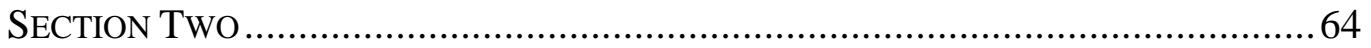

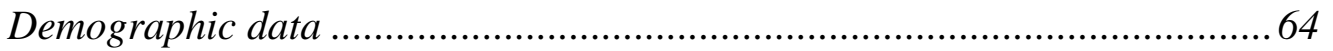

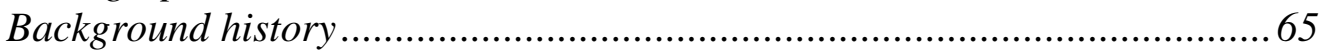

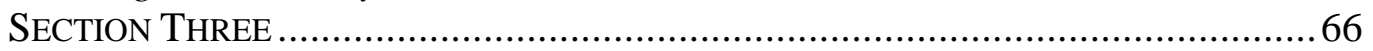

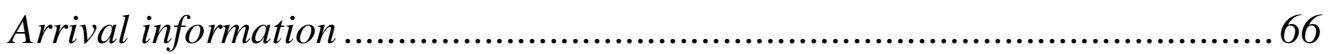

Emergency department management .................................................... 71

Referral and discharge from the emergency department ........................... 75

CHAPTER 6 - DISCUSSION .............................................................................79

INTENTIONAL SELF-HARM: A MAJOR ISSUE FOR ED ....................................... 79

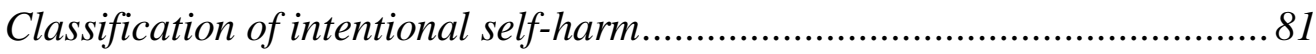

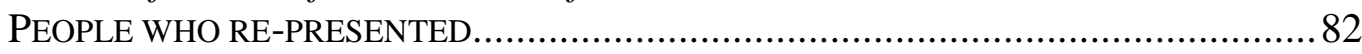

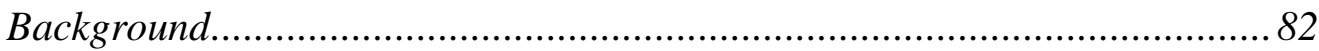

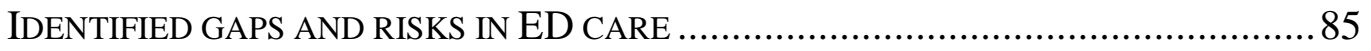

Assessment, management and referral ...................................................... 88

The Crisis Assessment and Treatment Team ........................................... 92

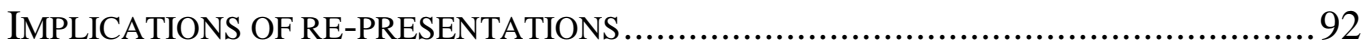

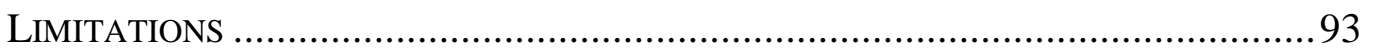

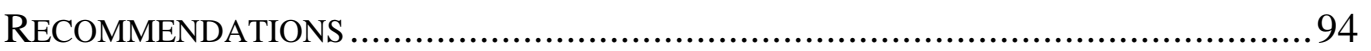

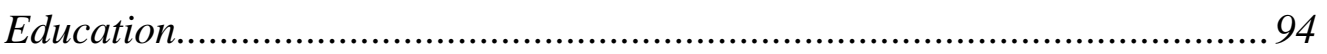

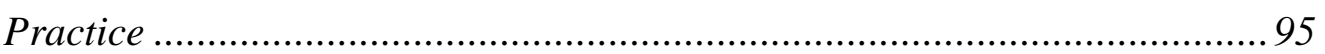

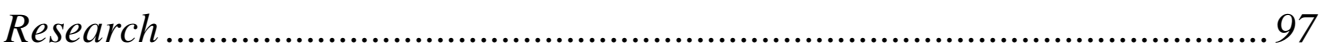

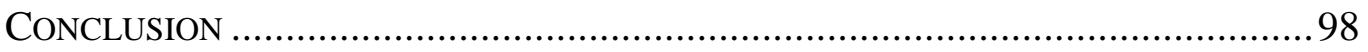




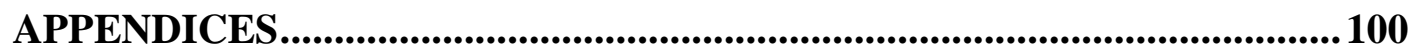

APPENDIX 1: MENTAL StATUS EXAMINATION .................................................. 100

APPENDIX 2: DATA EXTRACTION TOOL …................................................... 101

APPENDIX 3: LOCATION OF VARIABLES ON THE ElECTRONIC PATIENT

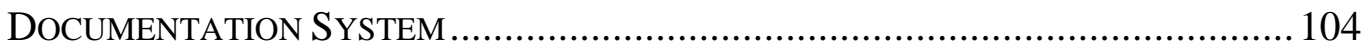

APPENDIX 4: ETHICS COMMITTEE APPROVAL …............................................. 106

APPENDIX 5: DIAGNOSIS DESCRIPTION .......................................................... 107

APPENDIX 6: MULTISECTORAL APPROACH TO SUICIDE PREVENTION.................. 109

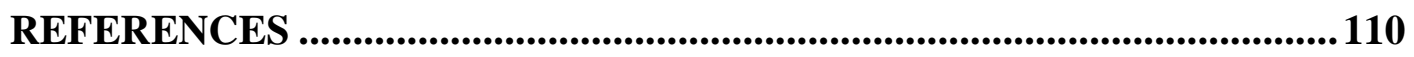




\section{List of Tables}

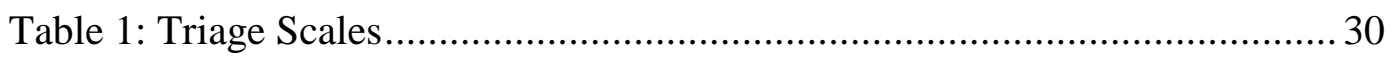

Table 2: Days to re-presentation by number and frequency .............................64 64

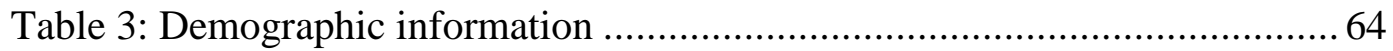

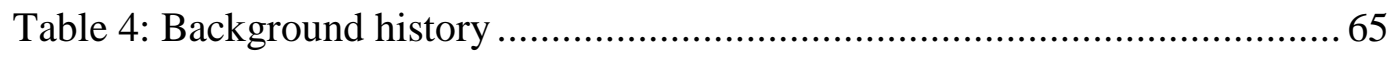

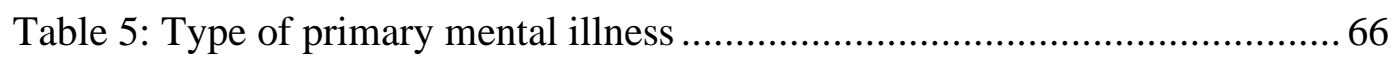

Table 6: Days of the week of first and second presentation ..............................67 67

Table 7: Support people at the person's first and second presentation.................69

Table 8: Presenting issues first and second presentation ................................. 70

Table 9: Deliberate self-harm (type) and attempts, both presentations ................ 71

Table 10: Nursing assessment and comfort care first and second presentation .... 72

Table 11: Rank of emergency department doctor first and second presentation .. 72

Table 12: Main triggers for first and second presentation .............................. 73

Table 13: ED assessment and medication provision, both presentations ............. 74

Table 14: Challenging behaviours first and second presentation......................75

Table 15: Referral and CATT assessment first and second presentation .............76

Table 16: Admission, discharge and follow-up first and second presentation ..... 77

Table 17: Arrangements for follow-up care first and second presentation........... 78

Table 18: Cost of the 73 re-presentation by triage code ................................... 93 


\section{List of Figures}

Figure 1: Five goals of The New Zealand Suicide Prevention Strategy 2006-2016*

Figure 2: The hierarchy of study types* ............................................. 49

Figure 3: Process of identification of sample included in study ........................51

Figure 4: Arrival time for first and second presentation.................................6 67

Figure 5: Triage Codes for first and second presentation ..............................6 68

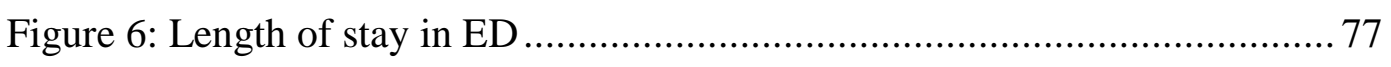

Figure 7: The Self-harm and Suicide Prevention Collaborative

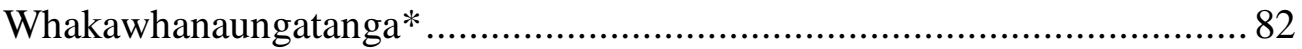

Figure 8: Suggestions for practice improvement in ED*............................... 96 


\section{List of Scenarios}

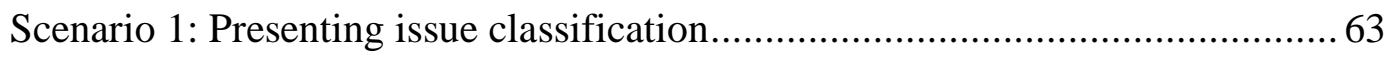

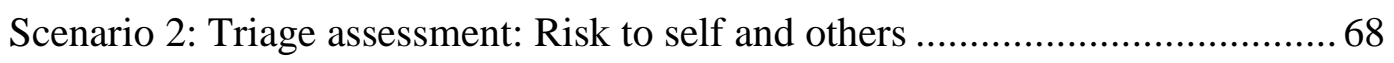

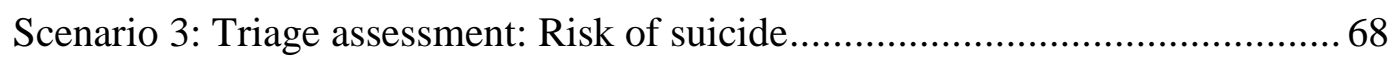

Scenario 4: Management of minor injuries ............................................. 73

Scenario 5: Link between physical and mental health issues............................. 74

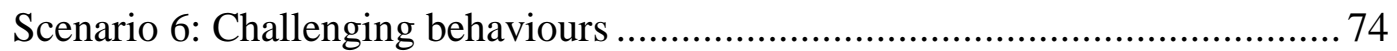




\title{
Prologue
}

\author{
Q: He aha te mea nui or te ao \\ A: He tangata, he tangata, he tangata \\ Q: What is the most important resource of all? \\ A: It is people, it is people, it is people
}

(Māori proverb)

\begin{abstract}
"You must be mad!" affirmed my colleagues when I left nursing in the emergency department (ED) to embrace mental health nursing a few years ago. Previously people found my job exciting - it had kudos, drama and, status. Conversely, my new career, mental health nursing, was a powerful conversation stopper. Now I am back working in ED, and not dissimilar to societal attitudes, I have noticed that my colleagues find mental health issues challenging.
\end{abstract}

The care of people who are involved in ISH has been of concern to me throughout my professional career. My first experiences of mental health included 18 months work in a 'halfway' house in the United States of America. This was the early 1990s - the midst of deinstitutionalisation. I was a 'counsellor', essentially an untrained worker who had no prior knowledge or understanding of mental health. Repeat intentional self-harm episodes of some people centred on desires for cigarettes and Coca Cola. I dealt with these crises with an awareness of my inexperience and helplessness.

After training as a registered nurse in the United Kingdom, I worked mostly as a nurse in Emergency Departments (EDs) in various countries, undertaking postgraduate studies, primarily related to trauma and emergency nursing. Eight years post graduation I left ED for a Post Graduate Diploma in Mental Health Nursing. I gained insight about mental illness, specifically the common 
presentations and their treatments. This resulted in deep respect and admiration for people who experience mental illness. Frameworks and philosophies such as 'recovery' and 'strength model' (Mental Health Commission, 2007) gave me hope that my 'walking alongside the person' could make a difference.

On return to $\mathrm{ED}$, I questioned if $\mathrm{ED}$ care made a contribution to recovery or if "what is good for the staff and the hospital is also good for the patient" (Johnson, 1990, p. 193). The lack of knowledge and confidence of ED nurses when dealing with people who attend with intentional self-harm has come to my attention. Regardless of nurses' 'comprehensive' registrations I believe that the knowledge and confidence demonstrated is generally specialised to the area they work in.

With combined specialist skills of emergency and mental health nursing I feel I can support ED staff in increasing their knowledge about mental health issues, leading to ED being an environment where people who intentionally self-harm are welcomed and receive high standard care. My part-time work as an Emergency Nurse Advisor for the Self-harm and Suicide Prevention Collaborative Whakawhanaungatanga ${ }^{1}$ gives me a national overview of current outcomes and best practice guidelines for people at risk of suicide who present to ED. This comprehensive knowledge was the impetus to critically examine what care is provided in ED for people who attended with intentional self-harm.

\footnotetext{
${ }^{1}$ Maori term for 'getting to know each other' or relationships. This service's aim is to improve crisis care in Emergency Departments, Mental Health and Maori ${ }^{1}$ Health/Mental Health services, in a way that recognises local situations, people and resources, and builds on the guideline for The Assessment and Management of People at Risk of Suicide (New Zealand Guidelines Group \& Ministry of Health, 2003)
} 


\section{Chapter 1 - Introduction}

Suicide is a worldwide problem with approximately one million deaths in the year 2000 (World Health Organisation, 2007). It presents a serious health issue for New Zealand that the New Zealand Health strategy is addressing. Nevertheless, within clinical practice it is obvious that this area is complex. Emergency Departments (EDs) are often overcrowded and ED staff uncomfortable in mental health care. The literature identified that some individuals re-presented to ED with intentional self-harm. However, the people that re-present within a short time to ED after an ISH presentation have seemingly not been addressed so far.

This first chapter describes statistics concerning intentional self-harm; and the current New Zealand Health Strategy. Definitions of 'Intentional self-harm' and 'Re-presentation' will follow. The third section explores historical and current service provision; overcrowding; rationale, aims and the method. Lastly, an outline of this thesis is provided.

\section{Statistics related to suicide and intentional self-harm}

In New Zealand a total of 502 people died by suicide in 2005 of whom a high percentage were Māori (Ministry of Health, 2007b). In 2003 - 2005 the average suicide rate for Māori males was 28.4 deaths per 100,000 people, compared to 18.4 deaths for non-Māori males (Ministry of Health).

Men are more likely to commit suicide (Hawton \& James, 2005) while women are three to four times more likely than men to engage in self-harming behaviour (Fox \& Hawton, 2004). The World Health Organisation's suicide statistics of $15-24$ year old females showed that in 2004 New Zealand had the highest rate (10.5 per 100,000) amongst 12 selected OECD countries (Ministry of Health, 2006b). A 2001 survey of 12,934 New Zealand adolescents found that 29 percent of female students reported having thoughts of suicide, 11 percent had made an attempt and 18 percent reported depression in the previous 12 months (Adolescent Health Research Group, 2003). 
The New Zealand Ministry of Health reported that there were 5,400 admissions to hospital for intentional self-harm in 2006 (Ministry of Health, 2007b). People who were admitted several times for the same ISH event were counted once only, whereas further separate ISH events were counted once for each event. Among Māori, the rate is nearly one and a half times that of non-Māori (Ministry of Health). Compared to 2005, the rate increased by 15 percent for Pacific people, by 9 percent for European/others and decreased for Asian people by two percent in 2006 (Ministry of Health). Excluded from this data were people who presented to their GP or who were seen in ED without being admitted. The true prevalence of ISH is difficult to determine but people who seek medical help are probably the 'tip of the iceberg' (Cleaver, 2007).

Non-fatal self harm is one of the strongest predictors of suicide (Gunnell, Bennewith, Peters, House, \& Hawton, 2005). Amongst those making non-fatal suicide attempts approximately 50 percent will make at least one further attempt with one in 10 ultimately dying by suicide (Associate Minister of Health, 2006). These statistics call for a national health strategy.

\section{New Zealand Health Strategy}

The overarching health strategy for New Zealand identified key goals related to suicide prevention, Māori health and consumer participation. The implementation of The New Zealand Health Strategy (Minister of Health, 2006) listed 11 population health objectives. A key objective was the reduction in the rate of suicides and suicide attempts. Hence the 10 year action plan, The New Zealand Suicide Strategies 2006 - 2016 was developed. Five of the goals will specifically be considered in the outcomes of my research (Figure 1). 
- Promote mental health and wellbeing, and prevent mental health problems

- Improve the care of people who are experiencing mental disorders associated with suicidal behaviour

- Improve the care of people who make non-fatal suicide attempts

- Support families/whānau, friends and others affected by suicide or suicide attempt

- Expand the evidence about rates, causes and effective interventions

Figure 1: Five goals of The New Zealand Suicide Prevention Strategy 20062016*

*Adapted from the Associate Minister of Health (2006)

The need to improve Māori health is reflected throughout the principles, goals and objectives of The New Zealand Health Strategy. Specific objectives for Māori health development are included. Accessible and appropriate services for Māori are of importance to the recommendations resulting from this research.

From a consumer perspective, Te Hononga 2015 promotes that all services and all sectors must be person-centred by "putting people first and striving to recognise, understand and meet their needs" (Mental Health Commission, 2007, p. 18). An aspect of this research explores if service provision in ED is aligned to this directive. In order to explore this topic further the key terms 'Intentional selfharm' and 'Re-presentation' are defined as per current literature and for the purposes of the research.

\section{Definitions}

\section{Intentional self-harm}

There are numerous terms within the literature which describe intentional selfharm (ISH). These include suicidal behaviour, deliberate self-harm, self-cutting, self-poisoning, self-injurious behaviour, attempted suicide and parasuicide. Attempted suicide is an intentional action that indicates risk of harm to self and often involves injury. It is either the ingestion of drugs in excess of the recommended therapeutic dosage, and/or self-inflicted injury, with some intention of ending one's life (Vajda \& Steinbeck, 2000). De Leo, Burgis, Bertolote, 
Kerkhof and Bille-Brahe (2006, p. 14) add that it is "initiated and carried out with the purpose of bringing about wanted changes".

Deliberate self harm is when a person wilfully inflicts injury on him or herself, without necessarily intending to commit suicide (Eastwick \& Grant, 2004). It explains a range of behaviours such as cutting, burning or bruising, and includes self-poisoning (Cleaver, 2007). Suicidal ideation means "wanting to take one's own life or thinking about suicide without actually making plans to commit suicide" or more generally "having the intent to commit suicide, including planning how it will be done" (Read \& Purse, 2006). It is included in the ISH definition as it is believed that if people have these thoughts, they are at risk of attempts of suicide. Furthermore, alcohol and drug misuse are included in some ISH statistics (Fox \& Hawton, 2004), however to keep the study manageable these presentations are excluded. All ISH thoughts and behaviours are associated with great distress and suicide risk until proven otherwise (New Zealand Guidelines Group \& Ministry of Health, 2003).

Of note, the classification systems Diagnostic and Statistical Manual of Mental Disorders (DSM-IV) (American Psychiatric Association, 1994) and the International Statistical Classification of Diseases and Related Health Problems (ICD-10) (World Health Organisation, 1990) do not provide diagnostic criteria for the identification of deliberate self-harm or suicidal behaviour. There is no finite consensus of a definition for ISH and ongoing confusion exists in regards to this terminology (Fox \& Hawton, 2004).

\section{Re-presentation}

Psychological distress exacerbated by borderline personality disorder (BPD), depression and post traumatic stress disorder (PTSD) can result in repeat presentations of intentional self-harm (Donald, Dower, Correa-Velez, \& Jones, 2006; Skeem, Silver, Aippelbaum, \& Tierman, 2006; Strong, 1998). Some people state that they have been suicidal for many years, especially when suffering from depression and BPD (Forman, Berk, Henriques, Brown, \& Beck, 2004; Paris, 2004). Making a definition of 'episode' is tricky and the person him/herself might be most appropriate to define if a visit is part of the same episode when re- 
presenting. Within one Australian study repeat visits within 26 weeks was described as the same episode of illness (Claassen, Kashner, Gilfillan, Larkin, \& Rush, 2005).

A re-presentation shortly after an initial visit is often linked to the same episode of psychological distress. Within ED terms, doctors and nurses ask if symptoms had receded and if things were 'back to normal' before they became worse again. If this is answered 'No', it is still the same episode. For this study, the assumption is made that a re-presentation within one week is probably linked to the initial presentation to the emergency department. Intentional self-harm and representations to ED are a fairly recent phenomenon in New Zealand.

\section{Historical and current service provision}

The way New Zealand and many other countries care for people with a mental illness and/or intentional self-harm behaviour has significantly changed since the colonial period. Williams (1987) portrayed that mental illness was poorly understood. People that were difficult to care for, unclean and had complicated behaviours were considered 'socially undesirable'. They were sent to jail for safe keeping. Taking humanitarian issues into consideration, asylums were established between 1854 and 1872 (Williams). People sent to asylums were referred to as 'lunatics'. Many people stayed for life. The mid $20^{\text {th }}$ century saw increased understanding of the origins of mental illness and the discovery of psychotropic medication. Asylums became known as psychiatric hospitals. Due to changes in societal perception and issues of funding these hospitals were transferred to the regional hospital boards in 1972. This saw the beginning of deinstitutionalisation and the concept of community care. The shift of resources to the community and the closure of the psychiatric hospitals directly impacted on the increase of ED presentations for intentional self-harm. Despite being cared for in the community these 'socially undesirable' people remain stigmatised.

Besides ED, General Practitioners (GPs), Community Mental Health Teams (CMHTs), Alcohol \& Drug Services and Child \& Adolescent Services provide care for people who engage in ISH behaviours in the community. However, 
families/whānau and friends frequently report that they find it difficult to access support from services, which is confirmed by Johnson (1990). The Mental Health Line and Samaritans are also community support providers.

The Mental Health Line provides telephone triage in order to facilitate access to mental health services, and to provide information on behalf of the District Health Boards (DHBs) (St. George et al., 2006). It has a role in directing and connecting users to the appropriate service based on need and urgency, using a standardised, computerised risk assessment tool. It does not provide counselling services; hence some people still feel the need to attend the emergency department. Samaritans is a service available 24 hours a day for people requiring confidential listening and telephone support. Their advice might be for the person in crisis to attend the nearest Emergency Department.

Despite ED being a busy environment, with little privacy and no staff specifically trained in mental health issues it serves as a key gatekeeper for admission to hospital, delivers health care and provides a safe environment for the person who intentionally self-harms.

\section{Overcrowding}

This study was undertaken in a tertiary hospital, situated in a multicultural city of approximately 400,000 inhabitants. The hospital's ED is typical of any large hospital in New Zealand, providing free 24 hour, 365 days a year emergency service for people requiring emergency health care. Health professionals in the ED have comprehensive knowledge and skills pertaining to physical and trauma conditions, the majority of their work. No clinicians with mental health expertise are specifically employed. In addition to the ED, there are two After-Hours Medical Centres open seven days per week until $11 \mathrm{pm}$. These facilities are decreased at the weekend. Despite these centres offering similar services to the ED such as suturing and X-rays, and having reduced waiting times compared with the ED, some people cannot afford the co-payments and choose to attend the emergency department. 
The ED where this study was conducted has figures that show a 19 percent increase in all presentations between 2002 and 2006 (Manager, personal communication, 1 May 2007). Internationally, most industrialised countries face similar challenges (Derlet \& Richards, 2000). A New Zealand study examining overcrowding proposed that ED is the heart of the hospital (Richardson, Ardagh, $\&$ Gee, 2005). It examined patient flow into ED, the capacity to deal with patient load and the ability to transfer patients out of the emergency department. This model highlights the need to intervene at each of the three points to promote hospital throughput. However, Stokowski (2007) indicates that a crowded hospital is the true source of a crowded ED, created by theatre lists and a mismatch in demand and supply.

Understandings of overcrowding by medical and nursing staff such as the aforementioned, influence care provision for people presenting with intentional self-harm. ED staff has the belief that people should not present unless it is an 'accident' or 'emergency' situation. Some ED staff feel frustrated with patients displaying characteristics of 'revolving door syndrome' (Heslop, Elsom, \& Parker, 2000, p. 140). Re-presentations contribute to overcrowding. Frequently, people who are perceived by staff to present with minor ailments that could be dealt with by a GP are classified as 'inappropriate attenders'. Sanders (2000) suggests these attitudes 'blame the patient' and are the results of a medical bias. Interestingly, a recent New Zealand study found that there was poor to moderate agreement between staff about which ED visits were appropriate (Elley, Randall, Bratt, \& Freeman, 2007). It showed that in 15 percent of cases, professionals gave a different response to the same case on different occasion. These findings suggest that those assessed as having a non-urgent ED problem may receive variable care depending on the clinician.

Overcrowding in ED impacts on where and how long people wait. Clarke, Dusome and Hughes (2007) found that mental health patients spent an average of two hours longer in the ED than patients with a medical or trauma presentation. Wide-ranging responsibilities of the mental health Crisis Assessment and Treatment Team (CATT) can affect their availability for performing mental health assessments in the emergency department. Long waiting times for people who 
present with ISH contribute to people leaving the ED without being seen (Thompson, 2005; Wishart, Knight, \& Gehlhaar, 1993), which in turn leads to people re-presenting (Crawford \& Wessely, 1998).

\section{Rationale}

The rationale for this study is manifold. Firstly, the number of people engaged in suicide and intentional harm in New Zealand is high. Secondly, the New Zealand Health Strategy has a strong focus on suicide prevention, improved care and expansion of the evidence around intentional self-harm. Thirdly, this is an opportunity to examine if guidelines published about people at risk of suicide are followed in this emergency department. Fourthly, documentation of clinical notes might illuminate if emergency nurses and doctors experience the care for people who intentionally self-harm challenging. Lastly, no other research regarding this subject was found. The knowledge gained from this study can contribute to change in service delivery with the aim of addressing the distress people involved in ISH face and to lessen the need for further presentations to the emergency department.

\section{Aims and objectives}

The aim of this study was to describe what factors contribute to people representing to the emergency department (ED) within one week of a previous visit for intentional self-harm. Objectives identified were to:

- describe the people included in the sample using demographic and clinical features

- describe and evaluate ED assessment and treatment pathways in ED including discharge and follow-up arrangements

- compare first and second presentations

- identify possible personal or system reasons as to why people re-present to ED within one week 


\section{Method}

The method chosen to achieve the aim and objectives was a descriptive retrospective study. A list of people that attended a New Zealand ED repeatedly with ISH in 2006 was examined and the people that presented with ISH and then re-presented within one week for any cause were selected. Variables to be examined were chosen before clinical notes of this sample were scrutinised. Analysis of the data consisted of descriptive and inferential analyses with the use of the Statistical Programme for Social Science (SPSS). In addition, a log book provided additional data where themes were identified and used for scenarios.

\section{Thesis outline}

This thesis is presented in six chapters.

Chapter 1 explored statistics concerning intentional self-harm; the current New Zealand Health Strategy; and definitions of 'Intentional self-harm' and 'Representation'. Historical and current service provision; overcrowding; rationale; aim and objectives; and the method of the study were provided.

Chapter 2 contains a literature review that describes and critiques what is presently known about intentional self-harm and the care provided by the emergency department. The literature on re-presentations to ED; repeat intentional self-harm; the link to physical complaints and risk factors are critically reviewed. Findings related to the different populations that are involved in repeat ISH are presented. Lastly, views of ED staff and patients in regards to ISH will be discussed.

Chapter 3 describes the clinical view from my perspective as a nurse, which focuses on people's journey through ED when they present with intentional selfharm. It will initially describe the emergency department setting; explain what happens on arrival and what the ongoing assessment and management in ED entails. Referral processes to the crisis assessment and treatment team (CATT), as well as various departure and admission options are stated. Finally, the representation process is discussed. 
Chapter 4 is the methodology chapter. It explores different methodologies that were considered to answer the research question, followed by the discussion of the chosen methodology, which was descriptive research. The development of the data extraction tool and chosen variables is explained. Ethical implications, as well as rigour and validity are discussed at the end of the chapter.

Chapter 5 contains the findings of this study. The findings are presented in three sections. Section one consists of a general overview of data acquisition and the sample. Section two includes variables concerning the person such as demographic data and background history. Section three presents variables that relate to peoples first and second presentation and includes arrival information, ED management; discharge and referral services from the emergency department.

Chapter 6 discusses the issues for ED and mental health services raised by this thesis. It makes recommendations for some areas of practice, education and further research. 


\section{Chapter 2 - Literature review}

This chapter explores the gap in knowledge about people who re-present to the emergency department within one week of a presentation for intentional selfharm.

Identified research was retrieved from many sources. Databases consulted were Cumulative Index of Nursing, and Allied Health Literature (CINAHL), Proquest, PsychINFO, Cochrane and Medline. Key words used were emergency services, emergency care, self-inflicted injury, self-injurious behaviour, intentional injury, attempted suicide, intentional self-harm, repeat presentation and frequent user. Other literature was obtained from the Self-harm and Suicide Prevention Collaborative Whakawhanaungatanga, which had up-to date research. Resources consulted were mostly journals, but also books, conference papers, government publications and other people's theses.

Issues of definition of ISH arose. Many studies used 'suicide attempt', indicating that people wanted to end their life. Other research used 'deliberate self-harm', 'self-poisoning' or 'cutting' which is related to self-injurious behaviour, many times related to great distress, but not necessarily associated with wanting to kill self. To encompass suicidal behaviour and deliberate self-harm within one definition, these behaviours have been referred to as 'intentional self-harm' (ISH) when appropriate in this literature review.

The chapter commences with literature findings in regard to re-presentations to the emergency department in general and related to intentional self-harm. The link between physical health and mental health presentations, as well as risk factors and populations who engage in intentional self-harm will be explored. The final section of the chapter reports on what is known about the views of ED staff and patients related to intentional self-harm. Findings from the literature review were used to shape the research design. 


\section{Re-presentations to the Emergency Department}

Various populations present to ED on numerous occasions, such as the homeless and people with a history of asthma, which will be briefly discussed. Redelmeier, Molin and Tibshirani (1995) in a Canadian randomised controlled trial found that homeless people visit ED on average seven times a year. The 133 adults were divided into a compassionate care group where volunteers provided food and conversation and a conventional care group where there was no contact with volunteers, but the treatment by clinical staff was the same. The compassionate care intervention resulted in a one third reduction in the number of return visits within one month. One explanation for repeat visits given by the authors is that patients tend to return frequently until they are satisfied with their treatment.

An Australian longitudinal observational study which involved 293 patients with moderate or severe asthma found that people who displayed an avoidance of coping and had resistance to self-management had a high rate of repeat visits (Adams, Smith, \& Ruffin, 2000). This included not liking taking medication, a low desire to be 'in charge', not possessing a written asthma action plan and no money for GP visits. Limited utilisation of GPs due to costs is also an issue in New Zealand (Raymont, 2004).

A commonality exists between people who intentionally self-harm and homeless people, as a proportion of both groups attempt to get their needs met on the second visit to ED (Pembroke, 2006; Redelmeier et al., 1995). The 'struggle to take charge of their lives' found with people who attend with asthma repeatedly can be compared with people who repeatedly intentionally self-harm, as they report feeling a "loss of thoughts, emotions and actions" (Strong, 1998, p. 41). Nevertheless, reasons for re-presentations to ED vary between individuals.

\section{Repeat intentional self-harm presentations to ED}

Little research was found concerning the time frame of return visits to emergency departments. Some studies focused on the number of repeat presentations whereas others mentioned the time to re-presentation. 


\section{Number of repeat presentations}

A United States of America (USA) descriptive study included 75,815 patient visits to a hospital-based psychiatric emergency service (Claassen et al., 2005). It compared the rate of return visits to the psychiatric emergency service for patients presenting before and after the adoption of 'Behavioural Managed Health Care'. They found that 26 percent of patients made at least one return visit within 26 weeks of a previous visit. Managed care, consisting of reduced inpatient care and increased outpatient care, delayed but did not eliminate return visits. Given the size of the USA compared to New Zealand, the study size is enormous and unable to be compared to a New Zealand setting.

In an Australian descriptive cohort study that included 239 presentations, Starling, Bridgland, and Rose (2006) used ED hospital records to obtain data on children who presented to a paediatric ED with mental health problems. The data collected included method of arrival, demographic information, symptoms at presentation, history and ED management for people who presented with ISH and behavioural disorders. They reported that 22 percent of children were seen in ED on two to five occasions. This study is specific to children and although it mentions the number of re-presentations during the study period, it does not look at a certain time frame post discharge from the emergency department.

Chitsabesan, Harrington, Harrington and Tomenson (2003) performed a randomised controlled study in the United Kingdom (UK) that involved 162 children that had taken an overdose. Family intervention was received by 85 children and 77 children had routine care. Data was collected at baseline, two months and six months with children undergoing a range of assessments. Increased repeat self harm happened within the first two months of the first attempt with the majority of children incorrectly being classed as low risk. A significant number of people $(n=273)$ did not participate in the study, which could have changed the outcome. 


\section{Time to re-presentation}

Three research studies addressed a small time-frame between presentations for ISH to emergency departments (Gilbody, House, \& Owens, 1997; Gunnell, Bennewith, Peters, Stocks, \& Sharp, 2002; Wilkinson \& Smeeton, 1987).

A UK retrospective cohort analytical study by Gilbody, House, and Owens (1997) included 1,576 patients that had a psychosocial assessment in ED after ISH and were followed up for 12 months. ISH was repeated by 193 (12\%) within one year; and was more common and occurred more quickly in those who had more than one previous presentation. Median time to repetition was 84 days, but about 10 percent repeated within a week. No further information about the type of ISH or the sample population was provided. In comparison, 127 people of different ethnicity and with various ISH presentations to an ED in New Zealand over 12 months was discussed by Hatcher et al. (2005). Re-presentation rate to ED was 15 percent and the median time between repetitions 49 days. This indicates that representations to ED with ISH are possibly more common in New Zealand, though requires further investigation. Information in regard to the time period of the representation after an index episode was not further investigated.

From a General Practitioner (GP) perspective, a UK study by Gunnell et al. (2002) included 968 consecutive patients who attended ED following an episode of intentional self-harm. Information on consultation patterns was available for 681 (70\%) of patients and showed that approximately one half of the people who attended ED with ISH had consulted their GP after one month, with 31 percent patients consulting their GP in the week following the episode. Over the 12 months follow-up 17 percent of patients attended ED for repeat ISH, 9 percent of these within one week and 28 percent within four weeks.

Wilkinson and Smeeton (1987) conducted a prospective study in 1980 and investigated repeat presentations of people with ISH to the Edinburgh Regional Poisoning Treatment Centre for one year. The study focused on gender and age of people in relation to single versus repeat presentations and time to re-presentation. For those 259 people who presented on several occasions, they found them to be 
more likely to be re-admitted from as little as four days after a given episode. This study is outdated, conducted in the UK and focuses on few specific variables.

Although the short time frame between presentations for ISH was investigated by the aforementioned studies, no link was made to re-presentations for any cause within a short time-frame after an ISH presentation.

\section{Link between physical and mental health presentations}

Re-presentations to ED with ISH are well researched, though the connection between ISH and physical health has received less attention. A nationwide cohort study in New Zealand found that a substantial relative risk for suicide was associated with previous hospitalisations for self-injury, injuries of undetermined causes, and assault (Connor, Langley, Tomaszewski, \& Conwell, 2003). Colman et al. (2004) conducted a prospective cohort study of 478 individuals in Canada and compared rates of utilisation of the ED by three groups: people who presented with ISH, asthma and 'other'. They found that rates of return visits for ISH was approximately 20 times greater than the other groups. The ISH group had higher rates for self-inflicted injuries, mental disorders, substance abuse, unintentional injuries, assault, headache pain, and other complaints. The findings were similar to those by Connor et al.

Strong (1998) found that while people with post-traumatic stress disorder (PTSD) try desperately to avoid reminders of the trauma, they often compulsively reexpose themselves to further victimisation in the form of abusive relationships, dangerous risk-taking behaviour, or acts of self-harm. One form of dangerous risk-taking behaviour can involve driving a car. In an Italian study the link between suicidal intent and single-car accident driver was researched (Pompili, Girardi, Tatarelli, \& Tatarelli, 2006). Although the suicide risk was found to be low, the participants reported that the accident played a role in looking for a solution to their problems. The study failed to mention if hospital staff was aware of the mental state of the person involved in the road traffic accident. Awareness could ensure risk assessments, appropriate follow-up care and possibly reduce representations to the emergency department. 
The above studies clearly showed a connection between physical health and ISH, yet specific time-frames between presentations to ED with ISH and physical health were not explored.

\section{Risk factors}

Risk factors associated with a one-off ISH episode differ from factors associated with repeated episodes (Forman et al., 2004; Vajda \& Steinbeck, 2000; Zahl \& Hawton, 2004). Forman and colleagues in the USA administered a series of assessment scales and clinical interviews to 153 participants who came to ED after intentional self-harm. The participants were predominantly poor and nonwhite. They found that individuals with histories of multiple ISH had a particularly severe clinical profile characterised by an extremely high degree of psychopathology, suicidality, and interpersonal dysfunction. Multiple attempters were likely to be at high risk for future ISH and were in great need of clinical intervention.

Vajda and Steinbeck (2000) on the contrary found that previous ISH was not a predictive risk factor for further intentional self-harm. Their study involved the investigation of potential risk factors associated with repeat ISH among 112 adolescents in Australia. They stipulated the possibility of the risk of repetition being directly related to the actual number of previous ISH episodes rather than their mere occurrence. Yet, they affirmed that the risk factors associated with a one-off ISH episode may differ from factors associated with repeated intentional self-harm.

The risk of suicide is elevated for people who repeatedly intentionally self-harm (Cooper et al., 2005; Zahl \& Hawton, 2004). The prospective cohort study by Cooper et al. included 7,968 ISH attendees at multiple EDs in the UK. An approximately 30-fold increase in risk of suicide compared with the general population was observed for the whole cohort and was highest within the first six months after the index self-harm episode. In agreement, Zahl and Hawton's mortality follow-up study in the UK on 11,583 people that presented with ISH to 
ED showed that 39 percent repeated intentional self-harm. The aforementioned studies showed that an increase number of ISH presentations are possibly linked to further ISH or even suicide, yet none investigated repeat ISH within a short time-frame.

Risk factors for ISH incorporate a complicated array of demographic, psychiatric, genetic, familial, personality and social factors (Donald et al., 2006; Wishart et al., 1993). Many people with exposure to risk factors do not develop suicidal tendencies. Of those with depression only a minority develop ISH behaviour (Beautrais, 2003), though between a quarter and a half of those committing suicide have previously carried out a non-fatal act (Hawton \& James, 2005). Intentional self harm is related to complex and confounding vulnerabilities and is not just a response to a single stressor (Fox \& Hawton, 2004). According to De Leo and colleagues (2006) ISH is undertaken with the intention to stop some unbearable situation. It is often linked to a clear precipitant, an event or circumstance, which has caused a crisis for this individual (Fox \& Hawton). Death presents a solution to a problem and sometimes a more appealing option than living (De Leo et al.). Some known stressors might affect some, but not others.

Reasons for distress can lie in problems with bullying, bereavement, housing problems, abuse, race/culture/religion, growing up, money and pressure to fit in (Fox \& Hawton, 2004). However, reasons for ISH are unique to the self harming individual and change over time (Cleaver, 2007; Pembroke, 2006). They are often associated with the onset of puberty in adolescents, a diagnosis of personality disorder (PD) and post traumatic stress disorder (PTSD). Surprisingly, self mutilation has been described as "a way of preserving life and avoiding suicide" (Strong, 1998, p. 153). The reasons why people cut them self include that they feel emotionally abandoned, which is strongly related to dysfunctional family system, sexual abuse, childhood illness. Parental mental health was also seen as a risk factor by researchers (Chitsabesan et al., 2003). According to Strong, cutting bouts are generally precipitated by an experience - real or perceived - of loss and abandonment. Cutting provides a move from a place of passive helplessness to active control. Self-cutting can become habitual and usually only visible when 
extreme (Fox \& Hawton, 2004), which is when they present to ED and possibly re-present numerous times.

Whilst genetic and biological factors, social dynamics, childhood adversity, and personality characteristics may act to determine individual susceptibility to suicidal behaviours, the major risk factors for ISH are mental disorders (Beautrais, 2003). Young people have a less concrete mental state (Fortune \& Clarkson, 2006) and the impairment to daily functioning caused by mental illness may exceed their coping capacity (Vajda \& Steinbeck, 2000). The most commonly identified psychiatric diagnosis in relation to suicidal behaviour is depression (Cleaver, 2007; Donald et al., 2006; Fox \& Hawton, 2004; Vajda \& Steinbeck, 2000), often in association with misuse of alcohol (Donald et al., 2006; Fox \& Hawton, 2004; Hunter \& Harvey, 2002; Modesto-Lowe, Brooks, \& Ghani, 2006; Vajda \& Steinbeck, 2000; Wishart et al., 1993) and drugs (Fox \& Hawton, 2004; Vajda \& Steinbeck, 2000).

Didham, Dovey and Reith (2006) examined the National Mortality database in New Zealand and examined 3,137 suicides. Risk factors identified were a general practice notation of depression and previous intentional self-harm. A previous hospital admission for a psychiatric condition had a strong association with subsequent suicide, also found by Connor et al. Skeem et al. (2006) reported similar findings when they interviewed 594 patients from a psychiatric hospital and followed them up for one year after discharge. They confirmed a high prevalence of ISH for people who have been admitted to psychiatric hospitals previously. Yet, a peak in the risk of ISH shortly after hospital discharge was not found. This is contrary to other studies, such as the systematic literature review by Pirkis and Burgess (1998) that found that up to 9 percent of people may commit suicide within one day of discharge from a psychiatric inpatient unit. Among those who died by suicide, contact with health services was common before death.

The number of identified risk factors associated with repeat ISH or suicide is enormous. Yet, there is agreement in the literature that the most common risk factors are a history of repeat ISH and a mental illness. Literature indicates that people who re-present to ED after ISH are a vulnerable group. Populations 
involved in ISH such as Māori, older people and younger people will be discussed next.

\section{Populations involved in intentional self-harm}

\section{Māori}

Epidemiological research regarding the reasons for intentional self-harm specifically for Māori is sparse as many studies do not have ethnicity as a variable (Coupe, 2000a). In a cohort analysis of Māori suicides, Coupe found that on the whole, risk factors were no different to other population groups. According to Durie (1999), Māori people with mental health issues often face stigma, discrimination, inadequate social functioning and limited financial means.

In the 1990s it became clear that Māori youth identified as at risk for mental disorders were not closely connected to family networks, to cultural resources or to the institutions of Māori society (Durie, 1999). Yet, they also lacked strong links with Pakeha ${ }^{2}$ society and its health services. Cultural alienation was not only a product of mental disorder and community alienation; it was as much a cause of distress as a sign of illness. Coupe (2003) found that after depression, the highest risk for committing suicide for Māori is a lack of cultural identity.

A New Zealand retrospective study explored ISH presentations and representation to the emergency department. It found that Māori were over-represented and used more lethal methods of ISH (Hatcher et al., 2005). The age-standardised rate of ISH for Māori males in this study was much higher at 120 per 100,000 populations, compared with the rate for non-Māori males of 36 per 100,000. For Māori $(n=50)$ one-third of presentations had evidence of involvement of drugs or alcohol in the ISH event, compared with one-quarter of cases for non-Māori. Admission rates differed, as approximately a quarter of the presentations by Māori were sent home following an assessment by a mental health professional in ED, compared to 44 percent of the non-Māori presentations. Despite the high number of Māori involved in ISH, studies that identify Māori re-presenting to ED within a

\footnotetext{
${ }^{2}$ Non-indigenous New Zealanders
} 
certain time-frame is missing. The lack of research is similar to the older population, which will be discussed next.

\section{Older people}

The number of older people is increasing and a rise in numbers of ISH among older adults is expected (Beautrais, 2003). Reasons for this were explored in a qualitative study in the United Kingdom where 15 older people (age 65 - 91 years old) were interviewed (Crocker, Clare, \& Evans, 2006). Participants recalled incidences in the community where they felt victimised or threatened on account of their age. They felt unimportant, a nuisance, or even vulnerable. The interval between the ISH episode and interview varied considerably among participants, therefore perceptions of the experience might have differed between people. Older people are thought to rarely make repeat visits to ED with intentional self-harm, as they either suddenly receive the needed support (Crocker et al.), or they die. There is very little research on ISH in the older person, yet they pose a 'significant risk' of suicide (Hawton \& Harriss, 2006) and no studies were found in respect to return to ED within a short time-frame. Yet, research involving young people and ISH are plentiful which will be discussed in more detail.

\section{Younger people}

In 2006 young people between 15-24 years had the highest self-harm hospitalisations rate at 299.9 per 100,000 for both genders (Ministry of Health, 2007b). Reasons for ISH such as impulsivity and low problem-solving skills (Fox \& Hawton, 2004) are often unique to this population group.

In a case control study Donald et al. (2006) investigated risk and protective factors for ISH among 18-24 year olds. The sample was recruited via an emergency department following an ISH episode $(n=95)$ and compared to a sample who participated in a population-based survey $(n=380)$. Identified risk factors for medically serious ISH included early school leaving, parental divorce (males only), distress due to problems with parents (females only) or friends, tobacco use, high alcohol use, depression and distress due to the break-up of a romantic relationship. Vajda and Steinbeck (2000) also discovered that 79 percent of 
Australian adolescents who were involved in ISH, did so in the context of a relationship break-up or a dispute with a family member or partner.

The New Zealand Adolescent Health Survey that randomly selected 9,570, 9 - 13 year old students from 114 schools (Fleming, Merry, Robinson, Denny, \& Watson, 2007) reported similar findings to Vajda and Steinbeck (2000). The study highlighted that 739 participants (4.7\% males, $10.5 \%$ females) were involved in ISH within the previous 12 months. Depressive symptoms, alcohol abuse, having a friend or family member attempt suicide, family violence and same-sex attractions were independently associated with increased rates of intentional selfharm.

The above section discussed different groups of people and their involvement in ISH, including the role of mental illness. It highlighted a high emphasis on risk factors, which were different within the groups. Although many studies involved young people, this was not the case for Māori and older people. None of the above studies explored risks in relation to repeat ED presentations within a short time frame.

\section{Views of intentional self-harm}

\section{Emergency Department staff}

Given that the emergency department is the place where people who intentionally self-harm often present, how ED staff work with this group is important. Various studies from the UK and Australia were reviewed. Although their health services serve more people, they are run in a similar way to New Zealand.

Herron, Ticehurst, Appleby, Perry, and Cordingley (2001) asked 218 front line professionals to complete a questionnaire to ascertain the attitudes toward suicide prevention. Mental health professionals working in the community and with previous training in suicide risk assessment were shown to have a positive attitude, whereas GP's and ED nurses showed a negative attitude. Negative attitudes such as 'suicide prevention is not my responsibility' may have resulted in staff being less likely to assess risk or to accept training in risk management. 
Mackay and Barrowclough (2005) also found a resistance to training. It involved 89 ED medical and nursing staff, that expressed higher levels of irritation and less helping behaviour where repeat ISH was perceived by staff as potentially controllable by the person. Staff did not think that their input would make a difference, so their helping behaviour decreased. Medical staff expressed higher levels of irritation, less personal optimism and reported less willingness to help people who ISH compared to nurses; which was similar for male staff compared to female staff. Male staff and medical staff saw less need for further training. Yet, many other nurses report a lack of knowledge and confidence in the management of people with mental health issues and for people who intentionally self-harm (Heslop et al., 2000; Kerrison \& Chapman, 2007; Reece, 2005).

In a participatory action research, ED nurses expressed concern about the lack of appropriate and coordinated care for patients seeking mental health services (Heslop et al., 2000). Poor attitude of ED staff was noted when they expressed that they were "dealing with those who purposefully and repetitively manipulate the health care system in order to be admitted" (p. 141). Nurses experienced frustrations and anxieties when caring for people who ISH and who had other mental health issues, especially as people waited up to 30 hours in ED and on many occasions people did not wait for an assessment or treatment.

Kerrison and Chapman (2007) held focus groups that gathered data on attitudes, experiences and opinions of ED nurses in regard to mental health patients. Participants reported that a lack of resources meant dealing with an increasing number of people with mental health issues that stayed many hours in ED; and they felt ill-prepared and reluctant to manage acutely unwell mental health patients. Communication problems arose when dealing with patient and visitors frustration due to the impact of long waiting times. Some staffs inappropriate aggressive and defensive attitude exacerbated volatile situations to the point where it caused some patients to be chemically or physically restrained. Effective communication was seen an important aspect of nursing care in ED considering that it is the first line of contact for most patients. 
Reece (2005) found some nurses were lacking an understanding of the meanings of cutting behaviour, especially when some referred to people who repeat ISH as "a waste of space" (p. 569). A number of nurses were able to see the communication of distress in ISH, though they felt inadequate to deal with it. Staff expressed that they had a desire to distance themselves as they themselves experienced distress, helplessness and rage when caring for people who intentional self-harm. Nurses felt a need to control the behaviour whilst the sample of women involved in ISH felt a lack of control over their bodies and lives.

This section indicates that many ED nurses feel overwhelmed by the high number of people that present with intentional self-harm. They report a lack of knowledge and confidence, which can create negative attitudes towards this group. This is significant to this research as documentation might highlight gaps in practice. Although clinical research in regards to staff management of people who ISH and consequent re-presentation was not found, consumer literature clearly identifies this link.

\section{Patients}

Published literature by people who intentionally self-harm was consulted to gain information on personal experiences of ED presentations and possible reasons for re-presentations. The literature portrayed people's experiences in relation to expectations of ED care; avoidance of services; choice and control; and experienced difficulties in getting help.

The foremost request of people who intentionally self-harmed and who presented to ED was that staff listened to them (Eastwick \& Grant, 2004; Reece, 2005; Storey, Hurry, Jowitt, Owens, \& House, 2005). Eastwick and Grant performed a literature review and concluded that some people who attended ED with repeat ISH thought that their needs were not met. The traditional model of a patient being assessed by a doctor was questioned as neither the most effective, nor the most important priority. Some women felt that their distress was not heard, which lead to further distress and ISH, often cutting (Reece). This is in line with Pembroke (2006) who states that when treated with respect and dignity, recovery 
is enhanced by increasing people's self-worth and further ISH episodes in the near future, especially within the following 24 hours are less likely. A group of 38 young people that had presented to ED with ISH previously, expressed that the services provided were often not helpful to them, though parents sometimes benefited (Storey et al., 2005).

The myth that people who ISH want to manipulate the system does not align with their strong desire to keep their ISH episode hidden from family and support people (Connor et al., 2003; Fox \& Hawton, 2004; Storey et al., 2005). Various studies found that people who intentionally self-harm avoid services (Storey et al., 2005; Strike, Rhodes, Bergmans, \& Links, 2006), some of these due to negative attitudes of ED staff (Cleaver, 2007; Strike et al., 2006). A number of selfharming young people reported that they were overall less likely to seek medical attention, which included overdoses and attempted hangings (Storey et al., 2005). This group of people will re-present to ED if in crisis and when usual coping strategies are not working.

The need for control and choice for people at risk of ISH was common. In a research from the United States of America, Saver et al. (2007) interviewed 15 volunteers that were being treated for depression. Many people reported that they did not receive enough information about depression and treatment options. People wanted to contribute in decision-making. This was similar to young people who took control by intentionally self-harming (Storey et al., 2005). Others voiced that they wanted ED staff to teach them how to intentional self-harm in the safest way, such as clean techniques (Pembroke, 2006; Reece, 2005). Empowerment potentially decreases the need for re-presentation to the emergency department.

A qualitative Canadian study of 15 men with a history of suicidal and aggressive behaviours and a diagnosis of bipolar disorder and/or antisocial personality disorder found that men followed a cyclical pattern (Strike et al., 2006). Negative experiences with health care providers were said to be followed by avoidance of health care settings, crisis and then by involuntary service utilisation. These men experienced fragmented pathways to mental health care; and irregular, infrequent, and unpleasant experiences with service providers. Some men interviewed felt 
that ED had more important things to do and they were not worth it. These men found it hard to develop relationships, so the provision of follow-up for this group presents a challenge.

Some people expressed puzzlement about the fact that people who presented in early stages of a physical disease such as cancer, had tests and treatments imminently offered, whereas with mental health issues, help is offered in crisis situations only (Lester, Tritter, \& Sorohan, 2004). In addition, Lincoln (2006) confirmed that the least socially advantaged group might be disproportionately denied needed care. This group included people that were male, black and arrived to the psychiatric ED alone. The possibility of returning to ED within a short time-frame is increased if no other intervention has been implemented, such as follow-up in the community.

In summary, this literature review showed that re-presentations to ED are a common phenomenon, not only for people who intentional self-harm. Yet, literature in regards to re-presentations within a short time-frame is sparse. Risk factors associated with intentional self-harm and different population groups involved in ISH were discussed. The deficit of knowledge by ED staff, and the views of patients who intentional self-harm that their needs are not met when attending ED could be seen as a contributing factor for re-presentations.

None of the studies reviewed looked in depth into the population that re-presents within a short time-frame to ED after an ISH episode. They did not mention related reasons for attendances, but concentrated on ISH re-presentations only. In addition, many studies examined re-presentations to ED generally, though none attempted to connect two presentations that were possibly related to one episode and happened within a short time-frame. That is the focus of this study. The aim is to explore re-presentations to ED within a week of an ISH presentation.

This study is significant as it explores an ED population that has probably never been examined in such detail before. Yet, it is well known that people who repeatedly become involved in ISH are at increased risk of suicide (Mitchell \& Dennis, 2006). Therefore, people that re-present to ED within a week of ISH are 
at high risk of suicide. This emphasises the rationale for this study. Given that so little is known about this group, an observational study design was chosen. It is expected that retrospective data will give adequate information on documented ED care. The next chapter will describe the clinical view of the documented care in the ED setting for people who present to ED with intentional self-harm. 


\section{Chapter 3 - Clinical view}

This clinical chapter explains what is expected to happen when people present to the Emergency Department with intentional self-harm. The documentation by receptionists, doctors and nurses of this process will be explained. The chapter commences with the arrival of people to ED, followed by the ongoing multidisciplinary assessment and management by ED; and the Crisis Assessment and Treatment Team (CATT) input. It explores what potentially happens to people on departure from ED, followed by an outline of care on re-presentation. The care that is provided is written from my perspective as a senior ED nurse. This personal viewpoint may be biased, therefore literature that confirms or provides evidence for clinical practice is referred to whenever possible.

Approximately 45,000 people presented to this Emergency Department per year, of which 34/1000 were acute re-admissions between July and September 2006 (Ministry of Health, 2006a). In 2006 there were 2,378 presentations for intentional self-harm (ISH); this included a percentage of people that attended on several occasions.

\section{Arrival at the emergency department}

The Emergency Department receives many patients with a variety of health issues at any one time and people who present with intentional self-harm arrive amid them. People who attend with ISH are often in a distressed state when they arrive; some have a definite wish to die and require foremost a place of safety, whereas others can be in a more chronic state of distress and need support. Many people arrive alone; others are accompanied by family/whānau, friends, health care professionals, police and ambulance staff. Support people can be involved in the event or aftermath of the intentional self-harm incident, provide transport to hospital, give additional information to ED staff and support a person during their stay in the emergency department. 
Some people arrive voluntarily, whilst others refuse to come to the emergency department. An involuntary arrival frequently involves the police and can take various forms. The person can either walk into the waiting room with the police or in extreme cases the person is handcuffed and restrained by them. The aim for the police is to take people at risk of ISH to a place where they can be medically and psychologically assessed.

People who attend with ISH present in different states of agitation and distress, related to thoughts or actions of intentional self-harm. Some people experience an episode of acute psychosis, which is associated with a distorted view of reality (Stuart \& Laraia, 2001). This can include command hallucinations that involve hearing voices that tell them to kill themselves or others. Aggression and violence is mostly associated with alcohol and drug use (Mental Health Commission, 2002) and can present a challenge for ED staff. This group of people are not only distressed and have decreased problem-solving abilities at hand, but further and more extreme forms of ISH is common when the desired support of the services is not provided initially (Strike et al., 2006).

The ED waiting room is not always a suitable place for people presenting with intentional self-harm. Quiet people are of serious concern as thoughts of ISH might not be conveyed to the triage nurse. People with depression who cry openly might be easier to assess, but the noisy and busy environment, especially with children present or many people arriving at once, can be further distressing to them. The typical ED environment has been considered as over-stimulating and frightening by patients with mental health problems, often adding to feelings of agitation (Clarke et al., 2007). In addition, for staff it is a challenge to assess people in this environment in a timely, sensitive and effective manner.

Some people who arrive in ED are expected by the Crisis, Assessment and Treatment Team (CATT) for a psychosocial assessment. The team consists mainly of mental health nurses that also perform the role of a Duly Authorised Officer $(\mathrm{DAO})^{3}$ and closely work with an on-call psychiatrist. CATT accepts referrals

\footnotetext{
${ }^{3}$ A Duly Authorised Officer can section people under the Mental Health Assessment and Treatment Act (1992)
} 
from people themselves, general practitioners (GPs), the police and relatives/whānau/friends. On arrival, people expected by CATT commonly receive a brief assessment by the triage nurse and a minority is initially seen by an ED doctor to assess their medical health. In the majority of cases doctors and nurses are not allocated to people expected by CATT. ED and CATT often work in isolation from each other. An interview room and office are used where people at risk of ISH are assessed, treated and admitted or discharged. The triage process for all presentations will now be explained.

\section{Triage}

All people that present to ED in New Zealand are triaged according to the Australian College of Emergency Medicine guidelines (2005). Triage is a systematic brief initial health screening process. It means to 'sort or choose' and is a way of ensuring that those who need the most urgent care are treated before patients with less urgent needs (Australasian College for Emergency Medicine, 2005). The triage assessment by the nurse is documented on the triage screen on the Electronic Patient Documentation System (EPDS); though a variety of different documentation tools are used in other ED' around New Zealand.

The triage nurse assigns all patients with a triage code from 1-5, which follows the Australian Triage Scale (ATS) (Australasian College for Emergency Medicine, 2005). Although originally only ATS was used, the publication of more specific mental health triage guidelines (New Zealand Guidelines Group \& Ministry of Health, 2003) gave additional triage guidance for certain patient groups, such as people who intentionally self-harm. The two triage scales focus on different things and as appropriate, should be consulted in combination with each other. Table 1 summarises the differences in these two codes.

The allocation of a code is based on clinical urgency as per ATS. People who are allocated a triage code 1 are to be seen immediately; they are in definite danger to themselves or others. It includes violent behaviour, possession of a weapon and restraint. 
Table 1: Triage Scales

\begin{tabular}{|c|l|l|l|}
\hline $\begin{array}{c}\text { Triage } \\
\text { Code }\end{array}$ & \multicolumn{1}{|c|}{$\begin{array}{c}\text { Treatment } \\
\text { acuity }\end{array}$} & $\begin{array}{c}\text { Description } \\
\text { (Australian Triage } \\
\text { Scale*) }\end{array}$ & $\begin{array}{c}\text { Description } \\
\text { (Emergency } \\
\text { Department } \\
\text { Mental Health } \\
\text { Triage**) }\end{array}$ \\
\hline 1 & Immediate & $\begin{array}{l}\text { Conditions that are an } \\
\text { immediate threat to } \\
\text { life }\end{array}$ & $\begin{array}{l}\text { Definite danger to } \\
\text { life (self or others) }\end{array}$ \\
\hline 2 & $\begin{array}{l}\text { Emergency } \\
\text { Within } 10\end{array}$ & $\begin{array}{l}\text { Time critical } \\
\text { intervention needed or } \\
\text { threat to life if } \\
\text { treatment is not } \\
\text { commenced within } 10 \\
\text { minutes }\end{array}$ & $\begin{array}{l}\text { Probable risk of } \\
\text { danger to self or } \\
\text { others }\end{array}$ \\
\hline 3 & $\begin{array}{l}\text { Urgent } \\
\text { Within } 30\end{array}$ & $\begin{array}{l}\text { Potentially life } \\
\text { threatening or } \\
\text { situational urgency }\end{array}$ & $\begin{array}{l}\text { Possible danger to } \\
\text { self or others }\end{array}$ \\
\hline 4 & $\begin{array}{l}\text { Semi-urgent } \\
\text { Within } 60 \\
\text { minutes }\end{array}$ & $\begin{array}{l}\text { Potentially serious or } \\
\text { situational urgency }\end{array}$ & $\begin{array}{l}\text { Mild to moderate } \\
\text { distress }\end{array}$ \\
\hline 5 & $\begin{array}{l}\text { Within } 120 \\
\text { minutes }\end{array}$ & $\begin{array}{l}\text { Less urgent or review } \\
\text { of previous results }\end{array}$ & $\begin{array}{l}\text { Should not be in this } \\
\text { group }\end{array}$ \\
\hline
\end{tabular}

*Adapted from the Australian College for Emergency Medicine (2005)

**Adapted from New Zealand Guidelines Group \& Ministry of Health (2003)

Triage code 2 is for people who present with a probable risk of danger to self or others and includes severe behavioural disturbances such as extreme agitation and aggression. It also involves suicide attempts. Triage code 3 is for people who could be a possible danger to themselves or others, which includes agitation, intrusive behaviour, withdrawal and suicidal ideation; they are classed as 'urgent' and should be seen within 30 minutes. Code 4 is for people who are in mild to moderate distress and present with no agitation or restlessness, depression or anxiety without suicidal ideation; people should be seen within one hour. A Code 5 should not be given to people who attend ED with intentional self-harm (New Zealand Guidelines Group \& Ministry of Health, 2003). People given a code 2 or below should be re-assessed every 5 - 60 minutes and up-triaged if there is a physical or mental deterioration to ensure that the urgency of care is reflected by the allocated triage code. 
A number of mental health consumers experienced that they were triaged 'at the bottom of the list', especially for self-harm presentations (Clarke et al., 2007). They found that they were labelled 'psychiatric' regardless of their presenting complaint. My experience is that people with mental health problems are at times under-triaged, possibly due to the triage following ATS, which focuses on physical issues. So, the mere presence of a mental health triage scale does not automatically lead to the nurses using it, as ED nurses are largely unprepared to triage mental health issues (Broadbent, Jarman, \& Berk, 2004). Yet, there is evidence that with the implementation of a triage scale specifically designed to highlight mental health emergencies, improvements in communication, nurses' confidence in triaging patients with mental health problems and time to intervention by mental health staff were made (Broadbent, Jarman, \& Berk, 2002).

In triage, physical aspects are considered first. People might be unconscious from an overdose, have seizures after a hanging attempt, or they are bleeding from a self-inflicted laceration. In an overdose, information regarding the amount, type of drug, lethality of drug, time of administration and the current consciousness level are important. The intent of the act should also be established early on, to ensure this persons safety.

Demographic details such as the patients' contact and GP details are taken by the receptionist and documented in the clerical window of the electronic patient documentation system. Each patient has a unique identifier called the National Health Index (NHI) number which enables present and previous presentations to be linked. Each presentation is automatically allocated an event number by the electronic patient documentation system. Both numbers are essential for ordering investigations such as blood tests or x-rays. Past presentations and 'Alerts' about the person such as allergies, management plans, a history of violence or the use of the Mental Health (Assessment and Treatment) Act 1992 can be established once the above information is obtained. An Accident Compensation Corporation (ACC) form will be completed for traumatic injuries, such as lacerations. Once triaged, people are taken to a cubicle if they need to be treated urgently or asked to take a seat in the waiting room until a cubicle is available. 


\section{Management in the Emergency Department}

The time between triage and further assessment by a primary nurse and medical staff varies. It depends on the urgency of people's presentations as per ATS/Mental Health triage guidelines and the number of people waiting. ED management discussed in this section includes physical and mental health assessment and treatment; self-discharge; legal issues; medical clearance; and the provision of a psychosocial assessment by CATT. The assessment process is ongoing and treatment is adjusted to the assessment findings. Assessment and management information is documented on the clinical notes screen on EPDS. For ease of presentation, ED care is divided into physical and mental health care, though in practice they happen simultaneously.

\section{Physical care}

Some people who intentionally self-harm require medical input before all else and psychological care is delayed until the person is medically stable, while for others psychological support is the foremost need. Arbuthnot and Gillespie (2005) found that treatments of patients attending ED after intentional self-harm tend to focus on medical rather than psychological intervention. For all patients there is an internationally recognised assessment framework (American College of Surgeons Committee on Trauma, 1997). It follows the principles of $\mathrm{ABCDE}^{4}$ and identifies in a systematic order any life threatening complications that can cause death, for example airway compromise after a hanging attempt. Vital signs such as blood pressure and pulse are taken as required and the person is monitored for deterioration or improvement. Further investigations and treatment will be performed as required and diagnoses reached or proposed. The physical care of people who have taken an overdose and who self-injured will be described, though many more ISH methods exist.

A drug overdose occurs when a person takes more than the medically recommended dose and/or medication that is not prescribed for them (Wilkinson

\footnotetext{
${ }^{4}$ Airway maintenance with cervical spine protection, Breathing and ventilation, Circulation and hemorrhage control, Disability: Neurological status, Exposure/Environmental control: undress patient, prevent hypothermia.
} 
\& Smeeton, 1987). If the person is unconscious after a serious drug overdose, intubation (insertion of a tube down the throat and machine-assisted breathing) is common. A general principle of the treatment of paracetamol (acetaminophen) overdoses is the inhibition of absorption and antidotes. Activated charcoal seems to be the best choice to reduce paracetamol absorption if administered within two hours of ingestion (Brok, Buckley, \& Gluud, 2006). Activated charcoal helps bind drugs, keeps them in the stomach and intestines, reduces the amount of drugs absorbed into the blood and is expelled in the stool (Anker, 2002). All patients have a blood test taken. A serum paracetamol concentration $>150 \mathrm{mg} / \mathrm{l}$ indicates the treatment with the antidote acetylcysteine (Bridger et al., 1998). Fortunately, most potentially toxic ingestions involve agents that are not toxic in the quantity consumed (Bond, 2002) and require observation only. Nevertheless, all overdoses are treated with caution as the person might have underestimated the amount taken or forgotten to mention all the substances ingested.

Self-inflicted injuries such as minor lacerations are cleaned, steristriped and dressed; and deeper lacerations are sutured. People with major self-inflicted lacerations are referred to the surgical or vascular team. In the past, some people have experienced health practitioners omitting local anaesthetic for suturing of self-harm lacerations (Batty, 2004). Adherence by clinical staff to hospital protocols and guidelines are vital to ensure evidenced based care. Once physical issues have been attended to, mental health care is provided.

\section{Mental health care}

The first aspect of mental health care is rapport building, which is especially important with a distressed and agitated person. The establishment of a therapeutic alliance can facilitate disclosure of information and may serve as a protective factor by encouraging a sense of hopefulness and connectedness (New Zealand Guidelines Group \& Ministry of Health, 2003). In practice, the nurse should listen to a person's distress with interest and empathy and gain an understanding of what is happening for the person. With the person's input, the nurse should facilitate a safe environment, treatment and care. The building of rapport and performing an assessment can be challenging as interruptions are 
often encountered in the emergency setting. Information gathering evolves with the trust of the person. Research has shown that the treatment by health care professionals can influence the recovery of the person (Pembroke, 2006). Effective communication skills by ED staff are essential, as these staff especially nurses, are in an optimal position to connect with people who have intentionally self-harmed.

ED staff should ask about weapons, instruments and pills that could be used for self-harm. The person should be asked to empty his/her pockets and bags if a high risk for further self-harm has been identified. Although this does not facilitate a trusting relationship and intrudes upon the privacy of the person, the safety of the person and others is the highest priority. Collateral information from family/whānau and friends is essential, especially if the person is unable or unwilling to provide a history.

Although many young people who engage in ISH tend to come from families with disturbed relationships and high interpersonal and social stress (Fox \& Hawton, 2004), which involves longstanding difficulties with family relationships (Fortune, Stewart, Yadav, \& Hawton, 2006), some parents are often unaware of their children's distress and self harm activities (Meltzer, 2000). Often family members want to be more involved, informed and supported (Clarke et al., 2007) and can often provide information surrounding the intentional self-harm.

The establishment of rapport, safety measures and appropriate family input contribute to an assessment. Within practice it tends to be brief, though should include aspects of a mental state examination (Appendix 1), a risk assessment, a history of the person's physical and mental health, as well as any relevant social issues (New Zealand Guidelines Group \& Ministry of Health, 2003). Details of this assessment are discussed later in this chapter in relation to the psychosocial assessment by CATT. Once the assessment has been performed, treatment is considered.

Mental health treatment consists primarily of medication provision. Tranquilizers such as clonazepam or lorazepam for agitation are the most frequently used 
intervention. On many occasions, zopiclone a sleeping medication is prescribed as poor sleep is a known cause for exacerbation of poor mental health. If the person is deemed to be a risk to self or others and wants to leave before an assessment, medications such as midazolam intravenously or intramuscularly might be given for sedation if restraint is needed. However, recently antipsychotic medication such as olanzapine wafers and tranquilisers such as lorazepam intramuscularly are sometimes used.

\section{Legal status}

ED seeks police assistance for people who present a danger to others including property, or if they acutely injure themselves. The police will stay until the person is deemed calm and safe. Police reported that they are not the right people to be dealing with suicidal people as they lack appropriate training (Moir, 2001). An orderly will usually take over from the police to assure a person's safety. Legally, the orderly cannot physically keep people in ED if they want to leave unless the patient is sectioned ${ }^{5}$ under the Mental Health (Assessment and Treatment) Act (1992). Section 111 is enforced if the person tries to leave ED and appears to have a mental disorder; and if he/she presents a danger to him/herself or others and/or is unable to care for him or herself. The sectioning is done by the allocated nurse in collaboration with the coordinator and senior doctor. It is often associated with the restraint of that person. Section 111 forces the person at risk of ISH to undergo a psychosocial assessment and treatment as appropriate by various health care professionals, including a senior psychiatrist within six hours. The person will be provided with a copy of the section papers and the process will be documented by the ED nurse on EPDS in the clinical notes.

The enforcement of the MHA is usually after ample communication between the nurse and the person, because ideally people should be involved in their care and consent to treatment whenever possible (National Institute for Clinical Excellence, 2004). If the Mental Health Act needs to be used, the family should be included.

\footnotetext{
${ }^{5}$ Involuntary detention
} 


\section{Medical clearance}

Irrespective of the use of the MHA, every person that presents to ED with ISH should be medically cleared. 'Medical clearance' means that the person is being 'checked out' physically to ascertain whether this person's mental un-wellness could be due to physical reasons. The process of medical clearance involves obtaining a history; performing an appropriate physical and mental status examination; and doing tests when indicated (Zun, 2005). In particular, it includes all overdoses and traumatic suicide attempts such as jumping and gassing. A sudden onset of unusual behaviour, especially in people over the age of 40 years, is often indicative of a physical cause and requires a Computed Tomography (CT) scan. Recent complaints of headache, feeling unwell and tiredness should be medically examined, as well as people with medical conditions such as diabetes or other chronic conditions. Again, family/whānau (extended family) input is of importance to get collateral information. Physical care includes a brief cardiac, respiratory and neurological examination. Routine blood tests or x-rays might be performed and treatment provided such as intravenous fluids for dehydration. If all these investigations and treatments result in the person being physically well and there is no reason to believe that a physical cause influences the person's mental state, the person is medically cleared. Only now will the person be referred to CATT by the ED doctor. Some argue that people who are 'sufficiently well and alert' could have an initial psychiatric assessment before being medically cleared (New Zealand Guidelines Group \& Ministry of Health, 2003). This recommendation is being slowly implemented and is contributing to a decrease in the wait for a comprehensive psychosocial assessment by the Crisis Assessment and Treatment Team.

\section{Psychosocial assessment}

The New Zealand Guidelines Group and the Ministry of Health (2003) recommends that all patients who attend ED with intentional self-harm should be offered a comprehensive psychiatric and psychosocial assessment, from hereon in referred to as 'psychosocial assessment', by a mental health clinician. This assessment should identify patients at risk of suicide or with vulnerabilities that make repeated self-harm more likely (Barr, Leitner, \& Thomas, 2005). When 
assessing the risk of suicide it is important to look at intent, lethality, precipitants and motivation (Fox \& Hawton, 2004). The National Institute for Clinical Excellence (2004) describes it as an "assessment of needs and risks" (p. 26).

The international literature in relation to ED reports a referral rate for a psychosocial assessment that ranged from 54 percent - 68 percent (Barr et al., 2005; Drew, Jones, Meldon, \& Varley, 2006; Gunnell et al., 2005; Starling et al., 2006; Wishart et al., 1993). Some studies found that the majority of people assessed as low or medium risk returned to ED with repeat intentional self-harm (Chitsabesan et al., 2003; Kapur et al., 2005; Vajda \& Steinbeck, 2000). Individuals who intentionally self-harm and attend ED can make a decision about how much to reveal to others (Fortune et al., 2006). The questions asked can result in answers that mean little. Literature reports debate on what should be assessed. Pembroke (2006) argues that formal assessments seem pointless in that they are too focused on risk and diagnoses. Others found that it is the meaningfulness of risk factors for the individual that is vital, not their mere presence (Crocker et al., 2006).

The assessment of protective factors for ISH should be conducted, such as social connectedness, problem-solving confidence and locus of control (Donald et al., 2006). For Māori, a cultural assessment should also be included by a person who is familiar with that culture (Coupe, 2003). The expectation is that following the assessment any necessary psychiatric treatment, social or aftercare will be provided (Barr et al., 2005).

In the ED where this research was located the psychosocial assessment is conducted by the Crisis Assessment and Treatment Team (CATT). On some occasions, CATT does not come to ED but makes plans on the phone with the patient in ED concerning the care and liaises with the appropriate community mental health team. This is in particular for people who are known to CATT and have management plans that detail the care that should be provided on each visit, unless the presentation is atypical. CATT has its own documentation system which cannot be accessed by the emergency department. 


\section{Departure from the emergency department}

Departures by patients from ED occur in the form of admission, discharge or selfdischarge. ED staff priorities lie in providing emergency care, patient safety and patient flow. Families and service recipients can view a hospital admission as a successful outcome to the ED visit, whereas mental health professionals perceive diversion to community resources as a successful outcome (Clarke et al., 2007). The most appropriate and least restrictive way of supporting people in a time of crisis should be chosen. An agreed plan of action on discharge is of benefit in order to meet people's needs and avoid further re-presentation. Information regarding a discharge plan should be documented on EPDS by CATT, though in practice the ED nurse often does their brief electronic documentation.

\section{Admission}

If people who attend ED with ISH are physically unwell, the ED doctor may admit or refer him/her to appropriate medical or surgical teams. Admissions by ED are made to the Short Stay Unit (SSU). People can be admitted for up to 24 hours observation. Surgical or medical teams admit people onto appropriate wards such as the Intensive Care Unit, medical, surgical and also the Short Stay Unit. All people at risk of ISH admitted for medical reasons should be seen by a mental health team for an assessment before discharge from these wards. Subsequently they will either be transferred onto a psychiatric ward or respite care; or discharged with follow-up by Mental Health Services.

Admissions to an acute mental health inpatient ward or Respite Care is done for people who are at risk to themselves or others and unable to guarantee their safety. Special inpatient facilities exist for children and adolescents. Admissions are decided upon and arranged by CATT and a psychiatrist. Respite Care admissions are linked with a referral to the Home Based Acute Treatment Team (HBT), which will be discussed later in this chapter. Most respite care facilities are for adults only, though some specialise for young people. The use of Respite Care is to give people an opportunity to get away from their daily routine and take 'time out'. 


\section{Discharge}

The process of discharge from ED can take many forms and should include consultation with family/whānau members. It should involve follow-up by the general practitioner, CATT, the home based treatment team (HBT) or other services.

Some people leave ED before being seen by a doctor or CATT. This is documented as 'Did not wait' or 'Self-discharge' on EPDS. Hospital records of this particular ED in New Zealand show that of all presentations to ED in 2002, $1042(6.5 \%)$ of people self-discharged (Manager, Personal Communication, 10 June, 2007). This figure reduced to 4.1 percent in 2006. It is difficult to know what follow-up is required in the case of self-discharge. Decisions about when and how much to intervene when somebody is suicidal can sometimes be difficult and arbitrary (Fortune et al., 2006). In practice, the senior doctor with nursing staff decides if the police, CMHT, CATT or the GP will be contacted. Studies from the United Kingdom found that in many cases there was no follow-up arranged (Wishart et al., 1993), and only 13 percent of patients who self-discharged received a specialist assessment (Barr et al., 2005). Self-discharge was found to contribute to repeat ED presentations (Crawford \& Wessely, 1998).

\section{Follow-up}

\section{General Practitioner}

Some people who attend the Emergency Department with ISH are asked by ED or CATT staff to arrange an appointment with their GP. The GP should have knowledge of these peoples ED presentations as ED clinical notes of all patients are faxed automatically to the GP after the day of discharge. Yet, there might be some reluctance for people to see their GP.

Lester et al. (2004) performed a study of eighteen focus groups that consisted of 39 GPs, eight practice nurses and 45 patients who had schizophrenia, depression or bipolar affective disorder. Care was described as dissatisfactory at times. Common issues reported were the difficulty in persuading reception staff that an 
urgent appointment was needed; the fact that this was discussed in close proximity to other people in the waiting room and that diminished assertiveness skills in a time of crisis were not taken into consideration.

The GP visit is associated with a cost (approximately $\$ 55$ in 2006) which could be a barrier to follow-up, even though in July 2006 the cost for GP visits have almost been halved for adults aged 25 to 44 here in New Zealand (Collins, 2007b). In the UK, where there are no GP fees, 50 percent of patients visit their GP after intentional self-harm (Gunnell et al., 2002). However, a study where people were invited by a GP who had additional mental health training found no decrease in repeat ISH episodes (Bennewith et al., 2002).

\section{Home Based Treatment}

The Home Based Acute Treatment service (HBT) consists of a team of mental health nurses. It provides support to people who are in an acute mental health crisis. In the past, these patients would have been routinely admitted to an inpatient facility. Services are provided in people's accommodation or respite care. People accepted for HBT need a level of insight into their illness so safety is assured in a less restrictive environment. Vital support people, such as family/whānau are also supported by HBT staff. During the day, patients are encouraged to attend a day program, where ongoing mental health assessments are done and activities are offered. HBT input depends on individual needs.

\section{Community mental health services}

Referral by CATT or ED to the Community Mental Health Team is common practice. The CMHT will either see patients in ED or in the community. Other community service providers are Personality Disorder Services, Child and Adolescent Services and Alcohol and Drug Services. Staff from these services is not usually seen in the ED environment.

The follow-up time from CATT services is six weeks, whereas the Home Based Treatment service intensively supports people for two weeks. After this crisis intervention, Community Mental Health services and GPs take over the care provision. Some people might choose to receive little support, though Chitsabesan 
et al. (2003) suggest a follow-up time of at least two months. ED is not involved in follow-up arrangements. Therefore, on re-presentation, ED has little idea about what happened since discharge of the person.

\section{Community management}

Information on pharmacological interventions, therapy and the internet are discussed next because on discharge from ED a combination of interventions should be in place so people do not need to return to ED unless their needs remain unmet or they experience an emergency.

Improved antidepressant drug utilisation is seen to be an important intervention for both suicide prevention and improved mental health by the Ministry of Health (2007a), though needs to be utilised with caution as $31 \%$ of antidepressant studies are not published due to negative or questionable outcomes (Turner, Matthews, Linardatos, Tell, \& Rosenthal, 2008). Some studies also showed that medication provision did not meet people's need for support (Eastwick \& Grant, 2004; Pembroke, 2006; Storey et al., 2005; Strike et al., 2006).

The Ministry of Health (2007a) performed an observational pharmacoepidemiological study (research of the use of drugs and their effects on the population) to investigate whether a relationship could be observed between antidepressant prescribing in New Zealand and suicide-related outcomes. This study found a statistically significant observed association between increased prescribing of nortriptyline ${ }^{6}$, paroxetine $^{7}$ and fluoxetine ${ }^{8}$ and increased hospitalisations for ISH events. Some reasons for this could be non-efficacy of the antidepressants; non-compliance with the medication treatment regime; and inadequate mental health and social support in the community. When commencing antidepressant medication, which is prescribed by psychiatrists, CMHTs or GPs, it takes up to six weeks for effects to set in (Lloyd, 2007). The implication is that the prescribing clinician should make regular contact with the person in the early period following prescribing and emphasises the need for

\footnotetext{
${ }^{6}$ Tricyclic antidepressant

${ }^{7}$ SSRI's - Selective Serotonin Re-uptake Inhibitor antidepressant
} 
services such as ED, GPs and mental health services to work together closely. At the onset, negotiations around medication is needed (Storey et al., 2005) to give control to the person, which can also be achieved by therapy.

Hawton et al. (1998) performed a systematic review of the efficacy of psychosocial and pharmacological treatments in preventing repetition of intentional self-harm. They concluded that there remained some considerable uncertainty about which forms of treatments were most effective. They found that significantly reduced rates of further intentional self-harm were observed for depot flupenthixol ${ }^{8}$ and dialectical behaviour therapy (DBT). Problems solving therapy and the provision of an emergency contact card indicated some effect. These results were similar to the studies by Hepp, Wittmann, Schnyder and Michel (2004) and Townsend et al. (2001).

A comparatively new medium for creating ISH awareness is the use of the internet. The Lowdown website (www.thelowdown.co.nz) provides information on depression; includes New Zealand celebrities and non-celebrities sharing their experiences of mental illness; and a chat room where people can e-mail and text, with the opportunity for a call back from staff. The identified risk for ISH is internet contagion with members organising suicide pacts, or describing ISH intentions and methods (Webb, Burns, \& Collin, 2008). As a means of communication the internet may discourage people with a mental illness from seeking psychiatric help (Alao, Soderberg, Pohl, \& Alao, 2006). At The Lowdown staff identifies people at risk of ISH, communicate with them, and potentially ISH can be prevented. Pembroke (2006) suggests that the internet is used by people who believe that mental health services will not be available for their needs. It can present an alternative to seeking help from the emergency department. In conclusion, managements in the community such as medication, therapies and the use of the internet potentially provide support to people after an ISH presentation to the emergency department.

\footnotetext{
${ }^{8}$ Intramuscular antipsychotic injection, administered approximately every four weeks
} 


\section{Re-presentation}

\section{Emergency department management}

People who re-present to the Emergency Department after an initial attendance for ISH follow the identical process of triage, ED assessment and management, CATT involvement and discharge arrangements than before. In my experience, people with a history of ISH rarely admit to previous presentations. Surgical or medical patients on the contrary often state "I was here and your treatment did not make me better!" Previous presentations can be accessed via the patient tracking screen on EPDS, though this is done arbitrarily by doctors and nurses in ED (Senior House Officer, Personal Communication, 20 February, 2008). Previous follow-up plans are often unavailable due to lack of shared documentation between services. Documentation by the ED staff in regard to follow-up is often incomplete.

The ED environment is not designed to provide continuity of care so people who re-present are usually not seen by the same doctor or nurse that cared for them previously. Each presentation should be treated seriously even if people attend ED many times with ISH (National Institute for Clinical Excellence, 2004; New Zealand Guidelines Group \& Ministry of Health, 2003). Existing management plans for people who present to ED on many occasions are consulted on arrival.

ED has a protocol that relates to 'Unscheduled patient return visits to the Emergency Department' (Name District Health Board, 2006). All ED patients who return within 72 hours with a similar complaint should be seen or reviewed by a senior doctor. However, in practice this protocol does not apply to people who re-present with intentional self-harm (Senior Clinician, Personal Communication, 29 March, 2007). These people should have been referred to CATT in the first instance and if they return to ED, it is viewed as a failure of the mental health services and not related to ED care. Although people will get seen by an ED doctor as required, CATT is expected to assess and follow this patient group up. People on management plans are excluded from this protocol. People that were asked to see their GP might not have done so and are the responsibility 
of whichever team advised a GP visit on their initial presentation to the emergency department.

It is my observation that CATT team members are resistant to assess some people who repeatedly attend with ISH, unless there is a history of life-threatening intentional self-harm. CATT deals with 'crisis' and has limited resources in staff and admission beds for supporting people with long-lasting complaints. This is confirmed by Barr et al. (2005) who found that with repeat visits for self-harm, especially for lacerations, the likelihood of a psychosocial assessment decreased. Management plans developed by all services and agreed by people involved in ISH are a key aspect to the care of this group.

This chapter described methods of clinical practice for people who present and represent to ED with intentional self-harm. It highlighted the usual care provided by ED and CATT with its challenges and difficulties. The following chapter presents an overview of the methodology chosen for this research. 


\section{Chapter 4 - Methodology}

\section{Introduction}

This chapter will outline methodologies considered suitable for this research on people who re-present within one week of a presentation for intentional self-harm (ISH) to the emergency department (ED). In order for the most appropriate study design to be used, various research options were explored. Research designs should be selected according to their appropriateness and ability to provide answers to the research question identified (Getliffe, 1998). There was very little known about this subject in the international and New Zealand context, and a broad view was required to get acquainted with this population and phenomenon. Hence, a descriptive study using retrospective data on ISH presentations to ED and re-presentations within one week was selected as the most fitting methodology. Prior to describing the particular design used in this research, this chapter provides a brief overview of other methodologies and provides the rationale for why these were not considered appropriate for this study. The chosen methodology of descriptive research will be further explored. The study design, including the development of the data extraction tool and chosen variables will be discussed. Issues concerning the retrieval of the data; the analysis; ethical implications, rigour and validity are discussed.

\section{Exploration of methodologies}

There are a vast number of different research approaches available to researchers. Experimental versus non-experimental designs were considered. In order to answer the question of this thesis, non-experimental was found to be the most suited, as the extent of the problem was unknown and thus there was no basis on which to develop an intervention. Once more is known about the issues in regard to re-presentations, it should be possible to determine whether one of the many ED based interventions (Kapur et al., 2005; Redelmeier, Molin, \& Tibshirani, 1995) could be trialled in the New Zealand setting to support this patient group. 
Non-experimental research designs are typically used when "it is not practical, possible, feasible, or desirable to manipulate an independent variable" as would be crucial in experimental research (Cottrell \& McKenzie, 2005, p. 186). Such research can be done retrospectively and prospectively, which will be discussed further later in this chapter. For this study it was recognised that a number of people re-presented to ED within one week after an initial visit with ISH, but as little else was known about the group, a retrospective study seemed most fitting. The research methodology needed to be able to provide a comprehensive description of the people who presented to ED with ISH and re-presented within one week.

In this section I will discuss methodologies that were taken into consideration in order to answer the research question; these consisted of qualitative studies using interviews, longitudinal prospective studies and prospective observational studies.

A qualitative study using semi-structured interviews was considered as it might have illuminated the reasons behind repeat presentations. Interviews attempt to "understand the world from the subjects point of view" and to unfold the meaning of peoples experiences (Kvale, 1996, p. 1). Interviews with either staff, consumers or family members, or with all three groups could have highlighted what was happening that led people to re-present to ED and could have identified system or treatment gaps. Interviews with ED doctors and nurses would have drawn attention to the knowledge base of best-practice guidelines regarding people who re-present within a short time-frame with ISH and their thoughts and feelings around those presentations. Interviews with consumers would have given some information about what the person experienced, or recalled of the experience of both what happened at the first and second ED presentation, as well as in the intervening period before the re-presentation. Family/whānau and peer support interviews would have highlighted what family/whānau considered contributed to presentations and re-presentations to the emergency department.

Although the interview technique has been used with young people who self-harm (Storey et al., 2005), with consumers who use a liaison service (Eales, Callaghan, \& Johnson, 2006), with suicidal men in relation to pathways of care (Strike et al., 
2006) and as a comparison between women who self-harm and nurses who care for them (Reece, 2005), no identified study focused on the population that represented to ED within one week after an ED presentation. However, the interview method was not chosen as the number of people who re-present was unknown, and the timing of interviews could be problematic clinically. Research would need to consider that in a time of crisis, a person's decision to participate and divulge information might be influenced by their current mental health status. In my case, people may confuse the role of the researcher with the clinical role if I had cared for them in the past. People who intentionally self-harm are a vulnerable group that requires strict ethical and clinical consideration (Health and Disability Commissioner, 1996).

A longitudinal prospective study was also considered. In such a design data are collected from the same group of participants at different points over a long period of time (Schneider, Whitehead, \& Elliott, 2007). Data can be collected via surveys or interviews at specific intervals. As there was no knowledge of what variables were worth looking at in the long term, this methodology seemed unsuitable. It also needed to be deliberated that when enrolling people for this kind of study consent from the person is needed. Participation in this kind of study might influence presentation behaviour to ED as people might stay away because they know that visits were being 'counted'. There is the possibility that this kind of study does not truly represent what is going on for people who attend ED with ISH and re-present within a short time-frame.

Finally, a prospective observational study was considered. Regular observations of ED presentations could identify people who re-presented within one week. Yet, at the start of this study it was unknown if this was an issue and what the number of participants would be. This was not considered due to the short length of time available to complete this research.

All of the above mentioned methodologies were found not to be the most fitting as they were not suitable to answer the question. For this study, descriptive research using retrospective data from clinical notes was found to be the most effective way of filling the gap in regard to baseline knowledge about the documented 
presenation and management of people that attended ED with ISH and then represented within one week in 2006. The 12 month period was chosen as it was expected to provide a sample size that could be managed within the requirements of this research project. Reasons for the selection of the year 2006 were that the records were easily available as they were reasonably current; it had computerised data available such as clinical documentation; and protocols and procedures in ED and mental health had not changed.

\section{Descriptive research}

Descriptive studies are most fitting if there is little known about a subject; in this case re-presentations to emergency departments within a short time frame after intentional self-harm. Descriptive studies involve the portrayal of the health status of a population or characteristics of a number of people and attempts to find correlations among such characteristics (McKenna, Hasson, \& Keeney, 2006). Descriptive studies state 'what is' and 'how many' of 'what'? (Gillis \& Jackson, 2002), in order to establish: "What is happening here?" It can often be the starting point for further studies that ask 'Why' questions (Walsh \& Wigens, 2003). Descriptive research cannot provide insight into why the phenomena of interest is occurring (Polit \& Hungler, 1985) as a cause-and effect relationships between variables cannot be established (Schneider, Whitehead, \& Elliott, 2007) as it is a non-experimental design. This research method enables looking at the broad picture.

Descriptive research does not fit neatly into the definition of either quantitative or qualitative research methodology, but can utilise elements of both, often within the same study (Knupfer \& McLellan, 2001). Areas such as criminology use descriptive research. Criminals and their characteristics, as well as interactions between criminals and their victims are intensely studied (Brink \& Wood, 1998). Within nursing, characteristics of patients and reasons for presentation to health services are frequently reported (Cook et al., 2004; Specht, Singer, \& Henry, 2005; Starling et al., 2006) to understand a phenomenon. 
Data collection methods in descriptive research include interviews, questionnaires and observations (McKenna, Hasson, \& Keeney, 2006). The latter was chosen for this study. Observational methods are the methodological backbone in disciplines such as anthropology, zoology and astronomy (Polit \& Hungler, 1985). Within health, observational study designs have become an increasingly important source of evidence technique and are seen as complementary to randomised controlled trials (Ligthelm et al., 2007). A retrospective observational study which was chosen for this study involves examining data that entails information about events in the past. Analysis of clinical records, in this case electronic hospital notes was performed. It provided an opportunity to look at the clinical practice of health practitioners. Findings in the data between the first and second presentation were compared to investigate whether there was a difference between them.

Although observational studies rank low according to the hierarchy of evidence (see Figure 2) it is still a fitting methodology to gain knowledge about this group.

1. Systematic reviews and meta-analyses of randomised controlled trials

2. Randomised controlled trials

3. Non-randomised intervention studies

4. Observational studies

5. Non-experimental studies

6. Expert opinion

Figure 2: The hierarchy of study types*

*Adapted from Harbour \& Miller (2001). British Medical Journal

In conclusion, the methodology chosen was a descriptive research that used a retrospective observational design.

\section{Study design}

Once the research approach was chosen, details of the design were determined. The remainder of this chapter will describe the included sample, the development of the data extraction tool and the variables used. This is followed by an outline of 
the retrieval of the data and the analysis undertaken. Ethical considerations and the steps taken to ensure valid findings from the research will be discussed.

\section{Sampling method}

The sample consisted of people who presented to ED with intentional self-harm in 2006 and then re-presented to that ED within one week for any reason. Inclusion criteria were people who attended ED at least twice within one week, the initial presentation being related to intentional self-harm. People of all age groups were included. The fact that people were suicidal, involved in self-harm or attempted suicide at the initial visit needed to be documented or strongly implied in the triage documentation or clinical notes on EPDS. It was not required that ISH was noted as the reason for their attendances. For example, people who attended with abdominal pain, which was the result of intentional ingestions of sharp objects; and people who attended for reasons of persecution that included hearing voices to harm themselves, needed to be included in the research.

Exclusion criteria included people who attended on more than 12 occasions in 2006 as New Zealand research had identified these as frequent users (Helliwell, Hider, \& Ardagh, 2001). This was also done to protect confidentiality, as it was felt such people would potentially be identifiable as initial data showed that more than $98 \%$ of the people had below 12 visits. This small percentage could possibly have different presenting issues. Others excluded were people who presented only once for ISH; those who re-presented after one week; and people who presented for a non-intentional self-harm cause and then re-presented within one week.

A person could have more than one re-presentation within one week over the 12 month period. As an example, where a person had three presentations that met the inclusion criteria, these were included as followed: One data entry for the first and second presentation; the other data entry for the second and third presentation, which was called first and second presentation again. Thus, the first and second presentations relate to an initial visit with ISH and a re-presentation within one week irrespective of the number of times this person presented in 2006. 
A list of people who had presented two or more times to ED for ISH in 2006 was obtained from the emergency department. This list was visually reviewed with the assumption that two presentations within one week would be for the same reason. Yet, when accessing electronic data it transpired that people had far more presentations for all causes. Total presentations were examined and people who had less than 13 presentations with any two happening within one week, the first one being related to ISH were included. Figure 4 illustrates the process of identification of the sample.

The systematic identification of the sample assured that the desired group of people was involved in this research. The data extraction tool will be discussed next.

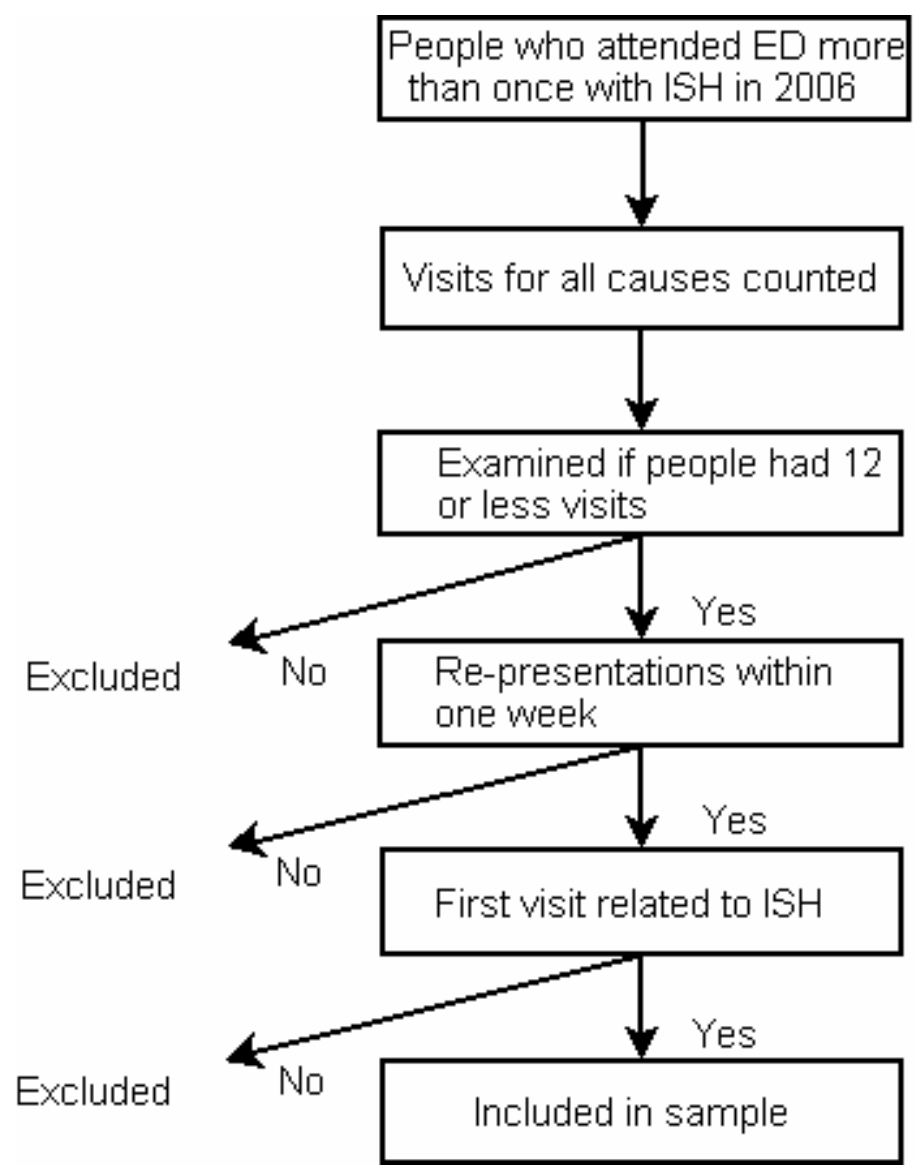

Figure 3: Process of identification of sample included in study 


\section{Development of the data extraction tool}

A data extraction tool was designed to extract data on the sample (Appendix 3). This tool was standardised which meant the same data was to be extracted from all eligible participants and their presentations to facilitate the development of a comprehensive description. The study by Hatcher et al. (2005) that looked at people who re-presented with deliberately self-harm to an Emergency Department in a New Zealand setting, also used a retrospective chart review of an ED database. Their objectives were to determine the number of people that attended the ED in 12 months; provide data on the methods of self-harm; explore current care pathways and access to referral services, and to provide a comparison between two hospitals. Their standardised data extraction form included variables that would meet the objectives of this current study.

Variables included in my research related to the assessment and treatment in ED, as well as discharge plans. The aim was to describe the management of people who intentionally self-harm on each presentation and to describe differences between presentations. A draft tool was developed and pre-tested on the first five cases to ensure that the desired information was available in the data and easily extractable. These first presentations were also included in the study. The adjusted changes are discussed so that the reader can appreciate the overall development of the tool.

One of my interests was in patient and relatives involvement in their care, and in who made the decision to attend the emergency department. As these were not documented in most of the five pilot files that I reviewed, the variables were not included. One of the variables was initially 'Nursing Care', but data extraction seemed a challenge as it was too general. Consequently it was divided into 'Nursing Assessment', 'Nursing Comfort Care', 'Bloods Taken' and 'Vital Observations Taken', which was divided into partial and full observations. Fourthly, from reading through a few documented visits, I was alerted to the fact that many visits were associated with certain behaviour of the person, which could be measured by the interventions that occurred such as restraint, police input, watch/security and the issuing of section 111 under the Mental Health (Assessment and Treatment) Act (1992). 
Finally, the documentation of individual social triggers was vague. It was occasionally mentioned in the first presentation, though often not documented for the second. Given the general state of documentation a decision was made to only document the presence or absence of a social trigger.

Other variables initially included but then omitted due to poor documentation were the presence of a management plan and a trigger related to complaints of current mental health service provision. Poor documentation by nurses and doctors meant that either nothing was documented or the notes found were incomplete to the point where no information could be gathered from them. The research design needed to accommodate that the documentation by doctors and nurses may not have been recorded consistently as some documentation might have been done retrospectively when ED was busy and recall of the management could be lacking (Kuehl, 2005). It is also known that ED managers do not monitor the standard of documentation (Porter et al., 2008); and clinical notes are not done for research purposes originally. These factors were taken into consideration by including an unknown value for variables.

The chosen variables on ISH presentations to ED and re-presentations within one week were based on the literature and from my experience as an ED and mental health nurse. The variables were grouped into nine different areas of interest and were divided into two data sets. The first set pertained to the socio-demographic and clinical characteristics of the individuals who presented; the second set pertained to the presentations. One data entry consisted of these two sets. It included the characteristics of the individual, variables of the first presentation, time to re-presentation and variables of the second presentation. In the following section of this chapter, variables are described in more depth and the differences for variables relating to the first and second presentation are explained.

\section{Variables related to the person}

Demographic features: Gathered for the individual person to provide a demographic description of the sample. Information for this description was taken from the documentation of the first presentation included in the research. 
Variables included person's age, gender, ethnicity and number of visits to ED during 2006. The information to complete these variables was obtained from the clerical site on each person's file. The person's age was determined by their age as recorded on their first presentations. If the person had a further set of two presentations, the person's age was determined by the first ever presentation that was included in the study. Gender initially consisted of male and female, however transgender was added as a third category when it transpired that a transgender person was amongst the sample.

Background history: Gathered to provide a background picture of the sample. As clinical and behavioural history data were often incomplete this information was gathered from the documentation of both presentations. When information was limited or not recorded, other presentations from 2006 that were not part of the study were also examined. Variables included were: History of intentional selfharm, physical illness, mental illness (diagnosis), alcohol use, drug use (type of drug), violence and total number of visits. The information was obtained from the clinical notes on the computerised system of the individual person. A history of intentional self-harm (ISH) was recorded if the person had any documented previous episodes of intentional self-harm. Only the presence or absence of physical illness was recorded as my interest was in mental health care provision. The diagnosis of a mental illness was classified via the hierarchy, rank-based on Axis I of the Diagnostic and Statistical Manual of Mental Disorders: DSM IV (American Psychiatric Association, 1994). For example the diagnosis of depression was used as a primary diagnosis, secondary ones were often post traumatic stress disorder (PTSD), personality disorder (PD) or bipolar affective disorder (BPAD). Alcohol, drug use and a history of violence were recorded if documented, and 'unknown' if this history was not documented as confirmed nor denied.

\section{Variables related to the presentation}

All data related to presentations was taken from the triage documentation and clinical notes that were written by doctors and nurses on EPDS at the time of the person's presentation. They included arrival information, presenting issue, trigger, 
challenging issues, care in $\mathrm{ED}$, the referral process and the management that follows the referral.

Arrival Information: Included arrival time, day of the week, triage code, presence of personal support, days between presentations. This data was obtained to ascertain if arrival circumstances could contribute to people's re-presentation within a short time-frame. Data was found by looking at the arrival time and date. Chapter 3 provided details on triage codes which are used to prioritise when patients should be seen by an ED doctor. Personal support people were classified into family/whānau, friends, paid, partner, unknown. Where more than one category of personal support was present, a hierarchy of closeness was used, following the order of family/whānau, partner, friends, and paid workers. For example, family/whānau was mentioned, even if a partner, friend or paid workers were also present. Unknown was used if it was documented that they were accompanied, but it was not stated who was there. Days between presentations were up to 7 days. A day is classified as on the computer from 00.00 until 23.59. Seven days are from 00.00 of the first day after the initial presentation to 23.59 of the $7^{\text {th }}$ day. Days between presentations were calculated manually.

Presenting issue: Included suicidality; deliberate self-harm (DSH); type of deliberate self-harm; alcohol and drug (type). This data gave information regarding reasons for presentations and re-presentations. Analysis of reasons would enable a description of how often the presenting issue remained constant.

Intentional self-harm included suicidal ideation, suicide attempt and deliberate self-harm. Suicidality included the documentation of the intent to harm them self in order to end life. Deliberate self-harm was an act that consisted of: Overdose, laceration, gassing, attempted hanging, ingestion/insertion of foreign body, selfinflicted head injury, self-stabbing, deliberately walking into traffic and burning. Types of drugs expected were cannabis, party pills, heroin, methadone, ecstasy, 'P', cocaine or benzodiazepines.

Trigger - the underlying reason people gave for attending ED: Included three types of trigger: social, physical and mental. A trigger was defined as a prompt for 
a crisis that required a visit to the emergency department. Social triggers were named as present if the notes mentioned problems with relationships, housing or finances. Physical triggers were not individually named, but included drug and alcohol withdrawal, abdominal pain after swallowing a foreign body and poor sleep. For the second presentation, physical triggers were identified individually, as a physical complaint could be the reason why people re-presented and could highlight relationships between ISH and certain physical complaints. Mental triggers included suicidality and DSH; but also anxiety, depression, psychosis and not taking prescribed medication.

Challenging issues: Included assaulting behaviour, restraint, Mental Health (Assessment and Treatment) Act 1992 (MHA), orderlies/security and police. The occurrence of challenging issues can indicate the personal and service cost of representations. Assaulting behaviour was classified as verbal and physical assault in the emergency department. Physical restraint by orderlies/security or the police are often in conjunction with the commencement of the Mental Health Act. These people are at risk to themselves or others, they present with distorted thinking and attempt to leave ED before a mental health assessment can confirm what management is required.

Care in the emergency department: Included nursing assessment, vital observations, nursing comfort care, blood tests, ED doctor (rank), physical assessment by ED doctor, mental health assessment by ED doctor, and medication for physical and mental health complaints. This data was aimed to highlight the care that was provided.

A nursing assessment included both physical and mental health assessments. An assessment tool is not routinely used by staff in this emergency department. The aim was to ascertain the level of assessment performed. Included was documentation that highlighted that the nurse had assessed this person's physical or mental state, irrespective of the length of it. Nursing comfort care was around documented activities that would make the person's stay more pleasant, such as the provision of food, assistance with phoning whānau/friends or providing a blanket for comfort. Basic vital observations consisted of the person's 
temperature, pulse, respiration and blood pressure. Further observations such as oxygen saturation (to assess quality of breathing), Glasgow Coma Scale (to assess consciousness level) and blood sugar level were too infrequently documented to be included in the data analysis. Observations were recorded as full when the basic observations were performed and partial when only some of these had been done.

The rank of the doctor was collected, such as a house officer, registrar or consultant. If more than one doctor cared for a person, the highest rank was counted. An ED doctor's physical assessment was included if it was short, but consisted of the presenting issue relating to physical health, past medical history or if the outcome of a physical examination was described. An ED mental health assessment needed to consist of the presenting issue relating to mental health issues, past mental health history and a risk assessment.

Referral: Included people expected by CATT as noted in the triage documentation, those referred to mental health or other services, assessment by CATT and cultural input. The aim was to establish the input of mental health services for people who attend ED with intentional self-harm. Once the person was identified by the ED doctor to require further input from other services, a referral to mental health and other services was made. These services included CATT; Community Mental Health Teams (CMHT); Child and Adolescent Services (CAS); and medical, surgical and plastic surgery teams. For the first presentations I did not extract data regarding referrals to other specialties as I was only interested in the services regarding mental health care. For the second presentation, I considered referrals to all services as people arrived for all reasons within one week.

Departure from ED: Included admission, discharge, self-discharge, follow-up and length of stay in the emergency department. The aim was to determine what the documentation reported should happen to people when they leave the emergency department. Evidence of discharge planning, such as giving written information to the person and family/whānau or having an appointment for follow-up were searched for. Common referral categories were used; these 
included the community mental health team, the crisis assessment and treatment team, the acute inpatient unit, Alcohol \& Drug services, Child and Adolescent services, the general practitioner (GP) and the plastic surgery team. Self discharge was divided into leaving ED before being seen by an ED doctor and leaving ED after being seen by ED staff but before a CATT assessment. Length of stay was calculated in minutes from the time of arrival to the time of discharge or departure from the emergency department.

In addition to the variables, a written log was kept. The log included details of descriptions by doctors and nurses of what happened between presentations as well as circumstances surrounding ISH episodes. It also noted ED management that differed from ED protocols and procedure guidelines of this DHB. Discrepancies in regard to the nurses competence and conduct as a professional expected by the Nursing Council of New Zealand (2007); and practice that did not follow best-practice recommendations of 'The management and treatment of people at risk of suicide' guideline (New Zealand Guidelines Group \& Ministry of Health, 2003) were logged.

\section{Retrieving the data}

Data extraction for this research required attention to detail. Clinical records were accessed via a computer in the Emergency Department using EPDS and were individually looked at in depth.. The included sample that originated from a list of all repeat ISH presentations in 2006, was located by searching the date and time of each presentation. Data collection commenced with a review of the persons' clinical window, from which the clerical and triage window, clinical notes and the alert and vital screen were able to be accessed. Previous visits of this person were accessed from the patient tracking window or the triage window. Appendix 3 lists the windows where variables were obtained.

\section{Analysis}

Before commencing analysis of the data, an analysis plan was developed. All clinical notes included in the study were viewed again and the related data entry checked for accuracy. The analysis needed to accommodate the fact that some 
people had more than one re-presentation during 2006. To prevent a skewing of results, it was important to think of the data as being in two sets: the first set included data of individual patients and these were only counted once. The second set included data that related to presentations. Some people had various presentations and re-presentations within one week. All the relevant presentations were listed and collated from the clinical notes. A three-stage analysis process was used.

Firstly, the data set containing the individual demographic and past history information was analysed. Secondly, variables regarding the two sets of presentations were analysed. Descriptive statistics such as mean, median, range and frequencies were used depending on variable type. Thirdly, differences between the first and second presentations were analysed. Given the limited sample size and a large number of unknown data, few inferential statistical tests were able to be used to establish whether there were statistical differences between the first and second presentation. Content analysis was undertaken of the open-ended data related to what happened between and during visits. A themebased content analysis was used which is a qualitative method that provides useful, detailed information by grouping data into meaningful categories (Neale \& Nichols, 2001). The analysis process highlighted different themes that were presented as fictional scenarios and referred to in the Discussion Chapter.

\section{Issues around the research}

\section{Ethical implications}

An application to the Central Regional Ethics Committee using the 'Expedited Review of Observational Studies Application Form' was made. The application included a letter from the nurse manager in ED, to ascertain that ED was informed and approved of the research. It also included a letter from a Māori advisor to assure that the study incorporated the Treaty of Waitangi and relevant cultural issues. 
The reason for the Ethics Committee involvement was that clinical records were to be used for a different purpose than originally intended. The use for another purpose without peoples' consent is potentially problematic (McKenna, Hasson, \& Keeney, 2006). Approval from the Ethics Committee was obtained for a retrospective review of patient notes or data (Appendix 4). The ethics application highlighted confidentiality and privacy matters. The research needed to be carried out in a safe and ethical way.

Confidentiality and privacy both during the data collection and beyond is important. The Electronic Emergency Documentation System was accessed with a generic department login and password. Clinical records were never taken off hospital premises. The list of patient data from the nurse manager was deidentified on an Excel sheet and peoples NHI numbers were substituted with a unique research number. The original list was locked in a filing cabinet in ED and was going to be stored until the examination and publication process was complete. The electronic data in ED is accumulative and has no time limit.

Given that the research could identify inadequate care for people who present to ED with ISH and re-present within one week it was agreed that the nurse manager, nurse educator and clinical leader would be informed of the findings of the study. Examples of practice gaps will be given in regards to systems and processes; and will not be related to individual staff. The author also intends to provide ED staff with up-to-date literature and guidelines regarding best-practice. When this study is published as a thesis, in journal articles or presented at conferences, the name of the emergency department or the DHB will not be revealed.

A need for consent from people involved in this study was considered. "The main scientific reason for not seeking consent to use health records for research is that failing to locate individuals to seek their consent may lead to less complete ascertainment of cases for study and therefore possibly a biased (and hence incorrect) result" (Health Research Council, 2005, p. 37). Also, the focus of the study was on ED systems and processes as opposed to individual staff members and consent from the individual was not considered necessary. It was feared that 
obtaining such consent could cause undue distress, and could influence people's future visits. Lastly, confidentiality was maintained by focusing on a certain group of people that re-presented after an ISH episode. Excluded were individual people who demonstrated a frequent presentation pattern that could potentially identify them.

\section{Rigour and validity}

Rigour in descriptive research means that it should be able to yield similar results if completed by another researcher in the same circumstances. The results should be reliable and repeatable. Some authors acknowledge that precise measurements are a challenge (Gillis \& Jackson, 2002). To address rigour and validity in this study, variables were described in detail to begin with, enabling the reader to understand what data was going to be measured. The aim was to achieve a consistent extraction data process that was maintained throughout the study. The researcher was the only person that extracted data from clinical records. This potentially reduced errors. After a trial with five re-presentations the data extraction framework was modified and a consistent approach followed for all presentations, including these first five re-presentations. Before analysis, the clinical notes of the included 48 people and their 73 initial and re-presentations were viewed again and the related data entry checked for correctness. The supervisor assisted with the analysis to ascertain accuracy.

The utilisation of the most appropriate methodology and adherence to the study design assured that this research was successful in describing the population that presented to ED with ISH and than re-presented within one week in 2006. The following chapter reports on the findings. 


\section{Chapter 5 - Findings}

\section{Introduction}

This chapter describes the findings of this retrospective review of clinical records that consisted of people who attended the Emergency Department (ED) in 2006 with intentional self-harm (ISH) and re-presented within one week for any reason. Descriptive research provided an excellent opportunity to explore this patient group.

For ease of presentation, the findings of the clinical data are divided into three sections. Section One consists of a general overview of data acquisition and the number of re-presentations of the identified population. Section Two includes information regarding the person such as socio-demographic data and background history. Section Three presents information regarding first and second presentations and includes arrival information, presenting issue, trigger, challenging issues, care in ED, referral and management after assessment. Within this section, cross correlations are used to highlight differences between the first and second presentation.

During the data extraction process, a log was kept to record additional data that appeared relevant but were not collected on the computer file. Scenarios of these notes are provided within certain sections of this chapter to highlight found circumstances of re-presentation, taking confidentiality into consideration. Given the frequent lack of documentation, limited inferential testing was possible between the two presentations. Reference to inferential testing is only made when such tests were carried out.

\section{Section One}

This section outlines the selection of the sample and shows the number of days between the first and second presentation to the emergency department. 


\section{Sample}

From $1^{\text {st }}$ January to $31^{\text {st }}$ December 2006, 1985 people attended ED with intentional self-harm; of these 120 people presented on two or more occasions. A list of presentations of these 120 people was provided to me by the hospital and consisted of peoples National Health Index (NHI) number, which is a unique person identifier used within the New Zealand health system; details of times of arrival and departure; presenting complaint and departure diagnosis. As there is no 'intentional self-harm' code on the emergency department information system, the list included 67 different diagnostic codes that were grouped as related to a mental illness (21), physical cause (18), poisoning-related (13), alcohol-and drug-related (9), others (4) and suicide-related (2) (see Appendix 5). These 120 people presented 393 times and nearly half, 58 people, re-presented within one week. Yet, when subsequently accessing the electronic patient documentation system it transpired that people had far more presentations which were either for physical causes, or related to ISH but classified as physical. The original sample of 120 people actually attended ED 852 times for any reason in 2006.

\section{Scenario 1: Presenting issue classification}

I was taking a 20 year old woman from the waiting room to a cubicle. She presented with a laceration to her right lower forearm. I introduced myself and asked what happened. She stated that she cut herself. I said "Ok, how did it happen?" She repeated that she cut herself. Again I acknowledged it and asked if she could give me some more information about how it had happened. She stated "I made the cut myself!" Only then did I understand that this woman attended with intentional self-harm. I felt embarrassed as my initial interpretation was accidental injury and not intentional.

In addition, some presentations on the list classified as ISH were not related to intentional self-harm. A lack of documented intentional self-harm complaints for initial visits and a high number of total presentations of 13 or more reduced the number being able to be included in this study to 48 people and 73 representations.

The majority of people included in the study (80\%) presented between one and four times in 2006. Table 2 shows the days to re-presentation and it highlights that the majority $(55 \%)$ of re-presentations occurred within one day of the initial 
presentation. Of these, $9(12 \%)$ re-presentations occurred on the same day and 31 (43\%) the following day. The mean time in days was 2.6 (median 1 day; sd 2.2).

Table 2: Days to re-presentation by number and frequency

\begin{tabular}{|l|r|r|}
\hline Days to representation & \multicolumn{1}{|c|}{$\mathbf{n}(\%)$} & Cumulative percent \\
\hline 0 (Same day) & $9(12.3)$ & 12.3 \\
\hline 1 & $31(42.5)$ & 54.8 \\
\hline 2 & $5(6.8)$ & 61.6 \\
\hline 3 & $6(8.2)$ & 69.9 \\
\hline 4 & $9(12.3)$ & 82.2 \\
\hline 5 & $6(8.2)$ & 90.4 \\
\hline 6 & $3(4.1)$ & 94.5 \\
\hline 7 & $4(5.5)$ & 100.0 \\
\hline Total & $73(100)$ & \\
\hline
\end{tabular}

\section{Section Two}

This section provides a brief description of the 48 people who returned to ED within a week after an ISH presentation. It includes demographic data and background history.

\section{Demographic data}

Demographic information is found on the clerical window of the Electronic Patient Documentation System (EPDS). Table 3 shows that the sample group included more women $(n=27)$ than men $(n=20)$ and one transgender person.

Table 3: Demographic information

\begin{tabular}{|l|r|r|}
\hline Demographic feature & Variable Label & n (100\%) \\
\hline Sex & Male & $20(42 \%)$ \\
& Female & $27(56 \%)$ \\
& Transgender & $1(2 \%)$ \\
\hline Ethnicity & Māori & $11(23 \%)$ \\
& Pacific & $2(5 \%)$ \\
& Pakeha/European & $33(67 \%)$ \\
& Other* & $2(5 \%)$ \\
\hline Age & Mean & 29.21 years \\
& Median & 27.00 years \\
& Range & $14-51$ years \\
\hline
\end{tabular}

* Other included Indian (1) and Middle Eastern (1) 
Ethnicity data showed that the two groups that mainly re-presented were Pakeha/European (67\%) and Māori (23\%). Age was determined from the age at the first presentation each person had over the 12-month period. The age of participants ranged from $14-51$ years, with a mean of 29 years (sd 10.7) and a median of 27 years.

\section{Background history}

Background information, though documented inconsistently at times, provided an opportunity to learn more about people's past history of physical or mental illness, alcohol and drug use, violence and intentional self-harm (Table 4).

A large proportion of the sample had a history of previous intentional self-harm $(65 \%)$ and a history of mental illness and/or a personality disorder (96\%), which is described further in Table 5. More than one third of the sample had a history of physical illness, though for the same number of people this history was not documented. A history of alcohol and drug use was found in $42 \%$ and $28 \%$ of the sample respectively though the history of drug use was unknown for the majority (56\%) of people. These were identified if alcohol or drug use was documented for previous presentations or if it was documented as an addiction issue. Of people who had a documented history of drug use, three $(6 \%)$ had a history of cannabis and methadone/benzodiazepine use and others attended with a history of heroin, benzodiazepines, pethidine and poly-substance use. For three people the type of drug was unknown. A history of violence was reported for 15 (31\%) people, though it was unknown for the same number of people.

Table 4: Background history

\begin{tabular}{|l|r|r|r|}
\hline & $\begin{array}{c}\text { Yes } \\
\mathbf{n}(\mathbf{\%})\end{array}$ & $\begin{array}{c}\text { No } \\
\mathbf{n}(\%)\end{array}$ & $\begin{array}{c}\text { Not } \\
\text { documented } \\
\mathbf{n}(\mathbf{\%})\end{array}$ \\
\hline Previous ISH & $31(65 \%)$ & $3(6 \%)$ & $14(29 \%)$ \\
\hline $\begin{array}{l}\text { Mental Illness and/or } \\
\text { Personality Disorder }\end{array}$ & $46(96 \%)$ & $1(2 \%)$ & $1(2 \%)$ \\
\hline Physical Illness & $18(38 \%)$ & $12(25 \%)$ & $18(38 \%)$ \\
\hline Alcohol Use & $20(42 \%)$ & $6(13 \%)$ & $22(46 \%)$ \\
\hline Drug Use & $13(28 \%)$ & $8(17 \%)$ & $27(56 \%)$ \\
\hline Violence & $15(31 \%)$ & $18(38 \%)$ & $15(31 \%)$ \\
\hline
\end{tabular}


Primary mental illness classifications used were depression, psychotic disorder and bipolar affective disorder; and also included personality disorder. Depression was the most common diagnosis (Table 5). The focus on the primary mental illness simplified an otherwise complex mental health picture as people often had more than one diagnosis of a mental illness. Additional disorders not mentioned in the table include post-traumatic stress disorder, anorexia/eating disorder, anxiety, attention-deficit hyperactivity disorder, and disorders related to blood letting/chronic anaemia.

Table 5: Type of primary mental illness

\begin{tabular}{|l|r|}
\hline \multicolumn{1}{|c|}{ Mental Illness } & n (\%) \\
\hline Depression & $29(63 \%)$ \\
\hline Bipolar Affective Disorder & $5(11 \%)$ \\
\hline Psychotic Disorder & $6(13 \%)$ \\
\hline Personality Disorder & $6(13 \%)$ \\
\hline Total & $46(100 \%)$ \\
\hline
\end{tabular}

\section{Section Three}

This section presents findings of the 73 first and second presentations of the sample that attended ED with ISH and then re-presented within one week. On 18 occasions a person had at least three presentations within a short time frame from each other. The first and second presentation were compared, as well as the second and third referred to as first and second presentation. In consequence, 18 presentations were both first and second presentations. This section refers to presentations and not to people. It includes arrival information, ED management, referral and discharge from the emergency department.

\section{Arrival information}

There was a fairly even spread of $8-15$ presentations between Monday and Sunday (Table 6) for first presentations to the emergency department. The highest number of presentations $(n=15 / 21 \%)$ occurred on a Sunday and the least 
$(\mathrm{n}=8 / 11 \%)$ on a Thursday and Saturday. Most second presentations occurred on a Wednesday $(\mathrm{n}=17 / 23 \%)$.

Table 6: Days of the week of first and second presentation

\begin{tabular}{|l|r|r|}
\hline \multicolumn{1}{|c|}{ Days of presentation } & $\begin{array}{c}\mathbf{1}^{\text {st }} \text { Presentation } \\
\mathbf{n}(\mathbf{\%})\end{array}$ & $\begin{array}{c}\mathbf{2}^{\text {nd }} \text { Presentation } \\
\mathbf{n}(\mathbf{\%})\end{array}$ \\
\hline Monday & $10(14 \%)$ & $8(11 \%)$ \\
\hline Tuesday & $11(15 \%)$ & $8(11 \%)$ \\
\hline Wednesday & $9(12 \%)$ & $17(23 \%)$ \\
\hline Thursday & $8(11 \%)$ & $10(14 \%)$ \\
\hline Friday & $12(16 \%)$ & $7(10 \%)$ \\
\hline Saturday & $8(11 \%)$ & $11(15 \%)$ \\
\hline Sunday & $15(21 \%)$ & \\
\hline
\end{tabular}

Arrival times between midday and midnight were similar for both presentations. However, a distinct difference was observed between 00:00 and 03:59 where 17 first presentations and only 8 second presentations were made. The least popular time of arrival was in the early morning between 04:00 and 07:59, with only five presentations in total for both visits.

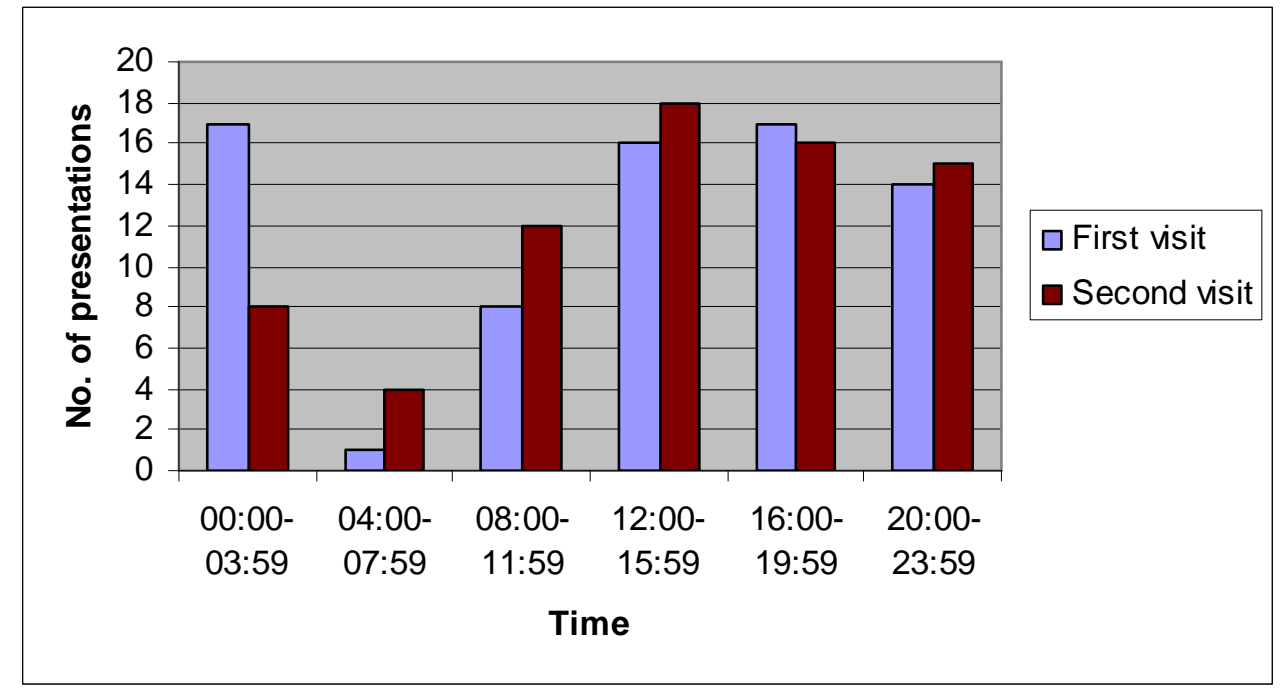

Figure 4: Arrival time for first and second presentation

On arrival to ED, all patients are triaged. The allocation of a triage code involves an initial assessment. The scenarios below show the triage assessment for two people. 


\section{Scenario 2: Triage assessment: Risk to self and others}

Person Y presented to ED with thoughts of killing his neighbour. He felt this person has done him a lot of harm. Although he was very angry with the other person, he also expressed suicidal thoughts. Y was assessed by CATT and sent home. He arrived back in ED two days later. The triage nurse's documentation is 'Expected by CATT. Appears calm' and allocated a code 4. CATT was delayed for three hours. No further assessments were done until they arrived.

\section{Scenario 3: Triage assessment: Risk of suicide}

Person M took a significant overdose of paracetamol and epilim (mood stabilizer and antiepileptic drug) two days earlier. On re-presentation to ED he was expected by CATT and was 'not distressed, pale and complaining of a headache'. He was triaged a code 4. CATT was delayed. Two hours after arrival, a nurse mistakenly took $\mathrm{M}$ to a cubicle and upon talking to him she found him to be acutely suicidal.

As discussed in the clinical chapter, the allocated code determines how long people can wait to be seen by an Emergency doctor, though in actual practice this is often much longer due to overcrowding.

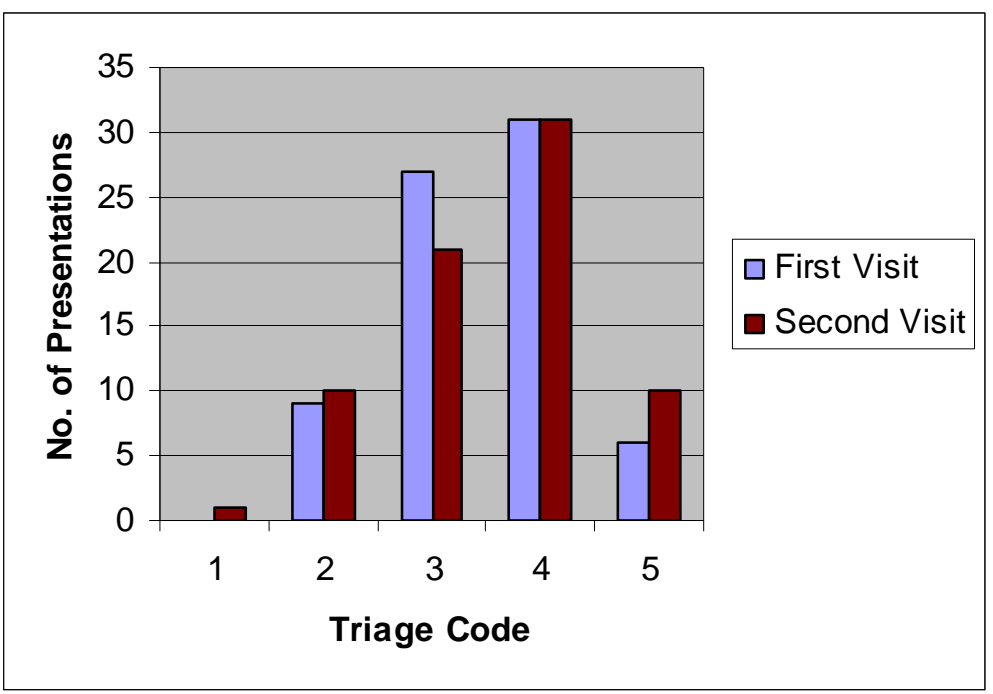

Figure 5: Triage Codes for first and second presentation

For this sample, most presentations were triaged Code 3 and 4 as shown in Figure 5 , which meant they should be seen within half an hour or an hour respectively. For the second presentations, there was one Code 1 (to be seen immediately) and more Code $2 \mathrm{~s}$ (to be seen within 10 minutes) and 5s (to be seen within two hours) 
compared to the first visit. Comparative analysis between triage codes found that a third of presentations received the same code on re-presentation, another third was less urgent and the final third was triaged as more urgent.

Support people can provide valuable information towards the assessment of the person. First presentations were accompanied by people they knew such as family/whānau, partners or friends (Table 7) $45 \%$ of the time, compared to only $32 \%$ for second presentations. Health workers and police were involved in $14 \%$ of first presentations and $21 \%$ of re-presentations. For a large proportion of presentations the presence of support people was not documented. Comparative analysis showed that 15 presentations had family/whānau/partners/friends present on both occasions. Fisher's exact analysis showed that the presence of support people differed for the first and second presentation $(p=.00)$. Second presentations had fewer family/whānau and more health workers and police in attendance.

Table 7: Support people at the person's first and second presentation

\begin{tabular}{|l|r|r|}
\hline & $\begin{array}{c}\mathbf{1}^{\text {st }} \text { Presentation } \\
\mathbf{n}(\mathbf{\%})\end{array}$ & $\begin{array}{c}\mathbf{2}^{\text {nd }} \text { Presentation } \\
\mathbf{n}(\mathbf{\%})\end{array}$ \\
\hline Family/whānau & $14(19 \%)$ & $9(12 \%)$ \\
\hline Partners & $11(15 \%)$ & $9(12 \%)$ \\
\hline Friends & $8(11 \%)$ & $6(8 \%)$ \\
\hline Health Worker & $10(14 \%)$ & $13(18 \%)$ \\
\hline Police & $0(0 \%)$ & $2(3 \%)$ \\
\hline Unknown what support & $1(1 \%)$ & $33(46 \%)$ \\
\hline None documented & $29(40 \%)$ & \\
\hline
\end{tabular}

The assigning of a triage category for ISH is based on clinical urgency such as the severity of injury, level of distress and level of intent. Table 8 presents the findings related to suicidality, deliberate self-harm (DSH), alcohol and drug use. A large majority of first presentations $(82 \%, n=60)$ were suicidal, compared to only $62 \%(n=45)$ for re-presentations. A substantial number of occasions $(n=36)$ included people that presented with suicidality for both presentations. On 29 occasions people presented with DSH for the first and second presentation. 
The number of presentations for deliberate self-harm in Table 8 include $4(6 \%)$ attempts for the first presentation and $3(4 \%)$ for the second. Alcohol use was poorly documented for both presentations. Comparative analysis showed that on 12 occasions first and second presentations had alcohol for the same person. Documented drug use was minimal and included benzodiazepines, cannabis and a combination of methadone and benzodiazepines.

Deliberate self-harm was noted as 'no' if the person was expected by CATT and there was no documentation regarding DSH for that presentation. It was assumed that if there had been any, such as an overdose or a laceration, it would have been documented in ED notes and treatment provided. The type of DSH varied between presentations as can be seen in Table 9. For the second visit there were fewer with overdoses $(n=21 / 29 \%)$ and lacerations $(n=8 / 11 \%)$, compared to $25(34 \%)$ and 12 (16\%) during their first visit.

Table 8: Presenting issues first and second presentation

\begin{tabular}{|c|c|c|c|c|}
\hline & $\begin{array}{c}\text { Suicidality } \\
\text { n }(\%)\end{array}$ & $\begin{array}{c}\text { DSH } \\
\text { n }(\%)\end{array}$ & $\begin{array}{c}\text { Alcohol } \\
\text { n }(\%)\end{array}$ & $\begin{array}{l}\text { Drugs } \\
\text { n }(\%)\end{array}$ \\
\hline \multicolumn{5}{|c|}{$1^{\text {st }}$ Presentation } \\
\hline Yes & $60(82 \%)$ & $47(65 \%)$ & $19(26 \%)$ & $6(8 \%)$ \\
\hline No & $1(1 \%)$ & $25(34 \%)$ & $21(29 \%)$ & $28(38 \%)$ \\
\hline Unknown & $12(16 \%)$ & $1(1 \%)$ & $33(45 \%)$ & $39(53 \%)$ \\
\hline \multicolumn{5}{|c|}{$2^{\text {nd }}$ Presentation } \\
\hline Yes & $45(62 \%)$ & $39(53 \%)$ & $15(21 \%)$ & $2(3 \%)$ \\
\hline No & $14(19 \%)$ & $30(41 \%)$ & $16(22 \%)$ & $19(26 \%)$ \\
\hline Unknown & $14(19 \%)$ & $4(6 \%)$ & $42(58 \%)$ & $52(71 \%)$ \\
\hline
\end{tabular}

On 13 occasions people arrived following an overdose for their first and second presentation. The number of other intentional self-harm injuries was constant at 10 (14\%) for both presentations, which consisted of attempted hanging, ingestion/insertion foreign body, gassing, jumping from a height, burn, head injury, self-stabbing and walking into traffic with the intention to self-harm. 
Table 9: Deliberate self-harm (type) and attempts, both presentations

\begin{tabular}{|l|r|r|}
\hline Type of DSH & $\begin{array}{c}\mathbf{1}^{\text {st }} \text { Presentation } \\
\mathbf{n}(\mathbf{\%})\end{array}$ & $\begin{array}{c}\mathbf{2}^{\text {nd }} \text { Presentation } \\
\mathbf{n}(\mathbf{\%})\end{array}$ \\
\hline Overdose & $25(53 \%)$ & $21(54 \%)$ \\
\hline Laceration & $12(26 \%)$ & $8(21 \%)$ \\
\hline Attempted hanging & $2(4 \%)$ & $2(5 \%)$ \\
\hline Ingestion/insertion foreign body & $4(9 \%)$ & $2(5 \%)$ \\
\hline Head injury & $2(4 \%)$ & $1(3 \%)$ \\
\hline Stabbing self & $1(2 \%)$ & 0 \\
\hline Traffic & $1(2 \%)$ & $1(3 \%)$ \\
\hline Gassing & 0 & $3(8 \%)$ \\
\hline Jumping from a height & 0 & $1(3 \%)$ \\
\hline Burn & 0 & $\mathbf{3 9}(\mathbf{1 0 0 \%})$ \\
\hline Total & $\mathbf{4 7 ( \mathbf { 1 0 0 \% } )}$ & \\
\hline
\end{tabular}

\section{Emergency department management}

Once demographic information has been acquired, the patient is taken to a cubicle and allocated a nurse. Most presentations had a brief nursing assessment, vital observations, bloods taken and comfort cares, as can be seen in Table 10. Documentation consisted on the whole of a description of the whereabouts of the person and what services were provided.

The number of nursing assessments was statistically different for the first and second presentation (Fisher's Exact $\mathrm{p}=0.016$ ) with more nursing assessments performed for the first presentation. Although on 13 occasions people did not receive a nursing assessment on both presentations, for 36 first and second presentations the nursing assessment was performed. Fewer vital observations were performed for the second presentation. On 16 occasions people had a full set of observations on both presentations, whereas on another 16 occasions this did not happen at all. The number of presentations where bloods were taken was similar on both occasions. A substantial number of presentations never had comfort care documented $(\mathrm{n}=28)$, whereas on 15 first and second presentation people did. There was no statistical difference between the two presentations (Fisher's Exact $\mathrm{p}=0.221$ ) in relation to documentation of comfort care. 
Table 10: Nursing assessment and comfort care first and second presentation

\begin{tabular}{|l|r|r|}
\hline & $\begin{array}{c}\mathbf{1}^{\text {st }} \text { Presentation } \\
\mathbf{n}(\mathbf{\%})\end{array}$ & $\begin{array}{c}\mathbf{2}^{\text {nd }} \text { Presentation } \\
\mathbf{n}(\mathbf{\%})\end{array}$ \\
\hline Nursing Assessment & $53(73 \%)$ & $43(59 \%)$ \\
\hline Vital Observations & $37(51 \%)$ & $31(43 \%)$ \\
- full & $6(8 \%)$ & $4(6 \%)$ \\
- partial & $28(38 \%)$ & $26(36 \%)$ \\
\hline Bloods taken & $34(47 \%)$ & $26(36 \%)$ \\
\hline Nurse comfort care & $16(22 \%)$ & $30(41 \%)$ \\
\hline No Nursing Assessment & & \\
\hline
\end{tabular}

In the majority of cases, an Emergency Department (ED) doctor was involved in the person's care (Table 11). Doctors were involved in fewer second presentations (70\%) compared to first presentations (82\%), though this was not statistically significant $(\mathrm{p}=0.742)$. On 41 occasions people were seen by an ED doctor on both presentations, whereas 3 never were. Most presentations involved house surgeons or registrars, with the number of assessments by consultants constant at 10 (14\%) for both presentations.

Table 11: Rank of emergency department doctor first and second presentation

\begin{tabular}{|l|c|c|}
\hline & $\begin{array}{c}\mathbf{1}^{\text {st }} \text { Presentation } \\
\mathbf{n}(\mathbf{\%})\end{array}$ & $\begin{array}{c}\mathbf{2}^{\text {nd }} \text { Presentation } \\
\mathbf{n}(\boldsymbol{\%})\end{array}$ \\
\hline House Surgeon & $25(34 \%)$ & $22(30 \%)$ \\
\hline Registrar & $25(34 \%)$ & $19(26 \%)$ \\
\hline Consultant & $10(14 \%)$ & $10(14 \%)$ \\
\hline Not seen by ED doctor* & $13(18 \%)$ & $22(30 \%)$ \\
\hline
\end{tabular}

* Not seen by ED doctor as person expected by the Crisis Assessment and Treatment Team (CATT)

The assessment by the ED nurse and doctor should ascertain what triggered the presentation to ED with an awareness of past history. Triggers were separated into physical concern, mental illness and social (Table 12). People could have more than one trigger. Where there was no documentation as to presence or absence of a particular trigger, it was coded as unknown because if assessed it should have been documented. 
Table 12: Main triggers for first and second presentation

\begin{tabular}{|l|r|r|r|}
\hline & $\begin{array}{c}\text { Mental Illness } \\
\mathrm{n}(\%)\end{array}$ & $\begin{array}{c}\text { Physical Concern } \\
\mathrm{n}(\%)\end{array}$ & $\begin{array}{c}\text { Social } \\
\mathrm{n}(\%)\end{array}$ \\
\hline $\mathbf{1}^{\text {st }}$ Presentation & \multicolumn{3}{|c|}{} \\
\hline Yes & $67(92 \%)$ & $11(15 \%)$ & $21(29 \%)$ \\
\hline No & $0(0 \%)$ & $34(47 \%)$ & $15(21 \%)$ \\
\hline Unknown & $6(8 \%)$ & $28(38 \%)$ & $37(51 \%)$ \\
\hline $\mathbf{2}^{\text {nd }}$ Presentation & \multicolumn{4}{|l}{} \\
\hline Yes & $60(82 \%)$ & $18(25 \%)$ & $18(25 \%)$ \\
\hline No & $6(8 \%)$ & $28(38 \%)$ & $16(22 \%)$ \\
\hline Unknown & $7(10 \%)$ & $27(37 \%)$ & $39(54 \%)$ \\
\hline
\end{tabular}

For many presentations the triggers were not documented. Social triggers included issues regarding housing, money, work and relationships. These were unknown for approximately half of first and second presentations. Mental illness was found to be a trigger on 55 occasions for both presentations. For people that were expected by CATT it was assumed that the trigger was 'mental', as there is a strict referral criterion to CATT that involves an acute mental health crisis situation. Second presentations were more often related to a physical concern. Detailed data for the type of physical complaints were not collected for the initial presentation. The emphasis was on the documentation of ISH for the first presentations. For the second visit physical complaints consisted of lacerations $(n=3 / 4 \%)$, pain $(n=6 / 8 \%)$, foreign body $(n=1 / 1 \%)$, drug dependence $(n=3 / 4 \%)$ and one presentation (1\%) each of alcohol dependence, seizure, pregnancy, anaemia/hypotension and sleep deprivation.

\section{Scenario 4: Management of minor injuries}

Person $\mathrm{X}$ presents with a deep laceration to the hand that requires plastic surgery. He states that he works in a professional occupation and got his hand caught in a grinder by accident. The person states that he has no past medical history. Previous admission notes showed that he had attended two days previously distressed and suicidal.

The trigger, background information and the presence of support people are all part of the overall assessment by the doctor and the nurse. For 23 (32\%) of presentations, people had a physical assessment both times and for 12 presentations no physical assessments were carried out on either occasion 
(Fisher's Exact $\mathrm{p}=0.637$ ). A physical assessment by an ED doctor was performed on both occasions for nearly half of all presentations (Table 13).

\section{Scenario 5: Link between physical and mental health issues}

Person T attends ED with severe hypotension and anaemia due to bloodletting behaviour.

Person $\mathrm{S}$ is routinely involved in self-cutting and is chronically anaemic. She has had many unsuccessful investigations for the cause. Health professionals do not ask about blood-letting.

The number of mental health assessments decreased from $55 \%(n=40)$ for the first visit to $38 \%(\mathrm{n}=28)$ for the second visit. Although on 18 occasions people had a mental health assessment on both presentations, 23 never had any. The documentation indicated that these were very brief, with only two documented Mental Status Examinations. Medication provision was scarcely documented, but there was a reduction of the administration of medication for mental health issues for the second presentation, compared to an increase for medication for physical problems.

Table 13: ED assessment and medication provision, both presentations

\begin{tabular}{|l|c|r|}
\hline & $\begin{array}{c}\mathbf{1}^{\text {st }} \text { Presentation } \\
\mathbf{n ( \% )}\end{array}$ & $\begin{array}{c}\mathbf{2}^{\text {nd }} \text { Presentation } \\
\mathbf{n}(\mathbf{\%})\end{array}$ \\
\hline Physical Assessment & $42(58 \%)$ & $42(58 \%)$ \\
\hline Mental Health Assessment & $40(55 \%)$ & $28(38 \%)$ \\
\hline Medication Mental Health & $12(16 \%)$ & $6(8 \%)$ \\
\hline Medication Physical Health & $14(19 \%)$ & $18(25 \%)$ \\
\hline
\end{tabular}

While in ED, people might become increasingly distressed, agitated and abusive. This can require a call for police, watch/special input, restraint and the use of the Mental Health (Assessment and Treatment Act) 1992 (MHA), which is presented in Table 14.

\section{Scenario 6: Challenging behaviours}

Person $\mathrm{N}$ presents to ED with lacerations to her lower legs. While waiting in a cubicle, she tries to set light to herself. She requires restraint and two security staff to ensure her safety. 
The number of occasions were people documented abusive behaviours was the same for first and second presentations $(n=7,10 \%)$. On one occasion a person was abusive on both presentations. More special/watch personnel were used for the second presentation; on six occasions people had a watch for both the first and second presentation.

Table 14: Challenging behaviours first and second presentation

\begin{tabular}{|l|r|r|}
\hline & $\begin{array}{c}\mathbf{1}^{\text {st }} \text { Presentation } \\
\mathbf{n}(\mathbf{\%})\end{array}$ & $\begin{array}{c}\mathbf{2}^{\text {nd }} \text { Presentation } \\
\mathbf{n}(\boldsymbol{\%})\end{array}$ \\
\hline Abusive behaviour & $7(10 \%)$ & $7(10 \%)$ \\
\hline Police involved & $22(30 \%)$ & $18(25 \%)$ \\
\hline Restraint use & $7(10 \%)$ & $6(8 \%)$ \\
\hline Watch/special & $14(19 \%)$ & $6(26 \%)$ \\
\hline Mental Health Act & $8(11 \%)$ & $6(8 \%)$ \\
\hline
\end{tabular}

There was a reduction in the use of police, restraint and sectioning under the MHA for the second presentation. Police input was required for nearly one third of all first presentations and a quarter of second presentations. On 9 occasions police were in attendance for both the first and second presentation. The Mental Health Act was enforced on four occasions for people on both presentations (Fisher's Exact $\mathrm{p}=0.01$ ).

\section{Referral and discharge from the emergency department}

All people should be 'medically cleared' by an ED doctor, which means that a physical cause for their intentional self-harm behaviour is excluded. After physical health matters are addressed a referral to the Crisis Assessment and Treatment Team (CATT) or other mental health teams is made. Details of these referrals can be viewed in Table 15. About a quarter of presentations were expected by CATT, with an increase by five for the second presentation. On seven occasions people were expected by CATT for both presentations.

There was a significant difference between referrals at first presentations and second presentations (Fisher's Exact $\mathrm{p}=0.046$ ). The decrease of referrals to CATT is probably related to the increase in presentations for physical causes. Referrals to other mental health services included Community Mental Health 
Teams (CMHT), the Children Assessment Service (CAS) and to Alcohol \& Drug Services. Referrals for people's physical health to plastic surgery; medical, surgical and physiotherapy services are not included in Table 15. On one occasion a person was expected by the inpatient psychiatrist and was included in the 'Already CATT referral' group in Table 15. There was a decreased number of assessments by CATT/MH for second presentations (Fisher's Exact $\mathrm{p}=0.044$ ). In 15 instances people never had an assessment on either presentation, though on 31 occasions, people had one both times. For one first presentation it was unknown if they had had an assessment by CATT, so it was omitted from Table 15.

Table 15: Referral and CATT assessment first and second presentation

\begin{tabular}{|l|c|r|r|}
\hline & \multicolumn{1}{|c|}{$\begin{array}{c}\text { Already CATT } \\
\text { referral }\end{array}$} & $\begin{array}{c}\text { Referred to } \\
\text { CATT/Mental } \\
\text { Health }\end{array}$ & $\begin{array}{c}\text { CATT/MH } \\
\text { assessment }\end{array}$ \\
\hline $\mathbf{1}^{\text {st }}$ Presentation & $64(88 \%)$ & $48(66 \%)$ \\
\hline Yes & $16(22 \%)$ & $9(12 \%)$ & $24(33 \%)$ \\
\hline No & $57(78 \%)$ & $54(74 \%)$ & $40(55 \%)$ \\
\hline $\mathbf{2}^{\text {nd }}$ Presentation & \multicolumn{3}{|c|}{} \\
\hline Yes & $21(29 \%)$ & $19(26 \%)$ & $33(45 \%)$ \\
\hline No & $52(71 \%)$ &
\end{tabular}

Referral to Māori specific services was not documented for any presentation. There was an increase in admission rates of approximately 50\% for second presentations (Table 16). On 10 occasions people were admitted both times. For the first admissions, 6 were to the Short Stay Unit (SSU) and 10 for mental health, including respite care. For the second presentation, 10 admissions were medical, including seven to SSU and one presentation each to a medical ward, surgical ward and the Intensive Care Unit. Mental health admissions included 7 to respite care and 6 to the acute inpatient ward. One person was discharged with the police due to being violent in the emergency department.

On two occasions people self-discharged during their first and second presentation before being seen by an ED doctor. There were four self-discharges before being seen by CATT for the first presentation and two for the second presentation. For one presentation the person was asked to wait in the waiting room after a brief assessment post overdose. The patient self-discharged, though the doctor documented it as 'treated and discharged'. On 38 occasions people were 
discharged on both presentations. The number of follow-up arrangements is similar for both presentations.

Table 16: Admission, discharge and follow-up first and second presentation

\begin{tabular}{|c|c|c|c|}
\hline & $\begin{array}{c}\text { Admission } \\
\text { n (\%) }\end{array}$ & $\begin{array}{c}\text { Discharge } \\
\text { n }(\%)\end{array}$ & $\begin{array}{c}\text { Follow-up } \\
\text { n }(\%)\end{array}$ \\
\hline \multicolumn{4}{|c|}{$1^{\text {st }}$ Presentation } \\
\hline Yes & $17(23 \%)$ & $49(67 \%)$ & $55(76 \%)$ \\
\hline No & $55(76 \%)$ & $23(32 \%)$ & $9(12 \%)$ \\
\hline Unknown & $1(1 \%)$ & $1(1 \%)$ & $9(12 \%)$ \\
\hline \multicolumn{4}{|c|}{$2^{\text {nd }}$ Presentation } \\
\hline Yes & $23(32 \%)$ & $46(63 \%)$ & $53(73 \%)$ \\
\hline No & $50(68 \%)$ & $27(37 \%)$ & $9(12 \%)$ \\
\hline Unknown & $0(0 \%)$ & $0(0 \%)$ & $11(15 \%)$ \\
\hline
\end{tabular}

Once people leave ED, they are discharged from the computer system and the length of stay can be determined. At times, documentation demonstrated that 'the person was not seen in the department and must have left'. This makes the following data only an estimate. Figure 6 shows that the group that stayed between two and four hours was highest for first and second presentations.



Figure 6: Length of stay in ED

For the first presentation less people waited under two hours, but more waited between four and six hours. For second presentations the wait was decreased compared to first presentations. The number of times, people waited more than 6 
hours was similar for both presentations. For the first visit, the mean time in minutes was 284 (median 236, sd 198, range 17 - 1159). This was higher compared to the second visit where the mean time was 233 minutes (median 188, sd 175, range 2 - 741). This difference was not statistical different (Mann Whitney $\mathrm{z}=-1.581, \mathrm{p}=0.114)$.

After discharge from ED, follow-up arrangements were arranged for approximately three quarters of first and second presentations (Table 17).

Table 17: Arrangements for follow-up care first and second presentation

\begin{tabular}{|l|r|r|}
\hline & $\begin{array}{c}\mathbf{1}^{\text {st }} \text { Presentation } \\
\mathbf{n}(\boldsymbol{\%})\end{array}$ & $\begin{array}{c}\mathbf{2}^{\text {nd }} \text { Presentation } \\
\mathbf{n}(\boldsymbol{\%})\end{array}$ \\
\hline CATT & $31(43 \%)$ & $25(34 \%)$ \\
\hline CMHT & $11(15 \%)$ & $12(16 \%)$ \\
\hline GP & $4(6 \%)$ & $2(3 \%)$ \\
\hline Inpatient & $4(6 \%)$ & $3(8 \%)$ \\
\hline CAF/Child Service & $4(6 \%)$ & $3(4 \%)$ \\
\hline A\&D & $1(1 \%)$ & $2(3 \%)$ \\
\hline Plastics & $0(0 \%)$ & $20(27 \%)$ \\
\hline No planned follow-up & $18(25 \%)$ & \\
\hline
\end{tabular}

In detail, it showed a decrease of follow-up from CATT for the second visit, though there was an increase in referral rates to Alcohol and Drug Services, the inpatient unit and plastics specialty. On two occasions there were no follow up plans made for both presentations, whereas on 41 occasions people received follow up both times $(\mathrm{p}=0.602)$.

This chapter presented the findings of this retrospective review of clinical records. Some of the findings illustrate that the people involved in ISH behaviour presented in a distressed state; and the management in ED and by mental health services was not fully known due to a lack of documentation. The following discussion chapter will explore the meanings of the results. 


\section{Chapter 6 - Discussion}

This is a significant study which highlights many issues regarding emergency department (ED) practice when people present with intentional self-harm (ISH). The description of people who re-present to ED within one week and why this might be the case provides important information to guide comprehensive ED management for people who intentionally self-harm.

A discussion of the findings commences with the exploration of intentional selfharm as a major issue in the emergency department, followed by an examination of the people included in this study. A discussion of identified gaps and risks and their implications for practice is provided, followed by limitations and the conclusion. Recommendations are made throughout this chapter. Where appropriate other literature is referred to when discussing the findings.

\section{Intentional self-harm: A major issue for ED}

This section discusses the surprising numbers of intentional self-harm presentations within one week and the challenges of classification that these presented.

The ED where this research was done had 44,882 total presentations in 2006; of these 6,912 (6.5\%) were re-presentations (Manager, Personal Communication, 3. March, 2007). Presentations for intentional self-harm amounted to 2,258 in total. Although most $(n=1865)$ were single presentations, 120 people presented on 393 occasions for intentional self-harm. Of these, 48 people re-presented 73 times within one week and constituted the sample that was studied. The number of representations indicates that on average at least one person re-presents within one week every week of the year. It is not a rare event and needs to be understood. In fact, the abovementioned 120 people presented 852 times for any cause, with 10 percent $(n=12)$ presenting more than 12 times and up to 173 times. 
People with mental health issues are known to re-present to ED, yet no formal definition exists of what constitutes a 'repeat attender'. Cook et al. (2004) classified people as single, repeat (at least 2 visits within 3 years) or serial (4 or more visits within a year). This is similar to another United States (US) study that defined a frequent user if they presented four or more times over 12 months (Locker, Baston, Mason, \& Nicholl, 2007). This current study's re-presentation rate appears to be far higher than detailed in other studies that reported representation rates of up to six times (Gilbody et al., 1997), 10 times (Hatcher et al., 2005) and one person 30 times (McDonough et al., 2004). It is unclear why this is and requires further research. Repeat non-lethal suicidal behaviour is indicative of particularly severe psychopathology and of high risk for future suicidal behaviour (Forman et al., 2004). Community services responsible for follow-up care might not be available, may not being utilised by this patient group or may not be what is required by the person. Consequently, people re-present to the emergency department.

Given the number of ISH re-presentations to ED in 2006, it is clear that they are an important aspect of ED work. In view of the high rate of suicide related to people who repeatedly intentionally self-harm (Cooper et al., 2005), it is fortunate that people are returning to the emergency department. Despite the high risk of suicide, they are still alive and seek support from the emergency department. Yet, re-presentation indicate that something continues to be wrong for them, especially as more than half (55\%) occur with one day of the initial presentation.

The New Zealand Health Strategy (Minister of Health, 2006) outlines the multiple agencies that have responsibility for suicide prevention (Appendix 6). The effectiveness of this Strategy to date is questionable considering the high numbers of people presenting to ED with intentional self-harm. It is of particular concern that some people come back so soon after an initial presentation for intentional self-harm. Although the representations are appropriate, the frequency of representations suggests that systems and processes in ED for people who intentionally self-harm are not working. Gilbody and colleagues (1997) recommend that interventions aimed at reducing repetition of intentional self harm, fatal or otherwise, must be made within days, not weeks, of an ISH episode 
if they are to be effective. If the lack of documentation on EPDS is a reflection of the actual service that is provided in ED, insufficient care is being given and more could be offered. People might return to ED in hope for a service that is not provided.

\section{Classification of intentional self-harm}

Identifying the people that present with ISH to this particular ED has been difficult, though many emergency departments within New Zealand have similar struggles (J. Fraser, Personal Communication, 2 February 2008). Presentations to ED are classified by the attending complaint, not the intent. Consequently, an intentional self-harm event that involves a person that swallowed razor blades and complaints of stomach pain is classified as 'abdominal pain'. An example of the challenges in practice is provided in Scenario 1, where the patient had self-harmed and it was documented as 'laceration'.

The difficulty in triaging people by their intent lies in the uncertainty of knowing if the presentation is related to intentional self-harm, especially if people arrive unconscious. On other occasions, people might not disclose their intent when they arrive, either because they do not want to or they are not asked. This leads to a lack of clarity in identifying intentional self-harm. The Ministry of Health (2007b) agrees that the basis for making a diagnosis of intentional self-harm is unclear and involves a likely element of inconsistency based on the clinician's judgment.

Triage that identifies ISH would provide valuable data. Admissions for ISH were statistically low for this District Health Board in 2006 (Ministry of Health, 2007b). These statistics ignore the fact that ISH is often not identified by the emergency department. Correct numbers would enable the DHB to gain more knowledge about the issue at hand.

The adoption of strategies such as the Self-harm and Suicide Prevention Collaborative Whakawhanaungatanga (New Zealand Guidelines Group, 2005) as described in Figure 7 could be of benefit to emergency departments. 
The 'Self-harm and Suicide Prevention Collaborative Whakawhanaungatanga' is a New Zealand service improvement project. It is designed to improve crisis care in Emergency Departments, Mental Health and Māori Health/Mental Health services in a way that recognises local situations, people and resources, and builds on the guideline for The Assessment and Management of People at Risk of Suicide (New Zealand Guidelines Group \& Ministry of Health, 2003). The methodology involves 'sharing like kin' (Whakawhanaungatanga), process mapping the journey of a person through ED and identifying gaps and duplications. It incorporates consumer and family advisors. Solutions will be tried out with a 'plan-do-studyact' cycle before implementation. It also includes working towards four targets:

1. An initial assessment within one hour of arrival.

2. A psychosocial, risk and mental health assessment, including a cultural assessment within 72 hours.

3. A discharge plan for the person, family/whānau and service providers such as GPs.

4. Follow-up within two days and if people do not attend their appointment they should be actively followed up within the following two days.

Participating District Health Boards collect data in order to report monthly on those targets.

\section{Figure 7: The Self-harm and Suicide Prevention Collaborative Whakawhanaungatanga*}

*Adapted with permission from: New Zealand Guidelines Group \& Ministry of Health (2005), downloaded on 9.12.2007 from http://collaborative.nzgg.org.nz

The above section provided discussion concerning the selection of the sample with its challenges and implications. Results in regard to the people involved in this study will be discussed next.

\section{People who re-presented}

This section will discuss the background of the sample involved, including gender, ethnicity and age. The health history of mental illness, including alcohol and drug use, and violence will also be discussed, followed by the presence of support people while in the emergency department.

\section{Background}

\section{Demographic}

Although the sample group included more women $(n=27)$ than men $(n=20)$, women were not two times more likely than men to be involved in ISH, as reported by the Ministry of Health (2007b). In developed countries males show 
consistently higher completed suicide rates than females, though females use increasingly more lethal methods (Maskill, Hodges, McClellan, \& Collings, 2005).

Given that poor mental health is a concern for Māori (Durie, 1999), attributed partially to colonisation and socioeconomic disadvantages (Beautrais \& Fergusson, 2006), it was not unexpected that there was a higher rate (23\%) of Māori in the study than in the general population (14.6\%) (Statistics New Zealand, 2006). Total hospital admissions to this ED involved 10.7 percent Māori in 2006. Inequalities in health involving Māori populations still exist. Strategies to improve Māori mental health have been suggested by Durie. Within the ED setting Māori should be included in the provision of ED care for Māori, such as providing a cultural assessment for Māori people who present with ISH, also recommended by Coupe (2003). Yet, there was no evidence of this. ED staff should be knowledgeable and aware of cultural issues and preferably should have Māori staff in their midst. A pathway on how to access cultural support would be of benefit if no on-site support is available.

In this study, the mean age range of 29 was unexpected as my recollection of caring for people who repeatedly intentionally self-harm is of teenagers that displayed extreme distressed and violent behaviour. Probably, others in higher age groups have been in my care but they blended in with the many other ED patients. The Ministry of Health (2007b) statistics show that for 2006 the highest self-harm hospitalisation rate for both genders was 15 - 24 years $(299.9$ per 100,000) followed by age group 25 - 44 (203 per 100,000). ISH statistics figures describe admission to hospital only, and exclude people that get discharged from ED (Ministry of Health, 2007b). An age discrepancy between people that get admitted for ISH and others that do not might lie in a greater concern for the younger person.

\section{Health history}

A history of ISH was found for most people (65\%), though it was not documented for nearly one third of all participants (29\%). Past information is important for the risk assessment as people who repeatedly self-harm are at increased risk of death 
(Collins, 2007a). The majority of this sample (96\%) had a history of a mental illness and/or personality disorder. This is in line with another New Zealand study which found that generally the most common disorders associated with ISH were mood disorders including depression, substance-use disorders and antisocial behaviours (Maskill et al., 2005). In line with other studies (Cleaver, 2007; Fox \& Hawton, 2004), the mental health diagnosis most people had was depression. People with a diagnosis of a psychotic disorder and personality disorder (PD) were equally presented (13\%). Schizophrenia occurs infrequently (approximately $1 \%$ ) in the general population, yet between 25 percent and 50 percent of this group will be involved in ISH (Beautrais, Collings, Ehrhardt, \& et al., 2005). Forman et al. (2004) compared people that presented once to ED for ISH with those who presented several times. People who presented more than once were found to be four times more likely to have a diagnosis of psychotic disorders. People who have a diagnosis of a psychotic disorder might also pose a risk for others due to paranoia and command hallucinations (Scenario 2, p. 66), though there is little evidence to support this notion (Rogers, Watt, Gray, MacCulloch, \& Gournay, 2002).

A history of alcohol use was reported for nearly half of the sample compared to approximately one quarter of people that had a history of drug use. Alcoholrelated admissions to ED are common. In one ED in New Zealand there was an overall six-fold increase in the number of drunken youths in hospital in 2007, with the suggestion that doctors act as counsellors (Chalmers, 2008). Although not all of these would be involved in ISH, Forman et al. (2004) found that people who had multiple ISH episodes were more likely to receive a diagnosis of substance abuse. Violence was reported in a third of the people in this sample.

Thirty eight percent of people in this sample had a history of a physical illness. Within the documentation it was indicated at times that it could have been the trigger for the presentation, such as pain from a medical condition or the nature of a disease. The presence of acute or chronic physical illnesses may influence a person's mood, perhaps through pain, fear of death or surgery (Maskill et al., 2005). Routine questioning by ED doctors could incorporate questions regarding mental health issues when assessing physical concerns. The provision of holistic 
care for every person that presents to ED might meet peoples need for acknowledgement that their needs matter. Support people are included in this management.

\section{Support people}

For the first presentation nearly half of the people arrived with family/whānau, partners or friends, whereas for the second presentation only a third did. The reason for the significant decrease in the percentage of support people accompanying the person for the second presentation is unclear. The finding raises the question as to what extent during the first presentation was family/whānau included into the management of the person. As discussed in the literature review, family members want to be more involved, informed and supported (Clarke et al., 2007). Reasons those who intentionally self-harm choose not to involve their family include domestic violence, existing sexual abuse, unresolved conflict following separation and family patterns that reinforce addiction issues (Kina Families and Addictions Trust, 2005). ED staff could ask people that attend ED with ISH if they want a support person to be contacted, which is done for the frail and elderly, but rarely for people who intentionally selfharm.

Some of the people that arrived with a health care professional were in a care facility already. This indicates that people experienced a high level of distress irrespective of the 'safe' environment. The needs of the person might not have been met within the health services. This raises the question as to whether friends and their families should be encouraged to be part of a network that supports the person who intentionally self-harms. The wider community should have the opportunity to assist people with mental health issues within our midst. This is further encouraged by an extensive media campaign about depression, involving New Zealand celebrities.

\section{Identified gaps and risks in ED care}

Repeat presentations may result from ongoing illness as shown by their history or acute episodes as revealed by the triage code. Key findings identified related to 
poor level of documentation; the assessment and management of presentations and the involvement of the crisis assessment and treatment team.

\section{Documentation}

A significant amount of data was missing, such as people's history of ISH; drug and alcohol use and triage assessment. This raises the question of whether these assessments were carried out and not documented or just not done. Of particular concern was the lack of triage assessment documentation. Maintaining good standards of clinical documentation remains a problem in the health service despite persistent and unfailing advice from professional bodies over many years (Cowan, 2000).

\section{Triage Assessment}

Triage assessments for people who had appointments with CATT often lacked documentation about their current mental health status. Some people had a substantial wait for CATT irrespective of the appointment time, though this information was not specifically gathered for this study. The physical location of CATT is not within the proximity of the hospital. The geographical area covered by them is extensive and covers the whole district. Referrals are made by GPs, ambulance personnel, police and Community Mental Health Teams. In addition, their priority lies with people who are in police cells or in the community because ED is classed as a 'safe' place by CATT. 'Safe' means people can be allocated to a cubicle and medical, nursing and security personnel is available. Yet, for those waiting for CATT, there were routinely no further assessment recorded and sitting in the waiting room for many hours was common.

The lack of an assessment at triage puts a person at risk for undetected distress and harm to self or others, which has been illustrated in Chapter 5 (Scenarios 2 and 3) where the people were not assessed on re-presentation. Unless the triage nurse asks and assesses the person, ED is unaware of the risk. A study by Kerrison and Chapman (2007) found that nurses lacked knowledge in using the Australian Triage Scale (Australasian College for Emergency Medicine, 2005). Also, a significant 'up-triaging' of clients after the introduction of a mental health triage scale was reported in several studies (Broadbent et al., 2004). The scale acts 
as guidance for non-mental health staff. For each triage category there is a description of behaviours; typical observed and reported presentations; and general principles of management (New Zealand Guidelines Group \& Ministry of Health, 2003). The outcome of this study suggest that staff require further training in the use of the Emergency Department Mental Health Triage scale, used in conjunction with ATS, to accomplish a more accurate triage for people who intentionally self-harm.

There is a need for an initial assessment tool at triage. One tool would be the Mental Status Examination (Appendix 1) that assesses the person in a systematic way and is documented on the Electronic Patient Documentation System. Another tool is the Rapid Assessment Tool (New Zealand Guidelines Group \& Ministry of Health, 2003). Copies of this form are available for triage staff but there was no evidence in the documentation to indicate that the tool was ever used. Although the tool takes time to complete, it provides a means of communication between the nurse and the person who attends with intentional self-harm. It is also useful as a referral agent to the Crisis Assessment and Treatment Team. The triage nurse requires support and guidance to perform either assessment, which a mental health consultation liaison nurse based in ED could provide. Although position descriptions can vary, the aim of this advanced nursing role is to provide timely and accessible mental health services by working with the ED triage nurse, improve mental health risk assessment and management activities in ED, and address educational needs of ED staff (McDonough et al., 2004).

In countries like Australia, mental health triage services have been operational for nearly one decade and play a pivotal role in mental health care (Sands, 2007). Participants in the Sands study acknowledged that mental health triage nursing is a unique, highly specialised area of practice that involves well-developed knowledge, clinical skills and experience. For this reason, specialised psychiatric emergency centres, co-located within ED have been developed in Australia. These centres consist of a waiting room, interview rooms, a seclusion room, dormitories and court yards (Frank, Fawcett, \& Emmerson, 2005). They result in patients being monitored in safety by specialised mental health staff, reduced inpatient numbers and effective working relationships between ED and mental health 
services. Mental health triage is a complex and difficult task that requires specific mental health triage scales (Broadbent et al., 2002) that are understood and used by ED and mental health services.

\section{Assessment, management and referral}

Some differences in presentations were noted in relation to physical complaints; mental health assessments by ED staff; challenging behaviours and admission rate. These will be discussed next.

\section{Physical complaints}

A connection between physical and mental health complaints and re-presentations to ED was found. In Scenario 5, ISH is not questioned for a person with chronic anaemia and a history of deliberate self-harm. The provision of holistic care for people who present to ED would facilitate the link between physical and mental health and referral to other services as appropriate. As an example, for Māori (as well as for Pacific Islanders) mental health is dependent on all aspects of a person's life being in harmony: wairua (spiritual), hinengaro (emotional), tinana (physical) and whānau (extended family) (Mental Health Commission, 2007), which is not addressed in a busy emergency department.

There was a 10 percent increase for physical triggers, such as trauma, for the second presentation. Scenario 4 highlighted that the first and second presentations were not treated as related incidences. The person presented with a substantial hand injury and denied that he had any past medical history. Previous ISH presentations were not consulted by ED staff. Consequently, people at risk for completed suicide can obscure the cause of their injuries (Connor et al., 2003). An easy to access overview of recent presentations to ED is called for. A study by Hansagi, Olsson, Hussain, and Ohlen (2008) investigated whether the provision of printout case notes of three previous presentations was useful in the emergency department. They found that ED health professionals appreciated them, though it did not change re-presentation rates of people. Routine questioning by reception staff could include "Have you been here within the last seven days?" Reception staff could enter a positive response into EPDS which should trigger an 'Alert'. 
An information technology specialist should be involved in finding the best avenue to achieve this. The 'Alert' screen should highlight the previous presentation with a direct link to it. This would facilitate easy access to previous documentation, yet might be of limited use if it was done poorly. The importance and significance of documentation should be stressed to staff.

The ED environment is also not always suited for questioning about past presentations. People with 'minor' injuries are seen in an ambulatory care room where individual benches are divided by curtains. Privacy is at a minimum. People are often consulted by the ED doctor for a few minutes only. If ED staff are aware of a recent presentation, they can ask "I see you were here a few days ago - how have you been?" therefore showing concern for the patient and providing holistic care. However, it questions the role of ED, where the emphasis is on fast service through the emergency department. The use of communication skills might prevent or reduce further presentations, especially the ones within a short time-frame, often related to the same episode. A previously mentioned role of a mental health consultation liaison nurse could be involved in the care of this group and take them to a more private area to have a chat if required.

\section{Mental health assessments in ED}

The documentation by doctors and nurses of mental health assessments is minimal. For the second presentation just over half of the presentations were assessed. Of note was that nurses had documented the whereabouts of a person, but failed to add an assessment. In the literature, some ED nurses voiced that they lacked confidence in asking probing questions (Kerrison \& Chapman, 2007). Some of those participants felt that they wanted to care for 'real patients' such as trauma victims, yet, more people die of suicide than in road traffic accidents and homicide combined (Beautrais et al., 2005). If assessments are not documented, there is no evidence that they occurred. If a person injures other people, harms him/herself or even commits suicide in the ED setting, involved staff and the organisation need to account for their actions. An assessment can establish risk, so safety measures for the person, staff and others can be taken. The nurse requires knowledge regarding communication, but also in regard to attitude and stigma. This might be reflected in the evidence that there was reduced nursing comfort 
care provided for the second visit. This is of concern, especially as consumers indicate that staff could really make a difference with compassionate, respectful and non-judgmental care (Clarke et al., 2007). The lack of standardised documentation is an issue for both individual nurses and the organisation. This could be addressed by using the Rapid Assessment Tool at triage.

On 23 occasions people did not receive a mental health assessment by an ED doctor for the first and second presentation. Although this seemed an extraordinary high number of occasions that people were not assessed for risk to self and others, some believe that the traditional model of people being assessed by a doctor is neither the most effective, nor should be considered a priority (Eastwick \& Grant, 2004). The Rapid Assessment Tool filled out at triage could be used as guidance, so the doctor needs to ask only minimal questions.

One third of presentations were by Māori, yet no cultural specific services were provided. This was sad to observe as many Māori-specific government initiatives such as He Korowai Oranga: The Māori Health Strategy (Ministry of Health, 2002a) are in existence. It recognises whānau as central to mental health, wellbeing and recovery (Ministry of Health, 2008). It is expected that the Ministry of Health, DHBs and other government agencies work together with whānau, hapu, iwi, Māori communities and providers in order to decrease disparities between Māori and others in terms of prevalence, severity and burden of mental illness (Ministry of Health, 2002b). Access to quality care to address these disparities is of essence (Ministry of Health, 2002a), though did not appear to have been provided in this district health board. The establishment of collaboration between ED and Māori Health could result in a protocol, which would see Māori Health Services contacted when somebody who identifies as Māori arrives in ED with intentional self-harm. This would allow Māori people to receive cultural assessment and support. A working relationship between ED and Māori Health could involve training of ED staff to explain the importance of a cultural assessment.

The triage assessment determines the urgency with which the person needs to be seen by an ED doctor. It does not consider the care nurses can provide before the 
doctor attends. This waiting time provides an excellent opportunity for nurses to provide psychological care to alleviate possible fears and anxiety by providing information and showing a caring attitude. Nurses play a pivotal role in the care for people who intentionally self-harm. They can instil hope in people, trigger positive coping mechanisms and possibly decrease ISH episodes that lead to representations to the emergency department.

\section{Challenging behaviours}

A high participation of police and orderlies was noted for up to one third of presentations. This indicates that people did not always willingly present or stay in the emergency department. Scenario 6 gives an example of a person who tried to set herself alight in a cubicle in ED and the need for security orderlies. Inadequate communication and calming skills can exacerbate volatile situations. This raises the question of skill level needed in order to talk to and manage distressed people. The Nursing Council of New Zealand expects certain competencies of a registered nurse, with communication being one of the main ones (Nursing Council of New Zealand, 2007). "I am afraid of these people" and "I avoid those people" is a comment I hear from fellow nurses. The consequent lack of engagement can easily contribute to people's distress and challenging behaviour. A study by McDonough et al. (2004) found that volatility in ED was greatly reduced when a psychiatric liaison nurse was present, probably due to decreased wait for the person and an opportunity to have rapport and contact established on arrival.

\section{Admission}

The number of admissions for re-presentations was significantly higher than for first presentations. On 10 occasions people were admitted as inpatients both for the first and second presentation. Re-admissions to hospital indicate that people were previously discharged too early or that they were admitted for different reasons. The assessment for the first presentation might have shown that the person was well enough to go home and the health status changed over a short time. On the other hand the assessment might have shown that the person was well, when in fact underlying issues were not addressed and they were still unwell and distressed on presentation. The follow-up plan might not have been what the 
person wanted or needed, or it was not made or implemented. Re-presentations are associated with great distress for the person, cost for the hospital and highlights that the care for people who ISH is insufficient.

\section{The Crisis Assessment and Treatment Team}

Prior to this study I assumed that most people re-presented because they had a follow-up appointment with CATT. In actual fact, only approximately a quarter of all second presentations did. Follow-up is appreciated by people (Eales et al., 2006) though it is questionable if a noisy and busy ED is the most appropriate environment. ED lacks privacy and staff skilled in mental health care.

Not all referrals to CATT received an assessment. Some people were medically admitted and did not require CATT assessment at that stage; others had management plans that only required medical clearance in ED (see clinical chapter) and for some there was no documentation on EPDS. There is little evidence of the care or follow-up CATT provided as their written notes were not shared with ED, though best-practice guidelines recommend sharing of notes between services (New Zealand Guidelines Group \& Ministry of Health, 2003). An evaluation of the CATT service for this client group was not feasible for this study and could be an opportunity for further research.

\section{Implications of re-presentations}

\section{Cost}

Re-presentations cost money. In 2002 the economic cost per ISH event was $\$ 6,350$ in New Zealand (O'Dea \& Tucker, 2005). Within the ED where this study was conducted, the costing for an ED visit in 2006 was based on what people have to pay for their presentation if they do not reside in New Zealand. It is estimated that somebody with a higher triage code where more urgent care is required will need more expensive intervention and treatment. Excluded in the set price below are tests such as x-rays, scans, electrocardiograms or blood tests. Table 18 presents these basic costs by triage code. 
Table 18: Cost of the 73 re-presentation by triage code

\begin{tabular}{|l|r|r|r|}
\hline \multicolumn{1}{|c|}{$\begin{array}{c}\text { Triage Code } \\
\text { (time to be seen) }\end{array}$} & $\begin{array}{c}\text { No. of re- } \\
\text { presentations }\end{array}$ & $\begin{array}{c}\text { Cost } \\
\text { per person }\end{array}$ & $\begin{array}{c}\text { Total cost of re- } \\
\text { presentations }\end{array}$ \\
\hline 1 (immediately) & 1 & 787.68 & 787.68 \\
\hline 2 (within 10 minutes) & 10 & 785.00 & $7,850.00$ \\
\hline 3 (within 30 minutes) & 21 & 546.88 & $11,484.48$ \\
\hline 4 (within 60 minutes) & 31 & 331.67 & $10,281.77$ \\
\hline 5 (within 120 minutes) & 10 & 221.00 & $2,100.00$ \\
\hline Total & $\mathbf{7 3}$ & & $\mathbf{3 2 , 5 0 3 . 9 3}$ \\
\hline
\end{tabular}

The above table shows that for 73 repeat presentations after an initial presentation with ISH amounted to a basic cost of approximately $\$ 32,500$. With an increased interest in budget and saving money, this is an incentive to provide evidencebased, high quality care to all people in view of reducing repeat presentations. The distress of the person is more difficult to measure and does not show up on benchmark reports that measure performances of DHBs. There is no feedback on ED care, CATT does not report back with follow-up reports and suicides are not reported back to the emergency department.

People with borderline personality disorders make a major impact on health services as they often present in crisis with ISH (Binks et al., 2006). Management plans assist the person to understand what care is going to be provided and could contribute to a decrease in ED re-presentations. The underlying assumption is that people re-present for the same reason as previously, which seems unnecessary in regard to human suffering and cost.

\section{Limitations}

Many people presented to ED with intentional self-harm. The short time frame of one week for re-presentation, and the inclusion criteria of up to 12 presentations in 2006, limited the number of people being able to be included in this study. The search for re-presentations was difficult due to EPDS and made the identification of the sample a challenge. There was no easy way to access an overview of all representations within a certain time-frame. Individual presentation data needed to be accessed for this. People with single presentations for ISH might have represented within one week for any reason, but this was not easily accessible to me 
due to the vast amount of presentations and my limited amount of time to do this research. For these reasons, figures in this study are highly conservative. Given the content of the ED records it was not possible to establish whether the services that were required between presentations were received. Nor was it possible to establish what other services or support people had received in the intervening period.

Various people attended ED several times within one week. Consequently, some presentations related to ISH were counted as both first and second presentations. In view of this, the number of re-presentations does not reflect the number of people involved.

Looking through the clinical notes for this study was an upsetting experience for me at times. It portrayed the severity of distress people endured; the uncaring, abusive and lonely background of many and the helplessness of services when it came to offering valuable and effective support. Retrospective observational research using clinical records with its limited scope for depth, made it impossible to demonstrate the anguish surrounding intentional self-harm behaviours and the meanings for the individual. In addition, documented ED practice consisted mainly of crisis intervention with little evidence of assessment or comfort care for people, which might or might not be reflective of the actual care provided. This practice issue is also present for other patients in the emergency department.

Patient documentation by nurses and doctors is often minimal and not meant for research, which is a common limitation of retrospective data.

\section{Recommendations}

Recommendations regarding education, practice and research are made in the following section.

\section{Education}

Ongoing education and training for ED doctors and nurses in how to care for people who are involved in ISH is necessary and should be mandatory. Yearly 
updates of core competencies for nurses should include mental health knowledge and skills. Joint teaching sessions for nurses and doctors, lead in collaboration between ED and mental health services should cover risk assessment, complex presentations and the use of the Mental Health (Assessment and Treatment) Act (1992). Communication and negative attitudes should be addressed, preferably by teaching that involves consumers. Exchange of staff with mental health services, especially CATT and Māori Health/Mental Health might also be of benefit for increased understanding of what other services provide.

In addition to education, Eastwick and Grant (2004) suggest reflective peer supervision, where clinicians are able to express anxieties and feelings. The New Zealand Guidelines Group and the Ministry of Health (2003) also recommend that all clinicians who work with people who intentionally self-harm should be in regular clinical supervision to lessen the negative impact that this work can have, both on them and on the quality of their work when caring for this group.

\section{Practice}

Suggestions for practice improvements for people who present to ED with ISH are extensive (Figure 9) and correspond with goals identified by the New Zealand Suicide Prevention Strategy (Associate Minister of Health, 2006). Westwood and Westwood (2001) suggest the identification of practice gaps, followed by the implementation of clinical pathways; collaboration between services and stakeholders, and education of ED staff. Recipients of mental health services and family members should be included in the process (Clarke et al., 2007) to assure that services provide what people need. 
Develop clinical pathways, risk assessment tools and mental health triage guidelines for ED

\& Address the gap in services to target the needs of those with mental health problems, particularly those at risk

+ Address issues of equity in mental health in ED

\# Develop and implement avenues for interventions

\# Educate staff

4 Increase multidisciplinary teams on a $24 / 7$ basis

— Create positions for dedicated psychiatric staff in ED

* Collaborate with CMHT

\& Develop good communication between all stakeholders

\section{Figure 8: Suggestions for practice improvement in ED*}

*Adapted from: Westwood, B., \& Westwood, G. (2001). Multi-presenter mental health patients in emergency departments - a review of models of care Australian Health Review, 24(4), 202 -213.

Participation in the Self-harm and Suicide Prevention Collaborative Whakawhanaungatanga (New Zealand Guidelines Group, 2005) would meet seven of the above 9 points suggested by Westwood and Westwood (2001). It encourages collaboration between services, service users and their families and would stress the importance of discharge and follow-up from ED. A consistent use of the Emergency Department Mental Health Triage guidelines presented in Table 1 would increase the understanding of mental health assessments by ED staff; and create a positive change in triage practice and attitude towards clients at risk of ISH, as found by Broadbent et al. (2002).

In line with what is provided for people who attend with physical issues to ED, staff should provide health education and promotion to people who intentionally self-harm so they can take active roles in their management (Eales et al., 2006). The philosophy of ED should move towards holistic care, making inquiry about mental health part of an ED basic assessment, irrespective of reasons for attendance. If mental health difficulties are identified a specialised person in ED such as a mental health consultation liaison nurse could follow it up and liaise with community services such as a GP. All of the literature reviewed identified that the presence of an identified expert psychiatric practitioner within an emergency department was valuable (Heslop et al., 2000; McDonough et al., 2004; Summers \& Happell, 2003). A mental health consultation liaison nurse can 
provide the link between the community and secondary care (Eales et al., 2006). This position is implemented in some larger DHBs in New Zealand. Positions should be fully funded and appropriately resourced.

Mental health provision in ED focuses on crisis. People need to be at risk to themselves or others in order for CATT to make an assessment. If people are supported when issues first arise, they can hopefully get through hard times without having to attend $\mathrm{ED}$ on several occasions or shortly after an initial visit. A service with increased mental health support based in ED or more mobile units out in the community after hours should be considered. An integrated care pathway for self-harm was implemented across a range of health and social care organisations in the UK (Harrison, Hillier, \& Redman, 2005). The emphasis was on ownership and active collaboration in the assessment and care process on the part of many stakeholders, including consumer involvement.

As detailed in Chapter 3, a form from the Accident Compensation Corporation (ACC) is filled out at reception for lacerations, overdoses with reduced consciousness and ingestion of foreign bodies that require surgery for removal. Everyone is entitled to seek their assistance after an accident, even if it was selfinflicted (Accident Compensation Corporation, 2006). The Accident Compensation Corporation's aim is injury prevention, care and recovery. Their claims, like in ED, are classed by type of injury and not intent, therefore it might not come to their attention that people re-present to the emergency department. In view of the high cost to society and to the individual taxpayer, a dedicated Selfharm Team, suggested by a New Zealand psychiatrist S. Hatcher (Collins, 2007a), could be set up. This team would be multidisciplinary, including Mental Health and Physical Health, Alcohol \& Drug Services, and non health staff from NonGovernment Organisations, ACC and social workers as people often has multifaceted problems.

\section{Research}

A prospective cohort study is required to determine the pattern and reasons for representations after an initial presentation to ED with intentional self-harm. All presentations should be monitored and people should be followed up regularly on 
a database over a period of time and provided with surveys or interviews at intervals in order to gain further understanding of this group.

People with psychosis featured frequently in this sample. A longitudinal study could identify the role of ISH in people with psychosis and presentations to ED. Quantitative description limits what can be learned about the meanings people give to events (Sandelowski, 2000), therefore interviews of this sample group could identify personal reasons for re-presentations.

Discharge and follow-up services of the Crisis Assessment and Treatment Team could be explored by another retrospective descriptive study to find out what their management involves and if follow-up plans are made and implemented. This could be combined with ED data to see if these people re-presented.

Further research in regard to people who present more than 12 times in this ED could highlight needs for this particular group. A retrospective descriptive design where electronic documentation of presentations is examined in combination with interviews of the people involved in ISH could provide valuable information on factors contributing to ISH and re-presentations to the emergency department.

A study that investigates people that present only once to ED with ISH could be further investigated. A retrospective descriptive study and interviews would be suitable in order to gain further understanding of this population.

\section{Conclusion}

This study highlighted that the number of ISH presentations in 2006 is far higher than expected. However, a lack of documentation and the data classification made it impossible to measure the extent of the issue. Risks for practice were identified in regard to ED management and CATT. Documented mental health assessments by doctors and nurses were scarce, Māori did not receive cultural assessments and previous ED presentations for the individual were not routinely consulted, creating a significant risk for staff and the organisation. The distress of individuals included in this sample evidenced by a high police involvement and increase in 
inpatient admissions for the second presentation indicates personal disadvantages of re-presentations. The input of the Crisis Assessment and Treatment Team in regard to discharge and follow-up was difficult to assess due to the lack of notes. People did not receive a better service on their second presentation and were often involved in further intentional self-harm. The people in this study were at increased risk of dying.

Results have provoked feelings of surprise, disappointment, anger and sadness in me. Yet, this study presents an opportunity to improve services. It has important implications for the management of people who present to ED with intentional self-harm and re-present within a week. Mental health care in this ED setting requires strengthening with additional mental health resources and collaboration between services that address people's needs. The promotion of safe, effective and quality care for this population group is essential. 


\section{APPENDICES}

\section{Appendix 1: Mental Status Examination}

\begin{tabular}{|c|c|}
\hline Category & Description \\
\hline $\begin{array}{l}\text { Appearance/general } \\
\text { behaviour }\end{array}$ & $\begin{array}{l}\text { Body language, posture, gesture, manner, attire, } \\
\text { grooming, eye contact }\end{array}$ \\
\hline $\begin{array}{l}\text { Attitude towards } \\
\text { interviewer }\end{array}$ & $\begin{array}{l}\text { Suspicious, hostile, evasive, tentative, cooperative, } \\
\text { rapport, disinhibited }\end{array}$ \\
\hline Affect/mood & $\begin{array}{l}\text { Facial expression, tone of voice, emotional } \\
\text { responsiveness (flat, apathetic, labile, irritable), sad, } \\
\text { tired, elated, euphoric, irritable, agitated, tense, anxious. } \\
\text { Is what the person reports congruent with what is } \\
\text { observed? }\end{array}$ \\
\hline Psychomotor activity & $\begin{array}{l}\text { Restlessness, agitation, slowing (of movements, speech } \\
\text { and thoughts) }\end{array}$ \\
\hline Speech & Loud, speed, pressure of speech, poverty of speech \\
\hline Thought ce & $\begin{array}{l}\text { Suicidal ideation? Beliefs about themselves and others, } \\
\text { delusional beliefs, anxious thinking, obsessions }\end{array}$ \\
\hline Thought $\mathrm{p}$ & $\begin{array}{l}\text { Perseveration ('stuck on one theme), tangentiality (side } \\
\text { tracked), loose association (absence of logical thought } \\
\text { processes) }\end{array}$ \\
\hline Perceptual disturbance & $\begin{array}{l}\text { Hallucinations, are they command hallucinations? How } \\
\text { much fear does that produce in the person? }\end{array}$ \\
\hline Orientation & $\begin{array}{l}\text { Place, person, time. Rule out delirium, intoxication, } \\
\text { organic complications }\end{array}$ \\
\hline Insight and judgment & $\begin{array}{l}\text { Awareness of present circumstances, their health and } \\
\text { reasons for presentation }\end{array}$ \\
\hline $\begin{array}{l}\text { Intelligence/cognitive } \\
\text { function }\end{array}$ & $\begin{array}{l}\text { Content of speech, educational history, vocational } \\
\text { background, attention, concentration, memory problems }\end{array}$ \\
\hline
\end{tabular}

Adapted from The management and treatment of people at risk of suicide. 2003. New Zealand Guidelines Group. 


\section{Appendix 2: Data Extraction Tool}

\section{Information from $1^{\text {st }}$ and $2^{\text {nd }}$ visit:}

Research Number:

Total number of visits:

Days between first and second visit:

$\underline{\text { Socio-demographic features }}$

\begin{tabular}{|l|l|l|l|}
\hline Age & \multicolumn{3}{|l}{} \\
\hline Sex & Male & Female & Transgender \\
\hline Ethnicity & Māori & Pacific & Other \\
\hline
\end{tabular}

History

\begin{tabular}{|l|l|l|}
\hline Intentional self-harm & Yes & No \\
\hline Physical Illness & Yes & No \\
\hline Mental Illness & Yes if yes what kind?-------------------------- & No \\
\hline Alcohol use & Yes & No \\
\hline Drug use & Yes if yes what kind?----------------------------- & No \\
\hline Violence & Yes & No \\
\hline
\end{tabular}

$\underline{\text { Arrival to ED }}$

\begin{tabular}{|l|l|l|}
\hline & First visit & Second visit \\
\hline Arrival time & & \\
\hline Day of the week & & \\
\hline Triage code & & \\
\hline Support person with patient & Yes/No & Yes/No \\
\hline Who is this support person? & & \\
\hline
\end{tabular}


Presenting issue

\begin{tabular}{|l|l|l|}
\hline & First visit & Second visit \\
\hline Suicidal & Yes/No & Yes/No \\
\hline Deliberate self-harm & Yes/No & Yes/No \\
\hline If yes - what type? & & \\
\hline Trigger social & Yes/No & Yes/No \\
\hline Trigger physical & Yes/No & Yes/No \\
\hline Trigger mental & Yes/No & Yes/No \\
\hline
\end{tabular}

$\underline{\text { Associated factors }}$

\begin{tabular}{|l|l|l|}
\hline & First visits & Second visit \\
\hline Alcohol use & Yes/No & Yes/No \\
\hline Drug use & Yes/No & Yes/No \\
\hline If yes - what drug/s? & & \\
\hline Assaulting in ED & Yes/No & Yes/No \\
\hline Required restraint & Yes/No & Yes/No \\
\hline Police involvement & Yes/No & Yes/No \\
\hline Watch/security present & Yes/No & Yes/No \\
\hline Mental Health Act enforced & Yes/No & Yes/No \\
\hline
\end{tabular}

$\underline{\text { ED care }}$

\begin{tabular}{|l|l|l|}
\hline & First visit & Second visit \\
\hline Nursing Assessment & Yes/No & Yes/No \\
\hline Comfort care by nurse & Yes/No & Yes/No \\
\hline Vital observations & Yes/No & Yes/No \\
\hline Blood test & Yes/No & Yes/No \\
\hline Seen by ED doctor & Yes/No & Yes/No \\
\hline Highest qualification of ED Dr. & & \\
\hline Physical assessment by Ed Dr. & Yes/No & Yes/No \\
\hline Mental Health Assessment & Yes/No & Yes/No \\
\hline Medication (physical) & Yes/No & Yes/No \\
\hline Medication (mental health) & Yes/No & Yes/No \\
\hline Cultural input & Yes/No & Yes/No \\
\hline
\end{tabular}

$\underline{\text { Referral }}$

\begin{tabular}{|l|l|l|}
\hline & First visit & Second visit \\
\hline Expected by CATT & Yes/No & Yes/No \\
\hline Referred to MH & Yes/No & Yes/No \\
\hline Referred to other & Yes/No & Yes/No \\
\hline Referred to whom & & \\
\hline CATT assessment & Yes/No & Yes/No \\
\hline
\end{tabular}


$\underline{\text { Post assessment }}$

\begin{tabular}{|l|l|l|}
\hline & First visit & $\begin{array}{l}\text { Second } \\
\text { visit }\end{array}$ \\
\hline Admission & Yes/No & Yes/No \\
\hline Where admitted & & \\
\hline Discharge & Yes/No & Yes/No \\
\hline Follow-up & Yes/No & Yes/No \\
\hline What service followed-up & & \\
\hline Self-discharge & Yes/No & Yes/No \\
\hline Length of stay & & \\
\hline
\end{tabular}




\section{Appendix 3: Location of Variables on the Electronic Patient Documentation System}

\section{Clerical window}

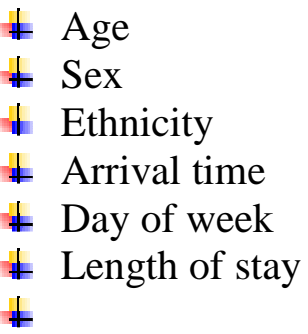

\section{$\underline{\text { Triage window }}$}

$\neq$ History of ISH

\# Physical history

* Mental health history - diagnosis

* History of alcohol

+ History of drug use - what kind

$\$$ Suicidal

\# Deliberate self-harm - what type

* Trigger - mental health, physical, social

* Alcohol intake current visit

\& Drug intake current visit - what type

\& Assaultive behaviour

$\$$ Police

\& Watch

* Expected by CATT

\# Triage code

* Personal support - who

\section{Clinical window}

Arrival time

Expected by CATT

+ ED doctor

* Bloods

* Referred to CATT/MH/Other

* CATT assessment

* Admission - where

\# Discharge

\& Follow-up - who

\& Self-discharge 


\section{Clinical notes}

History of ISH

Physical history

* Mental health history - diagnosis

History of alcohol

\& History of drug use - what kind

* History of violence

\& Suicidal

\& Deliberate self-harm - what type

* Trigger - mental health, physical, social

* Alcohol intake current visit

\& Drug intake current visit - what type

+ Assaultive behaviour

4 Restraint

\# Police

\# Watch

\# Nurse assessment

\# Nurse comfort cares

\# ED doctor - yes/no, rank

+ ED doctor physical assessment

\# Bloods

* ED doctor mental health assessment

* Medication for physical and mental health complaint

\# Cultural input

* Mental Health Act

\& Referred to CATT/Mental Health/Other

\# CATT assessment

* Personal support - who

* Discharge

\& Follow-up - who

* Self-discharge

\section{$\underline{\text { Alert screen }}$}

History of violence

\section{Vitals window}

Vitals 


\section{Appendix 4: Ethics Committee Approval}

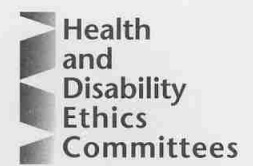

7 June 2007

Silke Kuehl

Masters Student

115 Pinehaven Road

Upper Hutt

Wellington

Dear Silke

CEN/07/20/EXP - Representations to the emergency department with intentional selfharm

Central Regional Ethics Committee

$$
\begin{array}{r}
\text { Ministry of Health } \\
\text { Level 2, 1-3 The Terrace } \\
\text { PO Box } 5013 \\
\text { Wellington } \\
\text { Phone (04) } 4962405
\end{array}
$$

Fax (04) 4962191

The above study has been given ethical approval by the Chairperson of the Central Regional Ethics Committee.

Final Report

The study is approved until May 2008. A final report is required at the end of the study and a form to assist with this is available from the Administrator. If the study will not be completed as advised, please forward a progress report and an application for extension of ethical approval one month before the above date. The report form is also available on http://www.newhealth.govt.nz/ethicscommittees.

\section{Amendments}

It is also a condition of approval that the Committee is advised if the study does not commence, or is altered in any way, including all documentation eg advertisements, letters to prospective participants.

Please quote the above ethics committee reference number in all correspondence.

It should be noted that Ethics Committee approval does not imply any resource commitment or administrative facilitation by any healthcare provider within whose facility the research is to be carried out. The organisation may specify their own processes regarding notification or approval.

Yours sincerely

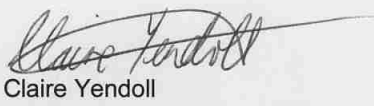

Administrator Central Regional Ethics Committee 


\section{Appendix 5: Diagnosis Description}

Suicide attempt - suicide risk or attempt Suicide risk-suicide risk or attempt

Alcohol Addiction

Alcohol withdrawal syndrome

Alcohol Intoxication - Alcohol Associated

Disorders

Other alcohol poisoning

Alcoholic psychosis

Opiod Poisoning

Opiod withdrawal syndrome

Drug induced Mental Disorder

Drug addiction

Paracetamol poisoning - poisoning by drugs, anagesics or ant

Beta-blocker poisoning

Other antihypertensive poisoning

Antidepressant poisoning

Antihistamine poisoning

Benzodiazepine poisoning

Other psychotropic agent poisoning

Other antidiabetic poisoning

Other systemic agent poisoning

Other analgesics or antipyretics poisoning, by drugs.

Other Sedative or hypnotic poisoning by drugs, sedatives and tra

Other CNS Stimulant Poisoning

Marijuana poisoning

Emotional crisis, nec - behavioural, emotional or developmental

Confusional states

Hallucinations- symptoms of nervous disorder

Psychotic episode - psychoses

Depression-Depressive disorders exl

bipolar

Depression with anxiety

Bipolar Affective Disorder, unspecified

Manic Disorder - Bipolar disorders \& manic disorder

Antisocial Personality Disorder psychiatric or mental disorder

Personality Disorder

Psychosomatic disorder

Bulimia - eating disorders

Behavioural problems, adolescent

Mental Status Alteration - symptoms of nervous disorder

Other Mental Disorders - Behavioural,

Emotional or Developmental 
Conversion Disorder

Insomnia - Sleep disorders

Neurosis - generalised anxiety

Panic attack - reaction to exceptional sanxiety disorders or fear states

Anxiety state/panic attack

Fearfulness - anxiety disorders

Loss of consciousness

Head injury, closed - Loc 1-24 hrs

Anaemia, due to chronic blood loss

Stomach foreign body

Wrist wound, uncomplicated

Forearm wound or non venomous bite

Finger wound uncomplicated

Hand \& Finger wounds/non ven. Bites

Foot and toe wound - uncomplicated

Leg wound - uncomplicated

Thigh wound

Knee wound- complicated

Upper arm wound - uncomplicated

Hand wound - uncomplicated

Unspecified open wound

Other specific open wounds

Head injury, closed - ?LOC

Swallowed foreign body - Gl foreign

body

Asphyxiation by strangulation

Marital Conflict

Lack of home care - social, financial, domestic

Acopia - social, financial, domestic

Parental anxiety only

For review

Medical check up

Feared complaint unfounded

No illness detected 


\section{Appendix 6: Multisectoral approach to suicide prevention}

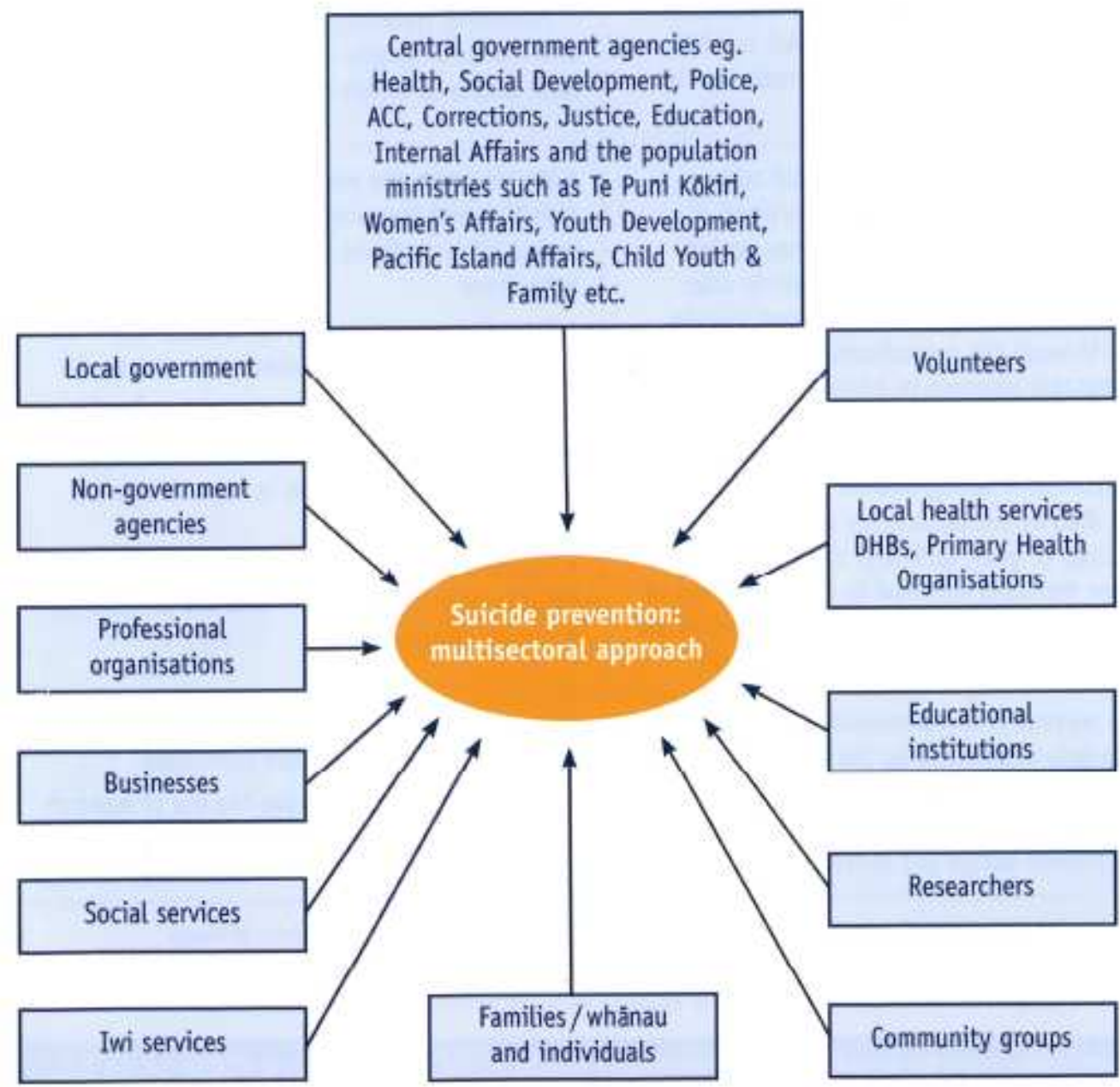

Reproduced with permission from: Associate Minister of Health. 2006. New Zealand Suicide Prevention Strategy 2006-2016. Wellington: New Zealand 


\section{REFERENCES}

Accident Compensation Corporation. (2006). About ACC. Retrieved 23 February, 2008, from http://www.acc.co.nz/about-acc/index.htm

Adams, R. J., Smith, B. J., \& Ruffin, R. E. (2000). Factors associated with hospital admissions and repeat emergency department visits for adults with asthma. Thorax, 55(7), 566 - 573.

Adolescent Health Research Group. (2003). A health profile of New Zealand youth who attend secondary school [Electronic Version]. The New Zealand Medical Journal 116. Retrieved 1.3.08 from http://www.nzma.org.nz/journal/116-1171/380/.

Alao, A. O., Soderberg, M., Pohl, E. L., \& Alao, A. L. (2006). Cybersuicide: Review of the role of the internet on suicide. CyberPsychology \& Behaviour, 9, 489 - 493.

American College of Surgeons Committee on Trauma. (1997). Advanced trauma life support for doctors (6th ed.). Chicago: First Impression.

American Psychiatric Association. (1994). Diagnostic and statistical manual of mental disorders: DSM IV (4th ed.). Washington: Author.

Anker, A. (2002, April 27, 2002). Drug overdose. eMedicine Retrieved 12 August, 2007 , from http://www.emedicine.com/AAEM/topic169.htm\#section author_informat $\underline{\text { ion }}$

Arbuthnot, L., \& Gillespie, M. (2005). Self-harm: Reviewing psychosocial assessment in emergency departments. Emergency Nurse, 12(10), 20 - 24

Associate Minister of Health. (2006). The New Zealand Suicide Prevention Strategy 2006 - 2016. Wellington: Ministry of Health.

Australasian College for Emergency Medicine. (2005). Guidelines on the implementation of the Australasian triage scale in emergency departments [Electronic Version], 1 - 7 . Retrieved 3.12.07 from http://www.acem.org.au/media/policies_and_guidelines/G24_Implementat ion ATS.pdf. 
Barr, W., Leitner, M., \& Thomas, J. (2005). Psychosocial assessment of patients who attend an accident and emergency department with self-harm. Journal of Psychiatric and Mental Health Nursing, 12, 130 - 138.

Batty, D. (2004). Self-harm patients 'deserve dignity'. guardian.co.nz Retrieved July 21, 2008, from http://www.guardian.co.uk/society/2004/jul/28/mentalhealth.medicineandh $\underline{\text { ealth }}$

Beautrais, A. L. (2003). Suicide in New Zealand II: A review of risk factors and prevention [Electronic Version]. Journal of the New Zealand Medical Association, $116 . \quad$ Retrieved 13.06 .07 from http://www.nzma.org.nz/journal/116-1175/461/.

Beautrais, A. L., Collings, S. C. D., Ehrhardt, P., \& et al. (2005). Suicide Prevention: A review of evidence of risk and protective factors, and points of effective intervention. Wellington: Ministry of Health.

Beautrais, A. L., \& Fergusson, D. M. (2006). Indigenous suicide in New Zealand. Archive of Suicide Research, 10, 159 - 168.

Bennewith, O., Stocks, N., Gunnel, D., Peters, T. J., Evans, M. O., \& Sharp, D. J. (2002). General practice based intervention to prevent repeat episodes of deliberate self harm: Cluster randomized controlled trial. British Medical Journal, 324, 1254 - 1257.

Binks, C. A., Fenton, M., McCarthy, L., Lee, T., Adams, C. E., \& Duggan, C. (2006). Psychological therapies for people with borderline personality disorder [Electronic Version]. The Cochrane Library. Retrieved 15 August 2008 from http://www.mrw.interscience.wiley.com/cochrane/clsysrev/articles/CD005 $\underline{652 / \text { frame.html. }}$

Bond, G. R. (2002). The role of activated charcoal and gastric emptying in gastrointestinal decontamination: A state-of-the-art review. Annals of Emergency Medicine, 39(3), 273-286.

Bridger, S., Henderson, K., Glucksman, E., Ellis, A. J., Henry, J. A., \& Williams, R. (1998). Deaths from low dose paracetamol poisoning. British Medical Journal, 316(7146), 1724 - 1725.

Brink, P. J., \& Wood, M. J. (1998). Advanced design in nursing research. Retrieved $24 \quad$ August 2008, from ttp://books.google.co.nz/books?hl=en\&lr=\&id=hDRwaJwmdcC\&oi=fnd\&pg=PP11\&dq=non+experimental+research+nursing\&ot $\mathrm{s}=\mathrm{cUqHOAW}-56 \&$ sig=brhDuceV-50zOOuKLznRQZW7j-g\#PPP1,M1. 
Broadbent, M., Jarman, H., \& Berk, M. (2002). Improving competence in emergency mental health triage. Accident \& Emergency Nursing, 10, 155162.

Broadbent, M., Jarman, H., \& Berk, M. (2004). Emergency department mental health triage scales improve outcomes. Journal of Evaluation in Clinical Practice, 10(1), 57-62.

Brok, J., Buckley, N., \& Gluud, C. (2006). Interventions for paracetamol (acetaminophen) overdose. Cochrane Database for Systematic Reviews Retrieved 10 August, 2008

Chalmers, A. (2008). Drunken youths flood into hospital. Retrieved 13.4., 2008, from http://www.stuff.co.nz/dominionpost/4473934a6479.html

Chitsabesan, P., Harrington, R., Harrington, V., \& Tomenson, B. (2003). Predicting repeat self-harm in children. How accurate can we expect to be? European Child \& Adolescent Psychiatry, 12, 23 - 29.

Claassen, C. A., Kashner, T. M., Gilfillan, S. K., Larkin, G. L., \& Rush, A. J. (2005). Psychiatric emergency service use after implementation of managed care in a public mental health system. Psychiatric Services, 56(6), $691-698$.

Clarke, D. E., Dusome, D., \& Hughes, L. (2007). Emergency department from the mental health client's perspective. International Journal of Mental Health Nursing, 16, 126 - 131.

Cleaver, K. (2007). Characteristics and trends of self-harming behaviour in young people. British Journal of Nursing (BJN), 16(3), 148 -152.

Collins, S. (2007a, September 11). Call for hospital 'suicide teams'. The New Zealand Herald, p. A4.

Collins, S. (2007b). Government boost lowers GP visit costs [Electronic Version]. The New Zealand Herald. Retrieved 06.08.2007 from http://www.nzherald.co.nz/section/story.cfm?c_id=204\&objectid=104501 $\underline{81 \& p n u m=2}$.

Colman, I., Dryden, D. M., Thompson, A. H., Chahal, A. M., Borden, K., Rowe, B. H., et al. (2004). Utilization of the emergency department after selfinflicted injury. Academic Emergency Medicine, 11(2), 136 - 142.

Connor, K. R., Langley, J., Tomaszewski, K. J., \& Conwell, Y. (2003). Injury hospitalization and risks for subsequent self-injury and suicide: A national study from New Zealand. American Journal of Public Health, 93(7), 1128. 
Cook, L. J., Knight, S., Junkins, E. P., Mann, N. C., Dean, J. M., \& Olson, L. M. (2004). Repeat patients to the emergency department in a statewide database. Academic Emergency Medicine, 11(3), 256 - 263.

Cooper, J., Kapur, N., Webb, R., Lawlor, M., Guthrie, E., Mackway-Jones, K., et al. (2005). Suicide after deliberate self-harm: A 4-year cohort study. American Journal of Psychiatry, 162(2), 297 -303.

Cottrell, R. R., \& McKenzie, J. F. (2005). Health promotion \& education research methods: Using the five chapter thesis/dissertation model Retrieved 26 August 2008, from http://books.google.co.nz/books?id=BXKQX8Adlb0C\&pg=PA186\&dq=n on-

experimental+research\&ei=LgmzSJLWEYKgswOZ1enwBA\&sig=ACfU3 U3dorT7gfwFuQ2jUrVurrs8JNflew\#PPR4,M1.

Coupe, N. M. (2000a). The epidemiology of Maori suicide in Aotearoa/New Zealand. South Pacific Journal of Psychology, 12(1), 1 - 12.

Coupe, N. M. (2003). Whakamomori: Mäori Suicide Prevention. Unpublished $\mathrm{PhD}$, Massey University, Auckland.

Cowan, J. (2000). Clinical governance and clinical documentation: Still a long way to go? British Journal of Clinical Governance 5 (3), 179 - 182.

Crawford, M. J., \& Wessely, S. (1998). Does initial management affect the rate of repetition of deliberate self harm? Cohort study. British Medical Journal, 317(7164), 985.

Crocker, L., Clare, L., \& Evans, K. (2006). Giving up or finding a solution? The experience of attempted suicide in later life. Aging \& Mental Health, $10(6), 638-647$.

De Leo, D., Burgis, S., Bertolote, J. M., Kerkhof, A. J. F. M., \& Bille-Brahe, U. (2006). Definitions of suicidal behaviour. Crisis, 27(1), 4 - 15.

Derlet, R. W., \& Richards, J. R. (2000). Overcrowding in the nation's emergency departments: Complex causes and disturbing effects. Annals of Emergency Medicine, 35, 63 - 68.

Didham, R., Dovey, S., \& Reith, D. (2006). Characteristics of general practitioner consultations prior to suicide: A nested case-control study in New Zealand. The New Zealand Medical Journal, 119(1247), 1 - 11.

Donald, M., Dower, J., Correa-Velez, I., \& Jones, M. (2006). Risk and protective factors for medically serious suicide attempts: A comparison of hospital- 
based with population-based samples of young adults. Australian \& New Zealand Journal of Psychiatry, 40(1), 87-96.

Drew, B. L., Jones, S. L., Meldon, S. W., \& Varley, J. D. (2006). Emergency Department visits for suicidality in three hospitals. Archives of Psychiatric Nursing, 20(3), 117 - 125.

Durie, M. (1999). Mental health and Maori development. Australian \& New Zealand Journal of Psychiatry, 33(1), 5 -12.

Eales, S., Callaghan, P., \& Johnson, B. (2006). Service users and other stakeholders' evaluation of a liaison mental health service in an accident and emergency department and a general hospital setting. Journal of Psychiatric \& Mental Health Nursing, 13, 70 - 77.

Eastwick, Z., \& Grant, A. (2004). Emotional rescue: Deliberate self harmers and A\&E departments. Mental Health Practice, 7(9), 12-15.

Elley, C. R., Randall, P.-J., Bratt, D., \& Freeman, P. (2007). Can primary care patients be identified within an emergency department workload? The New Zealand Medical Journal, 120(1256), 1 - 12.

Fleming, T. M., Merry, S. N., Robinson, E. M., Denny, S. J., \& Watson, P. D. (2007). Self-reported suicide attempts and associated risk and protective factors among secondary school students in New Zealand. Australian \& New Zealand Journal of Psychiatry, 41(3), 213 - 221.

Forman, E. M., Berk, M. S., Henriques, G. R., Brown, G. K., \& Beck, A. T. (2004). History of multiple suicide attempts as a behavioral marker of severe psychopathology. American Journal of Psychiatry [NLM MEDLINE], 161(3), 437.

Fortune, S., \& Clarkson, H. (2006). The role of child and adolescent mental health services in suicide prevention in New Zealand. Australasian Psychiatry, 14(4), 369 - 373.

Fortune, S., Stewart, A., Yadav, V., \& Hawton, K. (2006). Suicide in adolescents: Using life charts to understand the suicidal process. Journal of Affective Disorders, doi:10.1016/j.jad.2006.1010.1022.

Fox, C., \& Hawton, K. (2004). Deliberate self-harm in adolescence. London: Jessica Kingsley Publishers.

Frank, R., Fawcett, L., \& Emmerson, B. (2005). Development of Australia's first psychiatric emergency centre. Australasian Psychiatry, 13(3), 266 - 272. 
Getliffe, K. (1998). Quantitative research design. In B. Roe \& C. Webb (Eds.), Research and development in clinical nursing practice (pp. 372). London: Whurr Publishers.

Gilbody, S., House, A., \& Owens, D. (1997). The early repetition of deliberate self harm. Journal of the Royal College of Physicians of London, 31(2), $171-172$.

Gillis, A., \& Jackson, W. (2002). Research for nurses: Methods and interpretation. Philadelphia: F. A. Davis Company.

Gunnell, D., Bennewith, O., Peters, T. J., House, A., \& Hawton, K. (2005). The epidemiology and management of self-harm amongst adults in England. Journal of Public Health, 27(1), 67 - 73.

Gunnell, D., Bennewith, O., Peters, T. J., Stocks, N., \& Sharp, D. J. (2002). Do patients who self -harm consult their general practitioner soon after hospital discharge? Social Psychiatry and Psychiatric Epidemiology, 37, $599-602$.

Hansagi, H., Olsson, M., Hussain, A., \& Ohlen, G. (2008). Is information sharing between the emergency department and primary care useful to the care of frequent emergency department users? European Journal of Emergency Medicine, 15(1), 34 - 39.

Harbour, R., \& Miller, J. (2001). A new system for grading recommendations in evidence based guidelines. British Medical Journal, 323(7308), 334-336.

Harrison, A., Hillier, D., \& Redman, R. (2005). Utilizing practice development to implement an integrated care pathway for self-harm. Practice Development in Health Care, 4(2), 77-85.

Hatcher, S., Sharon, C., Lee, M., Lovell, C., Coggan, C., \& Ameratunga, S. (2005). Deliberate self-harm and associated re-presentation rates at the Emergency Department of Whangarei Hospital, New Zealand (No. Centre Report Series No 106). Auckland: Injury Prevention Centre, Te Puu Taki Aukati Whara, University of Auckland.

Hawton, K., Arensman, E., Townsend, E., Bremner, S., Feldman, E., Goldney, R., et al. (1998). Deliberate self harm: Systematic review of efficacy of psychosocial and pharmacolocical treatmtents in preventing repetition. British Medical Journal, 317(7156), 441 - 447.

Hawton, K., \& Harriss, L. (2006). Deliberate self-harm in people aged 60 years and over: Characteristics and outcome of a 20-year cohort. International Journal of Geriatric Psychiatry, 21, 572 - 581. 
Hawton, K., \& James, A. (2005). Suicide and deliberate self harm in young people. British Medical Journal, 330(7496), 891-894.

Health and Disability Commissioner. (1996). The HDC Code of Health and Disability Services Consumers' Rights Regulation 1996. Retrieved 5 August, 2007, from http://www.hdc.org.nz/theact/theact-thecodesummary

Health Research Council. (2005). Guidelines on ethics in health research: Health Research Council of New Zealand.

Helliwell, P. E., Hider, P. N., \& Ardagh, M. W. (2001). Frequent attenders at Christchurch Hospital's emergency department. The New Zealand Medical Journal, 114(1129), 160 - 161.

Hepp, U., Wittmann, L., Schnyder, U., \& Michel, K. (2004). Psychological and psychosocial interventions after attempted suicide. Crisis, 25(3), 108 117.

Herron, J., Ticehurst, H., Appleby, L., Perry, A., \& Cordingley, L. (2001). Attitudes toward suicide prevention in front-line health staff. Suicide \& Life-Threatening Behaviour New York, 31(3), 342 - 347.

Heslop, L., Elsom, S., \& Parker, N. (2000). Improving continuity of care across psychiatric and emergency services: Combining patient data within a participatory action research framework. Journal of Advanced Nursing, $31(1), 135-143$.

Hunter, E., \& Harvey, D. (2002). Indigenous suicide in Australia, New Zealand, Canada and the United States. Emergency Medicine Australasia, 14(1), 14-23.

Johnson, A. B. (1990). Out of bedlam: The truth about deinstitutionalization. United States of America: Basic Books.

Kapur, N., Cooper, J., Rodway, C., Kelly, J., Guthrie, E., \& Mackway-Jones, K. (2005). Predicting the risk of repetition after self-harm: Cohort study. British Medical Journal, 330, 394 - 395.

Kerrison, S. A., \& Chapman, R. (2007). What general emergency nurses want to know about mental health patients presenting to their emergency department. Accident \& Emergency Nursing, 15, 48 - 55.

Kina Families and Addictions Trust. (2005). Family inclusive practice in the addiction field: A guide for practitioners working with couples, families and whanau. Wellington: Mental Health Commission. 
Knupfer, N. N., \& McLellan, H. (2001). Descriptive research methodologies. Retrieved $26 \quad$ August 2008, from http://www.coedu.usf.edu/itphdsem/411.pdf.

Kuehl, A. (2005). Documentation crisis in the emergency department [Electronic Version]. MLMIC Dateline, 3, 5. Retrieved 20 August 2008 from http://www.mlmic.com/portal/Files/Dateline/DatelineSpring05_2.pdf.

Kvale, S. (1996). Interviews: An introduction to qualitative research interviewing. $\begin{array}{llll}\text { Retrieved } 24 & \text { August } & \text { 2008, from }\end{array}$ http://books.google.co.nz/books?id=lU_QRm-

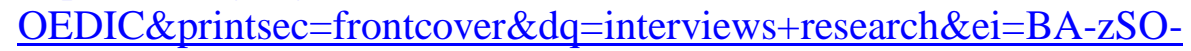
bK4rmtQPj--WRBA\&sig=ACfU3U2_Cv6rB1afypbYv3jDCcu3CLS_Q\#PPP1,M1.

Lester, H., Tritter, J. Q., \& Sorohan, H. (2004). Managing crisis: The role of primary care for people with serious mental illness. Family Medicine, $36(1), 28-34$.

Ligthelm, R. J., Borzi, V., Gumprecht, J., Kawamori, R., Wenying, Y., \& Valensi, P. (2007). Importance of observational studies in clinical practice. Clinical Therapeutics, 29(Theme Issue), 1284 - 1292.

Lincoln, A. (2006). Psychiatric emergency room decision-making, social control and the 'undeserving sick'. Sociology of Health \& Illness, 28(1), 54 - 75.

Lloyd, A. (2007). Selective serotonin re-uptake inhibitors. Depression Retrieved 30 January 2008, 2008, from http://www.netdoctor.co.uk/diseases/depression/selectiveserotoninreputak einhibitors_000147.htm.

Locker, T. E., Baston, S., Mason, S. M., \& Nicholl, J. (2007). Defining frequent use of an urban emergency department. Emergency Medicine Journal, 24(6), $398-401$.

Mackay, N., \& Barrowclough, C. (2005). Accident and emergency staff's perceptions of deliberate self-harm: Attributions, emotions and willingness to help. The British Journal of Clinical Psychology, 44, 255 - 267.

Maskill, C., Hodges, I., McClellan, V., \& Collings, S. (2005). Explaining patterns of suicide: A selective review of studies examining social, economic, cultural and other population-level influences. Wellington: Ministry of Health.

McDonough, S., Wynaden, D., Finn, M., McGowan, S., Chapman, R., \& Hood, S. (2004). Emergency department mental health triage consultancy service: 
An evaluation of the first year of the service. Accident \& Emergency Nursing, 12, $31-38$.

McKenna, H., Hasson, F., \& Keeney, S. (2006). Surveys. In K. Gerrish \& A. Lacey (Eds.), The research process in nursing (5th ed., pp. 260 - 273). Victoria: Blackwell Publishing.

Meltzer, H. (2000). The mental health of children and adolescents in Great Britain. London: The Stationery Office.

Mental Health Commission. (2002). Crime and Mental Illness Fact Sheet One. Mental Illness and Violent Crime. Retrieved 20 March, 2008 from www.mhc.govt.nz/publications/2002/MI\%20and\%20Violent\%20Crime\% $\underline{\text { 20FS.doc }- \text {. }}$

Mental Health Commission. (2007). Te Hononga 2015: Connecting for greater well-being. Wellington: Author.

Minister of Health. (2006). Implementing the New Zealand Health Strategy 2006: The Minister of Health's sixth report on progress on the New Zealand Health Strategy. Wellington: Ministry of Health.

Ministry of Health. (2002a). He Korowai Oranga: Maori Health Strategy. Wellington: Author.

Ministry of Health. (2002b). Whakatataka: Maori Health Action Plan 2002 2005. Wellington: Author.

Ministry of Health. (2006a). DHB hospital benchmark information reports. Retrieved. from http://www.moh.govt.nz/moh.nsf/indexmh/dhb-hospitalbenchmark.

Ministry of Health. (2006b). Suicide facts: 2004 - 2005 data. Wellington: Author.

Ministry of Health. (2007a). Patterns of antidepressant drug prescribing and intentional self-harm outcomes in New Zealand: An ecological study. Wellington: Author.

Ministry of Health. (2007b). Suicide facts: 2005 - 2006 data. Wellington: Author.

Ministry of Health. (2008). Te Puawaiwhero: The second Maori mental health and addiction national strategic framework 2008 - 2015. Wellington: Author.

Mitchell, A. J., \& Dennis, M. (2006). Self harm and attempted suicide in adults: 10 practical questions and answers for emergency department staff. 
Emergency Medicine Journal,

http://emj.bmj.com/cgi/content/full/23/4/251 $251-255$.

Modesto-Lowe, V., Brooks, D., \& Ghani, M. (2006). Alcohol dependence and suicidal behaviour: from research to clinical challenges. Harvard Review Psychiatry, 14(5), 241 - 248.

Moir, L. (2001). Breaking the silence: New Zealanders talk about suicide. Nelson, New Zealand: Craig Potton.

Name District Health Board. (2006). Unscheduled patient return visits to the emergency department. Emergency Department Policies Procedures and Guidelines 2. Retrieved 8. April 2007, from SilentOne

National Institute for Clinical Excellence. (2004). The short-term physical and psychological management and secondary prevention of self-harm in primary and secondary care. London: Author.

Neale, H., \& Nichols, S. (2001). Theme-based content analysis: A flexible method for virtual environment evaluation [Electronic Version]. International Journal of Human-Computer Studies, 55, 167-189. Retrieved 20 August 2008

from http://www.ingentaconnect.com/content/ap/hc/2001/00000055/00000002/a $\underline{\mathrm{rt} 00475}$.

New Zealand Guidelines Group. (2005). Self-harm and Suicide Prevention Collaborative - Whakawhanaungatanga. Retrieved 9 December, 2007, from http://collaborative.nzgg.org.nz/

New Zealand Guidelines Group \& Ministry of Health. (2003). The assessment and managment of people at risk of suicide. Wellington: Author.

Nursing Council of New Zealand. (2007). Guide to completing your application for practicing certificate. Wellington.

O'Dea, D., \& Tucker, S. (2005). The cost of suicide to society. Wellington: Ministry of Health.

Paris, J. (2004). Is hospitalization useful for suicidal patients with borderline personality disorder? Journal of Personality Disorders, 18(3), 240-247.

Pembroke, L. (2006). Limiting self harm. Emergency Nurse, 14(5), 8 - 10.

Pirkis, J., \& Burgess, P. (1998). Suicide and recency of health care contacts. A systematic review. Br J Psychiatry, 173(6), 462-474. 
Pompili, M., Girardi, P., Tatarelli, G., \& Tatarelli, R. (2006). Suicidal intent in single-car accident drivers: Review and new preliminary findings. Crisis, 27(2), 92 - 99.

Porter, A., Snooks, H., Youren, A., Gaze, S., Whitfield, R., Rapport, F., et al. (2008). "Covering our backs": Ambulance crews' attitudes towards clinical documentation when emergency (999) patients are not conveyed to hospital. Emerg Med J, 25(5), 292-295.

Raymont, A. (2004). Cost Barriers to Health Care: Provisional Analysis from the New Zealand Health Survey 2002/03. General Practitioners Fees Information Retrieved 20.7., 2008, from http://www.moh.govt.nz/moh.nsf/UnidPrint/MH3356?OpenDocument

Read, K., \& Purse, M. (2006). Suicidal ideation. About.com: Bipolar Disorder $\begin{array}{llll}\text { Retrieved } & 3 & \text { September, } & \text { 2008, }\end{array}$ http://bipolar.about.com/od/suicide/g/suicidalideatio.htm

Redelmeier, D. A., Molin, J.-P., \& Tibshirani, R. J. (1995). A randomized trial of compassionate care for the homeless in an emergency department. The Lancet, 345(8958), 1131 - 1134.

Reece, J. (2005). The language of cutting: Initial reflections on a study of the experience of self-injury in a group of women and nurses. Issues in Mental Health Nursing, 26(6), 561-574.

Richardson, S. K., Ardagh, M., \& Gee, P. (2005). Emergency department overcrowding: The Emergency Department Cardiac Analogy Model (EDCAM). Accident and Emergency Nursing, 13(1), 18 - 23.

Rogers, P., Watt, A., Gray, N. S., MacCulloch, M., \& Gournay, K. (2002). Content of command hallucinations predicts self-harm but not vioence in a medium secure unit The Journal of Forensic Psychiatry, 13(2), 251-262.

Sandelowski, M. (2000). Whatever happened to qualitative description? Research in Nursing \& Health, 23, $334-340$.

Sanders, J. (2000). A review of health professional attitudes and patient perceptions on 'inappropriate' accident and emergency attendances: The implications for current minor injury service provision in England and Wales. Journal of Advanced Nursing, 31(5), 1097 - 1105.

Sands, N. (2007). Mental health triage: Towards a model for nursing practice. Journal of Psychiatric \& Mental Health Nursing, 14, 243 - 249.

Saver, B. G., Van-Nguyen, V., Keppel, G., \& Doescher, M. P. (2007). A qualitative study of depression in primary care: Missed opportunities for 
diagnosis and education. Journal of American Board of Family Medicine, $20(1), 28-35$.

Schneider, Z., Whitehead, D., \& Elliott, D. (2007). Nursing \& midwifery research. Methods and appraisal for evidence-based practice (3rd ed.). Marrickville: Elsevier Australia.

Skeem, J. L., Silver, E., Aippelbaum, P. S., \& Tierman, J. (2006). Suicide-related behaviour after psychiatric hospital discharge: Implications for risk assessment and management. Behavioural Sciences and the Law, 24, 731 746.

Specht, J., Singer, A. J., \& Henry, M. C. (2005). Self-inflicted injuries in adolescents presenting to a suburban emergency department. Journal of Forensic Nursing, 1(1), 20-22.

St. George, I., Cullen, M., Wilson, A., Wilson, F., Dolan, B., \& McGeorge, P. (2006). The Mental Health Line [Electronic Version]. New Zealand Family Physician, 33, 336 - 337. Retrieved October 5, 2007.

Starling, J., Bridgland, K., \& Rose, D. (2006). Psychiatric emergencies in children and adolescents: An emergency department audit. Australasian Psychiatry, 14(4), 403 - 407.

Statistics New Zealand. (2006). QuickStats about culture and identity. Retrieved 27.11, 2007, from http://www.stats.govt.nz/NR/rdonlyres/5F1F873C5D36-4E54-9405-

34503A2C0AF6/0/quickstatsaboutcultureandidentity.pdf

Stokowski, L. (2007). Emergency department crowding: More than just a longer wait [Electronic Version]. Retrieved 28. May 2007 from http://www.medscape.com/viewarticle/554196.

Storey, P., Hurry, J., Jowitt, S., Owens, D., \& House, A. (2005). Supporting young people who repeatedly self-harm. Journal of the Royal Society for the Promotion of Health, 125(2), 71 - 75.

Strike, C., Rhodes, A. E., Bergmans, Y., \& Links, P. (2006). Fragmented pathways to care. The experiences of suicidal men. Crisis, 27(1), 31 - 38.

Strong, M. (1998). A bright red scream (1st ed.). Auckland: Penguin.

Stuart, G. W., \& Laraia, M. T. (2001). Principles and practice of psychiatric nursing (7th ed.). St. Louis, Missouri, USA: Mosby 
Summers, M., \& Happell, B. (2003). Patient satisfaction with psychiatric services provided by a Melbourne tertiary hospital emergency department. Journal of Psychiatric and Mental Health Nursing, 10(3), 351-357.

Thompson, C. (2005). Caring for people with mental health problems who present at the emergency department: A nurse educator's journey, Graduate School of Nursing \& Midwifery (pp. 51). Wellington: Victoria University of Wellington.

Townsend, E., Hawton, K., Altman, D. G., Arensman, E., Gunnell, D., House, A., et al. (2001). The efficacy of problem-solving treatments after deliberate self-harm: meta-analsysis of randomized controlled trials with respect to depression, hopelessness and improvement in problems. Psychological Medicine, 31, 979 - 988.

Turner, E. H., Matthews, A. M., Linardatos, E., Tell, R. A., \& Rosenthal, R. (2008). Selective publication of antidepressant trials and its influence on aparent efficacy. The New England Journal of Medicine, 358(3), 252 260.

Vajda, J., \& Steinbeck, K. (2000). Factors associated with repeat suicide attempts among adolescents. Australian \& New Zealand Journal of Psychiatry, 34(3), 437-445.

Walsh, M., \& Wigens, L. (2003). Introduction to research. Foundation in nursing and health care. Cheltenham, UK: Nelson Thornes.

Webb, M., Burns, J., \& Collin, P. (2008). Providing online support for young people with mental health difficulties: challenges and opportunities explored [Electronic Version]. Early Intervention in the Real World, 2, 108-113. Retrieved 10 August 2008 from http://www3.interscience.wiley.com/cgibin/fulltext/119423581/HTMLSTART.

Westwood, B., \& Westwood, G. (2001). Multi-presenter mental health patients in emergency departments - a review of models of care. Australian Health Review, 24(4), 202 -213.

Wilkinson, G., \& Smeeton, N. (1987). The repetition of parasuicide in Edinburgh 1980 - 1981. Social Psychiatry, 22, 14 - 19.

Williams, W. H. (1987). Out of mind out of sight: The story of Porirua hospital. Wellington: Porirua Hospital.

Wishart, J. A., Knight, S., \& Gehlhaar, E. W. (1993). Deliberate self-harm: An audit of a service to patients. International Journal of Health Care Quality Assurance, 6(2), $4-8$. 
World Health Organisation. (1990). ICD-10: International statistical classification of diseases and related health problems: Tenth revision (2nd ed.). Geneva, Switzerland: Author.

World Health Organisation. (2007). Suicide Prevention (SPUPRE). Retrieved 4.12.07, 2007 , from http://www.who.int/mental_health/prevention/suicide/suicideprevent/en/

Zahl, D. L., \& Hawton, K. (2004). Repetition of deliberate self-harm and subsequent suicide risk: Long-term follow-up study of 11583 patients. British Journal of Psychiatry, 185(1), 70-75.

Zun, L. S. (2005). Evidence-based evaluation of psychiatric patients. The Journal of Emergency Medicine, 28(1), 35 - 39. 